

\section{Compiladora}

$\checkmark$ Laura Stella Parra Espitia

Habilidades para la vida Aproximaciones
conceptuales

Autores

Laura Stella Parra Espitia Arcadio de Jesús Cardona Isaza

Sebastián Toro Vélez Germán Andrés Torres Escobar

Roger Martínez Correa Diana Margarita Morales Arrieta Gloria Inés De Salvador 
HABILIDADES PARA LA VIDA; PROBLEMAS SOCIALES; DELINCUENCIA JUVENIL; ABUSO DE SUSTANCIAS; EMBARAZO NO DESEADO; CONOCIMIENTO DE SÍ MISMO; TOMA DE DECISIONES: PENSAMIENTO CREATIVO; PENSAMIENTO CRITICO; EMOCIONES EN LAADOLESCENCIA; HABILIDADES SOCIALES; INTELIGENCIA SOCIAL; SALUD MENTAL; DESARROLLO DE LA PERSONALIDAD; DESARROLLO HUMANO; Parra Espitia, Laura Stella; Cardona Isaza, Arcadio de Jesús; Toro Vélez, Sebastián; Torres Escobar, Germán Andrés; Martínez Correa, Roger; Morales Arrieta, Diana Margarita; Salvador, Gloria Inés de; Universidad Católica Luis Amigó

\section{Habilidades para la vida.}

Aproximaciones conceptuales

\section{Universidad Católica Luis Amigó}

Transversal 51A 67B 90. Medellín, Antioquia-Colombia

Tel: (574) 4487666

www.ucatolicaluisamigo.edu.co - fondo.editorial@amigo.edu.co

\section{ISBN (Versión digital):}

978-958-8943-71-8

\section{Fecha de edición:}

16 de septiembre de 2021

\section{Autores:}

Laura Stella Parra Espitia

Arcadio de Jesús Cardona Isaza

Sebastián Toro Vélez

Germán Andrés Torres Escobar

Roger Martínez Correa

Diana Margarita Morales Arrieta

Gloria Inés De Salvador

\section{Compiladora:}

Laura Stella Parra Espitia

\section{Corrección de estilo:}

Rodrigo Gómez Rojas

Diagramación y diseño:

Arbey David Zuluaga Yarce

\section{Edición:}

Fondo Editorial Universidad Católica Luis Amigó

\section{Jefe Fondo Editorial:}

Carolina Orrego Moscoso

\section{Evaluación de contenido:}

Esta obra ha sido editada bajo procedimientos que garantizan su normalización, aprobada por el Consejo Editorial de la Universidad y evaluada los siguientes pares:

Juan José Giraldo Huertas, Universidad de La Sabana.

Ángela Marcela Güichá Duitama, Universidad Pedagógica y Tecnológica de Colombia.

Lesby Johanna Lora Carrillo, Universidad de Santander. 
Hecho en Colombia / Made in Colombia

Estos capítulos de divulgación son un aporte al proyecto "Las habilidades para la vida: su relación y efecto en el consumo de sustancias psicoactivas en población escolar", avalado y financiado por la Vicerrectoría de Investigaciones de la Universidad Católica Luis Amigó.

Los autores son moral y legalmente responsables de la información expresada en este libro, así como del respeto a los derechos de autor; por lo tanto, no comprometen en ningún sentido a la Universidad Católica Luis Amigó.

\section{Declaración conflictos de interés:}

Los autores de esta publicación declaran la inexistencia de conflictos de interés de cualquier índole con instituciones o asociaciones comerciales.

Esta publicación cumple con el depósito legal en los términos de la normativa colombiana (Ley 44 de 1993, Decreto reglamentario No. 460 de marzo 16 de 1995, y demás normas existentes).

Para citar este libro siguiendo las indicaciones de la cuarta edición en español de APA: Parra Espitia, L. E. (Comp.). (2021). Habilidades para la vida. Aproximaciones conceptuales. Fondo Editorial Universidad Católica Luis Amigó. https://www.funlam.edu.co/uploads/fondoeditorial/702 Habilidades_para_la_vida_Aproximaciones_conceptuales.pdf 


\section{Dedicatoria}

A todos los que leerán este libro les invitamos al viaje de la vida, a disfrutar de cada etapa del camino, al viaje emocional, a mirar al interior de sí mismos. Como lo expresa el poema que transcribimos para ustedes, en la vida lo más importante no es llegar, es enriquecerse de todo lo que nos aporta:

\section{Ítaca}

Cuando emprendas tu viaje a Ítaca pide que el camino sea largo, lleno de aventuras, lleno de experiencias.

No temas a los lestrigones ni a los cíclopes ni al colérico Poseidón, seres tales jamás hallarás en tu camino, si tu pensar es elevado, si selecta es la emoción que toca tu espíritu y tu cuerpo.

$\mathrm{Ni}$ a los lestrigones ni a los cíclopes ni al salvaje Poseidón encontrarás, si no los llevas dentro de tu alma, si no los yergue tu alma ante ti.

Pide que el camino sea largo. Que muchas sean las mañanas de verano en que llegues - ¡con qué placer y alegría!-

a puertos nunca vistos antes.

Detente en los emporios de Fenicia

y hazte con hermosas mercancías, nácar y coral, ámbar y ébano

y toda suerte de perfumes sensuales, cuantos más abundantes perfumes sensuales puedas. 
Ve a muchas ciudades egipcias a aprender, a aprender de sus sabios.

Ten siempre a Ítaca en tu mente.

Llegar allí es tu destino.

Mas no apresures nunca el viaje.

Mejor que dure muchos años

y atracar, viejo ya, en la isla, enriquecido de cuanto ganaste en el camino

sin aguantar a que Ítaca te enriquezca.

Ítaca te brindó tan hermoso viaje.

Sin ella no habrías emprendido el camino.

Pero no tiene ya nada que darte.

Aunque la halles pobre,

Ítaca no te ha engañado.

Así, sabio como te has vuelto, con tanta

experiencia,

entenderás ya qué significan las Ítacas.

Autor: Konstantino Kavafis 


\section{Aaradecimientos}

A la Universidad Católica Luis Amigó, la Vicerrectoría de Investigaciones, el Centro Regional Bogotá y los miembros del grupo Ayelén, por confiar en el equipo de investigación y permitirnos generar nuevo conocimiento en pro del fomento de las habilidades para la vida.

A los jóvenes, que en nuestro quehacer cotidiano y profesional nos inspiraron a aproximarnos a las habilidades para la vida, y convertirlas en una herramienta que contribuya a su desarrollo y al manejo de sus emociones, permitiéndoles enfrentarse a un mundo que, en palabras del Papa Francisco, les pide hoy ser protagonistas y dejar huellas. 


\section{Índice general}

Presentación

Capítulo I. Habilidades para la vida: Una aproximación conceptual para el abordaje los fenómenos sociales

Sebastián Toro Vélez

Introducción

1.1. Entendiendo las HpV desde una aproximación conceptual

1.1.1. Pensadas como estrategia

1.1.2. Las HpV como competencias psicosociales

1.1.3. ¿Cuáles son las HpV?

1.2. Las HpV y su pertinencia en fenómenos sociales

1.2.1. Consumo de sustancias psicoactivas (SPA)

1.2.2. Delincuencia juvenil

1.2.3. Embarazos adolescentes

1.2.4. Las HpV como enfoque

Conclusión

Referencias

Capítulo II. La salud mental y las habilidades para la vida

Roger Martínez Correa

Introducción

2.1. Las habilidades para la vida y la salud mental

2.2. La aplicabilidad de las HpV

Conclusión

Referencias

Capítulo II I. Habilidades cognitivas: Mecanismo para el proceso de aprendizaje y la resolución de problemas

Laura Stella Parra Espitia

Introducción

3.1. ¿Qué son las habilidades cognitivas?

3.2. Clasificación de las habilidades cognitivas

3.2.1. Autoconocimiento

3.2.2. Autoeficacia

3.2.3. Afrontamiento

3.2.4. Pensamiento creativo

3.2.5. Toma de decisiones

3.2.6. Pensamiento crítico 
Capítulo IV. ¿Cómo educar las emociones? Perspectivas a partir de la teoría de la construcción emocional

Arcadio de Jesús Cardona Isaza

Introducción

4.1. Las emociones

4.2. El episodio emocional

4.3. Las teorías psicológicas clásicas de las emociones.

4.4. Anatomía de las emociones

72

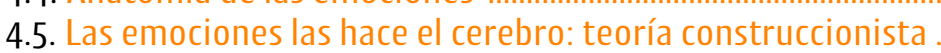

76

4.6. Avances en el estudio de las emociones

78

Conclusión

Referencias

Capítulo V. Habilidades sociales: Dimensión esencial de las habilidades para la vida.

Arcadio de Jesús Cardona Isaza, Margarita Morales y Gloria Inés De Salvador Introducción

5.1. El enfoque de habilidades para la vida.

5.2. ¿Qué son las habilidades sociales?

5.3. La competencia social

5.4. Modelos de habilidad social

5.5. Los aportes de la teoría del aprendizaje social ........................................... 107

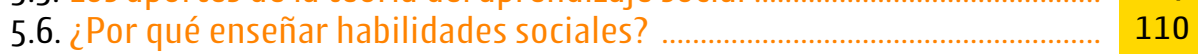

5.7. ¿Cuáles son los programas de entrenamiento en habilidades sociales más efectivos?

5.8. Medidas de habilidad social

Conclusión

Referencias

Anexo

Capítulo VI. Promover el desarrollo humano: El reto para las nuevas generaciones de jóvenes

Germán Andrés Torres Escobar

Introducción

6.1. El concepto de desarrollo humano

6.2. Enfoques del desarrollo humano

6.3. Concepto de desarrollo humano a partir del bienestar y la equidad

6.4. Concepto de desarrollo humano desde la sustentabilidad

6.5. Reflexiones sobre el desarrollo humano para las nuevas generaciones ....

6.6. Propuesta de un modelo de formación en emprendimiento sustentable y ético

Conclusión

Referencias 


\section{Indice de tablas v fiquras}

Tabla 3.1. Conceptos de afrontamiento .......................................................................................... 49

Tabla 3.2. Conceptos de pensamiento crítico …………................................................................. 56

Tabla 4.1. Áreas de interés, objetivos y retos en el estudio de las emociones ............................. 86

Tabla 5.1. Habilidades sociales en el contexto de la educación en competencia social y las competencias socioemocionales ............................................................................ 104

Tabla 5.2. Comparación de los diferentes enfoques de intervención en habilidades sociales .. 109

Tabla 6.1. Unidades temáticas dentro de la formación en emprendimiento sostenible y ético ..

Figura 1.1. Esquema general de las habilidades para la vida

Figura 3.1. Fases del autoconocimiento

Figura 3.2. Fuentes de la autoeficacia

Figura 3.3. Habilidades del ámbito cognitivo

Figura 3.4. Habilidades del ámbito socioafectivo

Figura 3.5. Pasos para la toma de decisiones

Figura 3.6. Habilidades del pensamiento crítico

Figura 4.1. Definición de las emociones

Figura 4.2. Funciones y componentes del episodio emocional

Figura 4.3. Teorías psicológicas clásicas de las emociones

Figura 4.4. ¿Cómo hace el cerebro las emociones?

Figura 4.5. Bases de la Teoría Construccionista de las Emociones 79

Figura 5.1. Modelo integrado de las habilidades para la vida 


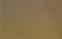

Presentación 
El presente texto surge de la necesidad de definir las habilidades para la vida desde una perspectiva psicológica y educativa, de manera que sirva como base conceptual para el trabajo investigativo de la Universidad Católica Luis Amigó entorno al rol que tienen dichas habilidades en la prevención e intervención de problemas de salud mental.

Para la construcción de los capítulos se acudió a la revisión sistemática, entendida por Kitchenham (2004) como la estrategia para evaluar e interpretar la información relevante respecto a un fenómeno de interés. Siguiendo esta línea, cada uno de los autores analizó variables asociadas a las habilidades para la vida como la salud mental, el desarrollo humano, la cognición, las emociones, y los procesos de socialización.

Cabe anotar que durante el proceso de búsqueda teórica realizada por los autores se observó que existen pocos libros que abordan el tema; si bien existen programas de prevención e intervención que se apoyan en este enfoque, se hace necesario validar y aportar evidencias que lleven a conocer sus bondades, pero también a reconocer sus limitaciones.

Las habilidades para la vida (en adelante $\mathrm{HpV}$ ) surgen como una propuesta educativa que ha sido promovida por la Organización Mundial de la Salud (OMS, 2001) para cuidar del ser humano y de su desarrollo vital. Este enfoque reconoce el riesgo psicosocial que enfrentan los adolescentes, en particular - pero no exclusivamente porque es transversal a diversas poblaciones- aquellos que habitan en contextos de pobreza que favorecen y producen situaciones de vulnerabilidad y exclusión.

Aunque la intervención en las habilidades para la vida se ha sugerido como una herramienta para la atención en salud y ha sido útil para problemas de índole educativo, a medida que avanzaron las prácticas y se aplicó a otros casos específicos como la prevención de embarazos adolescentes, prevención del VIH y demás, los organismos internacionales reconocieron en las destrezas sociocognitivas y la regulación de emociones un fundamento para la generación de políticas públicas.

Por lo anterior, este libro pretende conceptualizar las habilidades para la vida desde las dimensiones cognitivas, emocionales y sociales, así como dar a conocer su pertinencia para contrarrestar algunos fenómenos ya mencionados que están afectando a los adolescentes. Además, cada uno de los capítulos permitirá observar la relación del tema que nos atañe con la teoría del desarrollo humano y la salud mental. 
Finalmente, todo el desarrollo teórico sugiere elementos que pueden contribuir a la comprensión de este enfoque, dejando la puerta abierta para construir propuestas pedagógicas a partir de los sustentos conceptuales planteados a lo largo de este libro.

\section{Referencias}

Kitchenham, B. (2004). Procedures for performing systematic reviews. Keele, UK, Keele University, 33, 1-26. http://www.elizabete.com.br/rs/Tutorial_IHC_2012_ files/Conceitos_RevisaoSistematica_kitchenham_2004.pdf

Organización Mundial de la Salud. (2001). Informe sobre la salud en el mundo 2001: Salud mental: nuevos conocimientos, nuevas esperanzas. https://www.who.int/ whr/2001/en/whr01_es.pdf?ua=1 


\section{Capítulo I}

Habilidades para la vida:

Una aproximación conceptual para el abordaje los fenómenos sociales 


\section{Introducción}

Las $\mathrm{HpV}$ (habilidades para la vida) son propuestas por la Organización Mundial para la Salud (OMS,1993), para mitigar diversos problemas en la población desde el ámbito educativo, realizando actividades de prevención y/o la promoción de la salud enfocadas en las "destrezas psicosociales que les facilitan a las personas enfrentarse con éxito a las exigencias y desafíos de la vida diaria” (Mantilla, 2001, p. 7).

Lo anterior ha permitido que dichas habilidades se permeen de diversos contextos y fenómenos sociales mediante procesos sistemáticos, continuos e interdisciplinares, y no obedeciendo únicamente al espectro psicológico como pudiese pensarse.

Este capítulo desarrolla dos apartados. El primero inicia con un recorrido epistemológico frente al concepto de $\mathrm{HpV}$ presentándolo como una estrategia -tal como lo indicó la OMS (1993)- pasa a exponer las HpV como una competencia psicosocial inherente y fundamental para el desarrollo del ser humano; y finaliza con una descripción de diez habilidades que son reconocidas dentro de tres grandes grupos, no sin antes realizar una distinción de su complejidad a la hora de ser aplicadas en una realidad particular.

En el segundo apartado se recorren tres fenómenos sociales: consumo de sustancias psicoactivas, delincuencia juvenil y embarazo adolescente, en los cuales se pueden visualizar y desarrollar las $\mathrm{HpV}$ como factores protectores de cualquier individuo.

\subsection{Entendiendo las HpV desde una aproximación conceptual}

\subsubsection{Pensadas como estrategia}

Las HpV surgen inicialmente como una estrategia de la OMS (1993) para promover en el ámbito global la salud mental y emocional y el fortalecimiento de factores protectores en niños, adolescentes y jóvenes. Su enfoque pretende retrasar la edad de 
inicio del uso del tabaco, el alcohol y la marihuana; enseñar a controlar la ira; prevenir conductas sexuales de alto riesgo y la conducta criminal; mejorar conductas relacionadas con la salud y la autoestima e, incluso, el rendimiento académico, aspecto que posibilitará después una función puramente educativa o formativa, entre otras. Todo ello, como afirma Martínez (2014), “tenían un énfasis ‘informativo’ y técnico académico y centrado, generalmente en las habilidades sociales y en la solución de problemas" (p. 65).

Este aprendizaje, enfocado desde la teoría social propuesta por Bandura (1977), cobra valor al hablar de las $\mathrm{HpV}$, en cuanto que los niños aprenden a comportarse por medio de la instrucción y la observación; su conducta, entonces, se consolida o se modifica conforme a las consecuencias que surgen de sus acciones y a la respuesta de los demás hacia sus conductas.

Los niños aprenden a comportarse, afirma Martínez (2014), por medio de la observación y la interacción social, razón por la que se les deben enseñar habilidades. El mejor proceso para ello es permitiendo, en primer lugar, que adquieran las herramientas teóricas necesarias, para que luego las puedan poner a prueba sin temor a equivocarse, y así finalmente recibir una retroalimentación de su comportamiento. Bandura (1977), al respecto, hace hincapié en la auto eficiencia -entendida como la confianza en sus propias habilidades para desempeñar diversas conductas- como la herramienta más importante para aprenderlas y mantenerlas, especialmente en vista de las presiones sociales para que exista un comportamiento diferente.

Así, el desarrollo de destrezas no solo se convierte en una cuestión de comportamiento externo, sino de cualidades internas. Aspecto que devela la actuación de las habilidades de la vida como un ejercicio formativo o educativo, en cuanto permite el desenvolvimiento del sujeto en su entorno.

Ahora bien, asumir las $\mathrm{HpV}$ como estrategias permitió incluirlas en el abordaje de asuntos particulares y "poco a poco se fueron diseñando programas ajustados a problemas específicos de salud pública desde un enfoque preventivo, como consumo de sustancias psicoactivas, embarazos adolescentes, entre otros" (Martínez, 2014, p. 65). La injerencia de las $\mathrm{HpV}$ en los procesos de salud pública les facultó dar respuesta a otros problemas sociales propios de diferentes contextos, incluido el sector educativo. 
De acuerdo con Mantilla (2001), "la convocatoria del Ministerio de la Salud en 1996 para generar instrumentos didácticos que fueran utilizados en la educación formal posibilitó el arribo a Colombia de las HpV" (p. 1). La Fundación Fe y Alegría ${ }^{1}$ implementó esta estrategia de prevención y con su éxito afectó ámbitos propios de la salud pública y posibilitó llevarlos al educativo.

\subsubsection{Las HpV como competencias psicosociales}

Hablar de $\mathrm{HpV}$ es recrear imaginarios sociales fundamentados en los valores éticos que son enseñados en el colegio, con el único objetivo de aprender a vivir mejor, pues a lo largo de la existencia se posee el compromiso de enfrentar las exigencias del medio y, con ello, las lecciones y retos principales de la cotidianidad misma.

Al respecto, García et al. (2015) expresan que los usos inadecuados de la libertad en acciones, actitudes y comportamientos en diferentes contextos han hecho que se deteriore en parte la calidad de vida de las personas y, por ende, su desarrollo psicosocial, y es allí, donde aprender a vivir mejor y para la vida se convierte en un verdadero reto no solo en el seno familiar, sino también en las escuelas. Hoy por hoy, las $\mathrm{HpV}$ poseen un valor intrínseco y se están convirtiendo en un componente importante en la promoción de la inteligencia emocional, la salud y el bienestar integral.

Teniendo en cuenta lo anterior, es importante mencionar que las $\mathrm{HpV}$ se relacionan directamente con el concepto de competencia psicosocial, entendida como "la habilidad de una persona para enfrentarse exitosamente a las exigencias y desafíos de la vida diaria" (UNICEF, 2017, p. 54). En este sentido, se reconoce que la promoción de la salud es su principal objetivo y su interés específico es tener ciudadanos más saludables, que tengan conocimientos técnicos para enfrentarse al mundo laboral, pero que también cuenten con actitudes y valores que les permitan afrontar los desafíos de la vida cotidiana.

Las competencias juegan un papel importante en dicho afrontamiento; Fernández-Daza y Fernández-Parra (2012) las definen como las capacidades, habilidades, destrezas, conocimientos, actitudes y hábitos de conducta que posee una persona para realizar específicamente una actividad. La familia, como institución social, permite el desarrollo de lo mencionado, por lo que urge que trabaje mancomunadamente con la

${ }^{1}$ Es una fundación que ofrece programas de atención psicosocial, entre otras, brinda oportunidades de estudio a los sectores más pobres de la sociedad, además, coordina procesos de formación a profesores y gestiona un sistema de radio educativa en 21 países. 
comunidad educativa, de modo que se actúe con coherencia entre lo cognitivo, afectivo y lo social, en la formación de valores y aprendizajes que faciliten la inteligencia emocional y las competencias psicosociales; solo así se favorece una educación en $\mathrm{HpV}$.

Así, las $\mathrm{HpV}$ pueden pensarse como una competencia de índole puramente psicosocial, es decir, se convierten en la posibilidad de desarrollar una serie de habilidades que, aunque intrínsecas no desconoce la injerencia del entorno, por ello, se hace latente la necesidad de continuar formando en este tipo de competencias pensadas desde la transversalidad -ya no desde un problema particular- de todas las dimensiones del ser humano: laboral, familiar, académica, social e incluso la ciudadana.

\subsection{3. ¿Cuáles son las HpV?}

Muchas son las competencias que requiere el ser humano para enfrentar la vida diaria, sin embargo, la OMS (1993) se focaliza en diez: conocimiento de sí mismo, comunicación efectiva, toma de decisiones, pensamiento creativo, manejo de sentimientos y emociones, empatía, relaciones interpersonales, solución de problemas y conflictos, pensamiento crítico, manejo de tensiones y estrés. La definición y apropiación de cada una están marcadas por la complejidad del hombre y sus relaciones, desde aristas como lo cultural, lo etario, o el contexto mismo:

\section{Cada habilidad está compuesta por uno o más elementos, cuya naturaleza está determinada por las normas y valores que definen lo que es un comportamiento apropiado en cada contexto social y cultural. A su vez, las normas y valores dependen de factores como el género, la edad y la condición social. (Mantilla, 2001, p. 8)}

Las habilidades se agrupan en tres categorías (ver Figura 1.1). Las habilidades cognitivas permiten la "comprensión de las consecuencias de las acciones" (Mantilla \& Chaín, 2012, p. 106) y posibilitan la mirada de los actos, el análisis de sus resultados y de las perspectivas del individuo a futuro, dando cuenta de la realidad humana misma y enfocándose en situaciones reales propias de los contextos. De este grupo forman parte: conocimiento de sí mismo, pensamiento creativo, solución de problemas y conflictos y pensamiento crítico.

Las habilidades emocionales "están enlazadas de forma que, para una adecuada regulación emocional, es necesaria una buena comprensión emocional y, a su vez, para una comprensión eficaz requerimos de una apropiada percepción emocional" 
(Fernández-Berrocal \& Extremera Pacheco, 2002, p. 2). No basta con habilidades puramente cognitivas, ni puramente sociales, es necesario realizar procesos de auto conocimiento, de introspección y de reconocimiento emocional para alcanzar un equilibrio en la vida misma. En esta categoría se encuentran: toma de decisiones, manejo de sentimientos y emociones, empatía, manejo de tensiones y estrés.

Las habilidades sociales, por su parte, son todas aquellas capacidades que un individuo posee para relacionarse en contextos determinados; se definen como "la capacidad de la persona de ejecutar una conducta de intercambio con resultados favorables" (Morales Rodríguez et al., 2013, p. 100), por lo que su desarrollo es fundamental para el establecimiento y mantenimiento de relaciones interpersonales sanas y positivas. Serán reconocidas dentro de este grupo la comunicación efectiva, la empatía y las relaciones interpersonales.

Figura 1.1. Esquema general de las habilidades para la vida

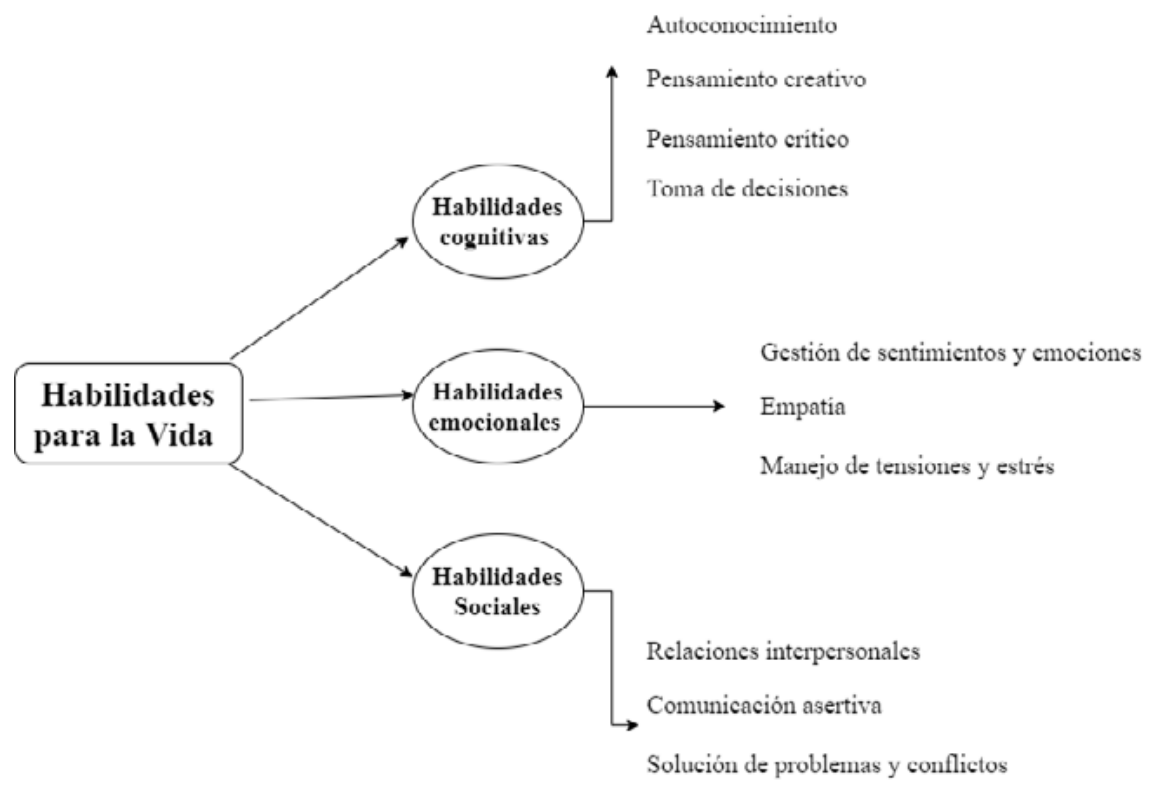

Estos tres grandes grupos permiten realizar un análisis de las $\mathrm{HpV}$ desde lo conceptual, sin embargo, ello no implica que respondan únicamente a su categoría, pues son transversales a las esferas humanas y su alcance es fundamental para el sujeto mismo. Recordemos, además, que su participación no se reduce a procesos preventivos o 
educativos o de promoción de la salud -aunque allí siguen teniendo vigencia- sino que ahora se piensan como competencias psicosociales que intervienen directamente en la vida de todos.

\subsection{Las HpV y su pertinencia en fenómenos sociales}

Antes de abordar los diferentes fenómenos sociales en los cuales la $\mathrm{HpV}$ tiene una injerencia directa, es necesario explicar los factores de riesgo y factores protectores, pues desde allí las $\mathrm{HpV}$ operan como protección contra el riesgo.

El factor de riesgo es "una característica interna o externa al individuo cuya presencia aumenta la probabilidad o predisposición de que produzca un determinado fenómeno" (Laespada et al., 2004, p. 16). Es importante acotar que los fenómenos sociales son dinámicos y variables de acuerdo con factores como el contexto, las particularidades de cada caso, la vida misma, en consecuencia, existen múltiples aspectos que pudiesen convertirse en riesgo, bien sean los pares, la escuela, la calle como lugar de tránsito y de socialización, o incluso la familia misma.

En cuanto a los factores protectores, son definidos como aquellos "rasgos de las personas, entornos, situaciones y/o acontecimientos que parecen moderar las predicciones de psicopatología basadas en niveles de riesgo individual. Los factores de protección, si están presentes, favorecen la resistencia ante el riesgo y fomentan resultados caracterizados por patrones de adaptación y competencia" (Rutter, como se cita en Blasco, 2012, p. 6); sin embargo, últimamente se han considerado como protectores todos aquellos factores que de una u otra manera influyen positivamente en el sujeto, cuando este se encuentre mediado por el riesgo mismo. Este planteamiento otorga cabida a vislumbrar las $\mathrm{HpV}$ como factores protectores ante posibles riesgos, ante fenómenos latentes y plausibles.

Al respecto, Bronfenbrenner (1979) propuso el llamado modelo ecológico que tiene como objetivo el análisis psicológico del desarrollo humano basado en círculos concéntricos divididos en macrosistema, exosistema y microsistema. El primero influye en las formas de organización, creencias culturales y estilos de vida; el segundo lo conforman los sistemas de relaciones enmarcadas por las instituciones culturales; y el último nivel lo conforman las relaciones más próximas que caracteriza la familia. 
Los espacios y ambientes en los que se desenvuelve el ser humano, en especial los adolescentes, contribuyen a la formación de su estilo de vida y afectan directamente sus microsistemas. La familia y el colegio, entonces, son los espacios en los que fluctúa la comunicación de esta población y donde se potencializan sus conductas, ya que cada una de ellas son reforzadas en estos dos microsistemas, y su interacción permite que el individuo pueda establecer o no el acceso a un apoyo social para resolver cualquier tipo de situación que se le presente.

De este modo, las $\mathrm{HpV}$ son pertinentes para el abordaje de diferentes fenómenos sociales como el consumo de SPA, la delincuencia juvenil y los embarazos en adolescentes; asuntos de gran interés para diferentes actores y/u organizaciones, que no escatiman esfuerzos por dar respuesta a ellos.

\subsubsection{Consumo de sustancias psicoactivas (SPA)}

Según la Organización Mundial para la Salud (OMS, 2002), las sustancias psicoactivas, al ser introducidas en el organismo por cualquier vía, producen una alteración en el funcionamiento del sistema nervioso central del individuo (SNC), ocasionando consecuentemente una alteración en el comportamiento. En otras palabras, las SPA son productos químicos que afectan el sistema nervioso central, trastornando el pensamiento de la persona que los consume, su estado de ánimo y/o sus conductas (Beck et al., 1999, p. 20).

La OMS (2002) clasifica las diferentes clases de sustancias de acuerdo con el efecto que tienen sobre el Sistema Nervioso Central existiendo tres grandes grupos: las depresoras, estimulantes y alucinógenas. Las primeras disminuyen el nivel de funcionamiento del SNC; en dosis moderadas provocan euforia, personalidad bromista y ocurrente, pocas reservas de sus deseos y emociones; y en dosis altas, enlentecimiento generalizado, sueño y sensación de postración, pueden ocasionar pérdida del conocimiento, detener las funciones cardiorrespiratorias y producir la muerte; en este grupo encontramos: el alcohol, los barbitúricos, sedantes, ansiolíticos, el opio, la heroína, derivados de la gasolina y la acetona, como por ejemplo el bóxer. 
Por el contrario, explica la OMS (2002), las sustancias estimulantes proporcionan la impresión de una agudeza tanto psicológica como física y producen aceleración del funcionamiento de diversos sistemas tanto fisiológicos como psicológicos; los principales estimulantes son la cocaína, anfetaminas, el bazuco, la cafeína y el cigarrillo.

Por último, los fármacos alucinógenos son conocidos como psicodélicos, producen cambios o alteraciones perceptivas (visuales, sonoras y somestésicas) provocando alucinaciones, trastornos en el pensamiento, autoconciencia, emoción, pueden generar efectos depresores o estimulantes o ambos; entre las drogas alucinógenas encontramos: LSD (ácido lisérgico extraído de un hongo), hongos, yahé, éxtasis, hachís, fenciclidina, marihuana (OMS, 2002).

Ahora bien, vislumbremos los resultados de la promoción de $\mathrm{HpV}$ entre jóvenes escolarizados en cuanto a la disminución del consumo de SPA en adolescentes escolares.

La investigación De La Barrera (2012) efectúa un recuento de programas basados en HpV. Uno de ellos es Life Skills Training Program (LST, por sus siglas en inglés), dirigido a estudiantes, enseña habilidades sociales, cognitivas y emocionales, y les informa acerca del consumo de drogas desmitificando creencias erróneas. El análisis de su gestión indicó que más del 50\% de los estudiantes atendidos en un periodo de 25 años han disminuido significativamente el consumo de sustancias ilegales. Así mismo el programa Chimalli, que se rige por un modelo de prevención y protección basado en los riesgos psicosociales y que se dirige a individuos y comunidades, ha realizado su proceso mediante el fortalecimiento de habilidades de protección sociales, emocionales y cognitivas.

Siguiendo esta línea, se encuentra el proyecto Construye tu vida sin adicciones; dirigido a adolescentes, jóvenes y adultos, utiliza material específico para cada población con el que busca la conformación de estilos de vida que permitan desarrollar al máximo el potencial de cada persona y propiciar condiciones que mejoren la calidad de vida de las familias y comunidades.

Al dar una mirada a la aplicación colombiana, se resalta la investigación cualitativa de Díaz-Alzate y Mejía-Zapata (2018), quienes abordaron un grupo de jóvenes escolares y determinaron, en primera instancia, que las habilidades carentes eran las sociales, lo que indica la necesidad de fortalecer los procesos relacionales entre los pares; además de ello, se determinó que impartir las $\mathrm{HpV}$ como una cátedra o una asig- 
natura anclada al plan de estudios es limitado y poco práctico puesto que no alcanza el objetivo de convertirse en un factor protector, por ende, se proponen usarlas como herramienta transversal a todo el proceso formativo de los estudiantes, de manera que se alcancen los resultados esperados en materia de prevención.

De este modo validamos que las $\mathrm{HpV}$ emocionales, sociales y cognitivas, focalizadas de la manera adecuada, se convierten en un mecanismo de desarrollo de competencias fundamental para prevenir o disminuir el consumo de SPA.

\title{
1.2.2. Delincuencia juvenil
}

Otro de los fenómenos sociales coyunturales es la delincuencia juvenil. Según Toro (2018), hablar de delincuencia es hablar de un asunto multicausal que se interrelaciona con diversos factores culturales, económicos, políticos, familiares y, por supuesto, individuales. Se convierte en un tema de profundo interés en cuanto es medible en variables correlacionales a la ciudadanía respecto a percepciones de seguridad y otras.

Como fenómeno social propiamente descrito, trastoca la realidad de los jóvenes, de tal forma que ellos asumen una cosmovisión diferente y unas perspectivas particulares de vida; tanto así que ya no hablamos de delincuencia en su nivel macro, sino que se particulariza al plantearla como delincuencia juvenil.

Algunos estudios del tema coinciden en que el fenómeno está conectado con el estrato socioeconómico:

\begin{abstract}
La situación de extrema pobreza en que viven grandes núcleos de población en los países de América Latina nos muestra una imposibilidad estructural de inserción de muchos jóvenes en las estructuras formales de la sociedad. De ahí que los jóvenes y su identidad se construyan mayoritariamente por fuera de la formalidad social, de esta manera, la identificación con los objetivos y valores culturales dominantes resulta compleja, ya que la identidad social de una gran mayoría de jóvenes de los sectores populares no se constituye como clase trabajadora, ni como estudiantes, ni mucho menos como ciudadanos de grandes metrópolis. (Jiménez Ornelas, 2005, p. 222)
\end{abstract}

Así mismo, no es extraño notar que social y culturalmente se asocia la pobreza como un factor causal que conduce de manera prematura a los sujetos a asumir comportamientos delincuenciales, en aras incluso de sobrevivir (Bonalume \& Jacinto, 2019). 
A diferencia del consumo de SPA, las $\mathrm{HpV}$ no han sido muy replicadas en el ámbito de la reeducación que, a partir de la pedagogía social, se encarga de trabajar con los jóvenes. Al respecto, la investigación de Gonzáles (2007), titulada Entrenamiento de habilidades sociales en menores infractores, deja entrever la dificultad a la hora de aplicarlas con este tipo de población si antes no se han generado los espacios necesarios para que, a su vez, las HpV sean aprovechadas de la mejor manera; aunque su apuesta fue por las habilidades sociales, se estipula la importancia de desarrollar otro tipo de habilidades en estos jóvenes, quienes sin algún tipo de factor protector optan por el delito como sentido de vida.

La investigación de Toro (2018), titulada Reincidencia juvenil en conductas delictivas. Un acercamiento comprensivo al problema en el Instituto de Formación Toribio Maya, muestra que existe un gran problema en la institucionalización ${ }^{2}$ de los jóvenes, cuyos porcentajes de reincidencia son altísimos; así mismo evidencia que la pedagogía en el Centro de Atención Especializado $(\mathrm{CAE})^{3}$ posee prácticas que no son sometidas a evaluación para verificar su eficacia y esto contribuye -no es el único factor asociado ${ }^{4}$ - al fenómeno, no de la delincuencia juvenil, si no de la reincidencia juvenil en conductas delictivas. Aunque dicha investigación no trabaja las $\mathrm{HpV}$, puede deducirse de esta la necesidad de replantear procesos formativos, pedagógicos y/o educativos dando cabida al desarrollo de competencias psicosociales, que sin lugar a dudas dotarían de elementos a los jóvenes para enfrentar un proceso de socialización.

Lo descrito corrobora que el trabajo de las $\mathrm{HpV}$ con este tipo de población facilitaría sus procesos de socialización en cuanto enfoca las diferentes competencias psicosociales: emocional, cognitiva y social. Se constituye entonces como una posibilidad de exploración en estos contextos particulares y se evocan sus buenos resultados en otros fenómenos impajaritablemente asociados. la estructura parte de los logros obtenidos por el adolescente o joven en su proceso reeducativo" (Toro, 2016, p. 8).

${ }^{3}$ Lugar donde son ubicados los jóvenes por orden de un juez de conocimiento cuando son hallados responsables de la comisión de un delito; se entiende que esta es una sanción privativa de la libertad en medio institucional en la cual permanece el adolescente hasta tanto la sanción cese o se modifique (Ley 1098, Art. 187).

${ }^{4}$ Durante la investigación se trabajaron tres grandes categorías que dan cuenta de la reincidencia juvenil en conductas delictivas: procesos relacionales entre el riesgo y la protección, el sujeto en condición juvenil mediado por el consumo y el delito, y la institucionalización formal y reeducativa. 


\title{
1.2.3. Embarazos adolescentes
}

Los embarazos adolescentes se han convertido en un verdadero problema del ámbito mundial, al cual diversas organizaciones de la salud pública prestan atención. La OMS (2018) publicó los siguientes datos:

\footnotetext{
Unos 16 millones de jóvenes de 15 a 19 años y aproximadamente 1 millón de niñas menores de 15 años dan a luz cada año, la mayoría en países de ingresos bajos y medianos. Las complicaciones durante el embarazo y el parto son la segunda causa de muerte entre las jóvenes de 15 a 19 años en todo el mundo. Cada año, unos 3 millones de jóvenes de 15 a 19 años se someten a abortos peligrosos. Los bebés de madres adolescentes se enfrentan a un riesgo considerablemente superior de morir que los nacidos de mujeres de 20 a 24 años.
}

Los datos anteriores son similares a los presentados en Colombia por el Departamento Administrativo Nacional de Estadística, en el año 2016, que afirma que el 20,5 \% de las mujeres con hijos en el país, los tuvieron entre los 15 y los 19 años, lo que muestra una alta prevalencia de embarazo adolescente.

\begin{abstract}
A nivel de determinantes estructurales o distales, la evidencia es muy amplia explicando como los ingresos del hogar; la pobreza; la cobertura y acceso oportuno a servicios públicos; la oportunidad de participar en las decisiones públicas y el ejercicio de la democracia en las comunidades; las normas sociales sobre la sexualidad, la feminidad, la masculinidad, las relaciones de pareja o la participación de las niñas, los niños y adolescentes en los procesos de decisión e identidad social; la existencia de oportunidades de desarrollo personal y alternativas de vida; y la atención de la comunidad a los derechos sexuales y reproductivos, a la prevención de su vulneración y la adecuada valoración de los mensajes transmitidos a través de las Tecnologías de la Información y la Comunicación (TIC). (Profamilia, 2018, p. 21)
\end{abstract}

Este fenómeno multicausal evoca necesariamente un factor educativo en el que las niñas, niños y adolescentes de este país, no son informados y mucho menos formados en temas tan cruciales para el futuro de la vida misma como lo es una maternidad o paternidad a temprana edad.

En Colombia, el Ministerio de Salud y Protección Social (2014), mediante el programa Caminemos Juntos, plantea un escenario formativo para el abordaje de la problemática a través de orientaciones y herramientas para la prevención y atención del embarazo en adolescentes, en el que otorga especial importancia a las $\mathrm{HpV}$ como competencia psicosocial a la hora de la toma de decisiones de los adolescentes frente a su vida sexual y reproductiva.

Por otra parte, en México se realizó una investigación en la que se relacionaban las variables de las $\mathrm{HpV}$ y el uso de anticonceptivos; los hallazgos muestran las 


\begin{abstract}
diferencias manifiestas en la habilidad de comunicarse asertivamente entre los estudiantes que se protegen siempre que tienen relaciones sexuales con una pareja sexual ocasional y los que no han tenido su debut sexual respecto a los que se protegen pocas veces. La habilidad para la comunicación asertiva con la pareja a fin de negociar el uso de anticoncepción se ha documentado ampliamente como una variable predictora de la conducta sexual protegida. (De la Barrera, 2013 p. 44)
\end{abstract}

Este resultado devela la importancia de desarrollar habilidades emocionales y comunicativas para constituir y consolidar relaciones afectivas con otros.

El trabajo De la Barrera (2013) corrobora la afirmación de que este fenómeno social es producto de la falta de formación e información recibidas por los adolescentes y jóvenes; dicha responsabilidad no es solo de la escuela, es importante ampliar la mirada y delegar aún más responsabilidades tanto en la familia como en la sociedad misma, lo que implicaría desarrollar $\mathrm{HpV}$ con todos y así dar fuerza al planteamiento de que este es un asunto de competencias y no únicamente de ejercicios teóricos o temáticos aislados de la vida misma.

La falta de comunicación termina siendo un indicador de la necesidad de formar a los escolares, en este caso en habilidades, que les permita asumir las vicisitudes que la vida misma presenta.

\title{
1.2.4. Las HpV como enfoque
}

Los resultados en fenómenos sociales complejos después de los programas de prevención y/o promoción mediante las $\mathrm{HpV}$, permitieron que pasaran de ser considerados como una estrategia (medio para) a convertirse en un enfoque (aquello que permite permear la realidad misma).

Las habilidades para la vida permiten entonces el fortalecimiento de los factores protectores de un adolescente, promoviendo la competitividad necesaria para lograr una transición saludable hacia la madurez y promover la adopción de conductas positivas:

Los programas efectivos ponen en práctica habilidades en asuntos relacionados con las tareas de desarrollo y del contexto social del adolescente, tal como el desarrollo de la identidad sexual, comprensión de la presión por parte de los pares y manejo de emociones. Se ha demostrado que esto influye las conductas. Por más de una década, la investigación de intervenciones que tienen que ver con estas áreas específicas ha demostrado su efectividad para promover conductas deseables, tales como socialización, mejor comunicación, toma efectiva de decisiones, solución de conflictos y prevención de conductas negativas o de alto riesgo, tales como el uso de tabaco, alcohol u otras drogas, sexo inseguro y violencia. (Mangrulkar et al., 2001, p. 320) 
El uso de estos programas aún es tema de análisis en diversos escenarios académicos, sin embargo, es importante resaltar que la práctica de habilidades desde el desarrollo de la identidad y el manejo de emociones todavía impacta los procesos de intervención que tienen como objetivo la búsqueda de conductas deseables en adolescentes.

\section{Conclusión}

Las $\mathrm{HpV}$ se han convertido en un tema de interés para la comunidad académica, en particular para los entes relacionados directamente con la salud pública. Si bien este apartado da cuenta de algunos soportes teóricos e investigativos que las fundamentan, aún es un aspecto poco documentado y explorado en diferentes escenarios, lo cual es una oportunidad para los investigadores y/o científicos.

Es necesario entonces redoblar esfuerzos, pero sobre todo articular las intenciones de los diferentes entes tanto en pro de la formación de los individuos cuando de competencias de vida se habla, como del abordaje de fenómenos sociales coyunturales y latentes en una sociedad que cada vez más exige atención, educación y formación en la toma de decisiones.

Este propósito de desarrollar el concepto de $\mathrm{HpV}$ nos permite, entre otras cosas, concluir que las $\mathrm{HpV}$ desbordan la idea de ser concebidas como un tema anclado a la psicología; por el contrario, han de ser vistas como el desarrollo de una serie de competencias psicosociales que, aunque poseen un bagaje ampliamente teórico y conceptual, son perfectamente aplicables a la cotidianidad de los sujetos. Así mismo, se convierten en una herramienta fundamental para el abordaje de múltiples fenómenos sociales sin importar la condición etaria puesto que pueden ser trabajadas con todos $\mathrm{y}$ en cualquier momento de la vida, incluso en la niñez misma. 


\section{Referencias}

Bandura, A. (1977). Social Learning Theory. General Learning Press.

Beck, A., Wright, C., Newman, C., \& Liese, B. (1999). Terapia cognitiva de las drogodependencias. Paidós

Blasco, C. (2012). Descripción y análisis de los factores protectores de adolescentes en la prevención del delito. Departamento de Justicia.

Bonalume, B. C., \& Jacinto, A. G. (2019). Encarceramento juvenil: o legado histórico de seletividade e criminalização da pobreza. Revista Katálysis, 22(1), 160-170. https://doi.org/10.1590/1982-02592019v22n1p160

Bronfenbrenner, U. (1979). The ecology of human development. Harvard University Press.

De La Barrera, C. P. (2012). Habilidades para la vida y consumo de drogas en adolescentes escolarizados mexicanos. Adicciones, 24(2), 153-160. https://www. adicciones.es/index.php/adicciones/article/view/108/105

De la Barrera, C. P. (2013). Habilidades para la vida y uso de anticoncepción por tipo de pareja sexual en Adolescentes. Enseñanza e Investigación en Psicología, 18(1), 35-49. https://www.redalyc.org/pdf/292/29228948003.pdf

Díaz-Alzate, M. V., \& Mejía-Zapata, S. I. (2018). Desarrollo de habilidades para la vida en la prevención del consumo de sustancias psicoactivas: un enfoque crítico al modelo existente. El ágora USB, 18(1), 204-211. https://doi.org/10.21500/16578031.3450

Fernández-Daza, M. P., \& Fernández-Parra, A. (2013). Problemas de comportamiento y competencias psicosociales en niños y adolescentes institucionalizados. Universitas Psychologica, 12(3), 797-810. https://doi.org/10.11144/Javeriana.upsy12-3.pccp

Fernández-Berrocal, P., \& Extremera Pacheco, N. (2002). La inteligencia emocional como una habilidad esencial en la escuela. Revista Iberoamericana de Educación, 29(1), 1-6. https://doi.org/10.35362/rie2912869 
Gonzáles, R. (2007). Entrenamiento de habilidades sociales en menores infractores [Tesis de grado]. Universidad Pedagógica Nacional. http://200.23.113.51/pdf/24564. pdf

Jiménez Ornelas, R. A. (2005). La delincuencia juvenil: fenómeno de la sociedad actual. Papeles de población, 11(43), 215-261. http://www.scielo.org.mx/pdf/pp/ v11n43/v11n43a9.pdf

Laespada, T., Iraurgi, L., \& Aróstegi, E. (2004). Factores de riesgo y de protección frente al consumo de drogas: hacia un modelo explicativo del consumo de drogas en jóvenes de la CAPV. http://www.codajic.org/sites/www.codajic.org/files/ Factores\%20CAPV.pdf

Mangrulkar, L., Whitman, C. V., \& Posner, M. (2001). Enfoque de habilidades para la vida para un desarrollo saludable de niños y adolescentes. OPS. http:// dx.doi. org/10.21500/16578031.3450

Mantilla Castellanos, L. (2001). Habilidades para la vida. Una propuesta educativa para la promoción del desarrollo humano y la prevención de problemas psicosociales. $\mathrm{Fe}$ y Alegría. https://bit.ly/2GRRuQc

Mantilla, L., \& Chaín, I. (2012). Habilidades para la vida, manual para entenderlas y enseñarlas. EDEX.

Martínez, V. (2014). Habilidades para la vida: una propuesta de formación humana. Itinerario Educativo, (63), 61-89. https://dialnet.unirioja.es/servlet/ articulo? codigo $=6280206$

Ministerio de Educación Nacional. (1996). Proyecto Educativo Institucional. Lineamientos (Documentos de Trabajo), Santafé de Bogotá.

Ministerio de Salud y Proteccion Social. (2014). Caminemos juntos: algunas orientaciones y herramientas para la prevención y atención del embarazo en adolescentes. MinSalud. https:/www.minsalud.gov.co/sites/rid/Lists/ BibliotecaDigital/RIDE/VS/PP/AJ-Caminemos-juntos.pdf 
Morales Rodríguez, M., Benitez Hernandez, M., \& Agustín Santos, D. (2013). Habilidades para la vida (cognitivas y sociales) en adolescentes de zona rural. Revista Electrónica de Investigación Educativa, 15(3), 98-113. http://www.scielo.org.mx/ scielo.php?script=sci_arttext\&pid=S1607-40412013000300007

Rosabal García, E., Romero Muñoz, N., Gaquín Ramírez, K., \& Hernández Mérida, R. A. (2015). Conductas de riesgo en los adolescentes. Revista Cubana de Medicina Militar, 44(2), 218-229. http://scielo.sld.cu/scielo.php?script=sci_ arttext\&pid=S0138-65572015000200010\&lng=es\&tlng=es

Organización Mundial de la Salud. (1993). Life skills education for children and adolescents in schools: Introduction and guidelines to facilitate the development and implementation of life skills programmes. Division of Metal Health and Prevention of Substance Abuse.

Organización Mundial de la Salud. (2002). Informe sobre el consumo de SPA en el mundo. https://www.unodc.org/pdf/WDR_2004/wdr2004_vol1_spanish.pdf

Organización Mundial de la Salud. (2018). El embarazo en la adolescencia. https:// www.who.int/es/news-room/fact-sheets/detail/adolescent-pregnancy

Profamilia. (2018). Determinantes del embarazo en adolescentes en Colombia, explicando las causas de las causas. https:/www.minsalud.gov.co/sites/rid/Lists/ BibliotecaDigital/RIDE/VS/ED/PSP/informe-determinantes-sociales-embarazoen-adolescente.pdf preprint.pdf

Toro, S. (2018). Reincidencia juvenil en conductas delictivas. Un acercamiento comprensivo al problema en el Instituto de Formación Toribio Maya (Documento Universitario). Universidad del Cauca, Popayán, Colombia.

Toro, S. (2016). Estructuras: visualización del proceso. Religiosos Terciarios Capuchinos.

UNICEF. (2017). Habilidades para la vida, herramientas para el buen trato y la prevencion de la violencia. UNICEF. https://www.unicef.org/venezuela/media/431/ file/Habilidades $\% 20$ para\%20la\%20vida.\%20Herramientas\%20para\%20el $\% 20$ \#BuenTrato\%20y\%201a\%20prevenci\%C3\%B3n\%20de\%201a\%20violencia.pdf 


\section{Capítulo II}

\section{La salud mental y las habilidades}

para la vida

Roger Martínez Correa 


\section{Introducción}

En el presente capítulo se aborda la relación entre la salud mental y las habilidades para la vida $(\mathrm{HpV})$ desde un enfoque de prevención e intervención comunitaria que favorece el desarrollo personal, la mitigación de riesgos, el incremento del bienestar subjetivo y el fortalecimiento de las relaciones sociales positivas.

La conceptualización de la salud mental es compleja, por lo que presenta diversas acepciones; por ejemplo, la Organización Mundial de la Salud (OMS, 2001) la define como un estado completo de bienestar mental, físico y social y no simplemente la ausencia de la enfermedad. Aunque reconoce que el uso común e histórico tiende a igualar salud mental con profesionales y servicios asociados al diagnóstico, tratamiento y rehabilitación de personas afectadas por trastornos mentales, esta también abarca la promoción del bienestar, la prevención de los trastornos mentales y es un derecho, al igual que la salud física del más alto nivel e importancia (World Health Organization, 2010). La salud mental entonces

\footnotetext{
incorpora todas las dimensiones de la experiencia humana: biológicos, psicológicos, socioculturales, de desarrollo, políticos, ecológicos y espirituales. Si bien es un tema de investigación científica y estudio empírico, es también una construcción social. En la medida en que diferentes culturas y grupos sociales determinan cómo se entiende y cómo las perturbaciones surgen y se remedian. (Dudley et al., 2012, p. 3)
}

Desde una perspectiva integral, la salud es un estado de bienestar donde los factores psicológicos, emocionales y físicos del individuo interaccionan de forma armónica con el ambiente; es una condición tanto interna como externa, que puede verse afectada o favorecida por múltiples factores y puede variar en su comprensión entre una cultura y otra (Suman, 2014). De hecho, las personas que han estado expuestas a situaciones de guerra, pérdida de la libertad y otras condiciones extremas, presentan un mayor riesgo de sufrir trastornos de salud mental y de ver afectada de forma significativa su bienestar (Aggarwal, 2015); y las condiciones de pobreza, exclusión social y falta de acceso a servicios como la educación, como ocurre a muchas poblaciones en América Latina, constituyen factores de riesgo en salud mental (Grey \& Hall-Clark, 2015).

Son muchos los determinantes sociales que pueden afectar la salud mental entre ellos, las experiencias adversas de la vida, la discriminación, la pobre educación, el empleo en condiciones riesgosas, el empleo informal, el desempleo, la inequidad social, la pobreza, la inseguridad alimentaria, la falta de vivienda, subsistir en un 
ambiente físico en condiciones precarias, vivir en territorios inseguros o en guerra, acceso limitado a los servicios de salud y la inestabilidad política (Compton \& Shim, 2015).

En el caso de Colombia, la Encuesta Nacional de Salud Mental (MINSALUD, 2015) revela la prevalencia de trastornos mentales no transmisibles, especialmente el suicidio en adolescentes, el uso de drogas, la ansiedad y la depresión. Asimismo, da cuenta de los problemas de salud mental asociados a la exposición a la violencia infringida por el conflicto armado, entre ellos, el estrés postraumático, la depresión, la melancolía y los episodios depresivos. Teniendo en cuenta que la violencia ha generado daños emocionales, psicológicos y morales, y afectación en las esferas individuales, familiares y colectivas, se hace necesaria la atención de la población local a varios niveles, que incluya tanto a los sobrevivientes como a los excombatientes, los que permanecen en la guerra y los demás miembros de la sociedad.

La política nacional de salud mental (MINSALUD, 2018) que adoptó Colombia en el año 2018 cuenta con ejes de intervención y de prevención con alto énfasis comunitario y consideró los factores que afectan de modo más directo a la población local. La implementación de programas de habilidades para la vida es una de las estrategias sugeridas en la política para atender la prevención y el desarrollo social en las comunidades. Los ejes de dicha política son:

1. La promoción de la convivencia y salud mental.

2. La prevención de los problemas de salud mental individuales y colectivos.

3. La atención integral de trastornos mentales y problemas que requieren atención en salud mental.

4. La gestión, articulación y coordinación sectorial de los entes responsables.

5. La rehabilitación integral e inclusión social de personas que requieren atención por trastornos mentales o que presentan problemas que demandan atención en salud mental. 


\subsection{Las habilidades para la vida y la salud mental}

Las sociedades actuales requieren el desarrollo de competencias que den respuesta a los desafíos de los contextos sociales y culturales, a fin de lograr la formación de seres humanos que generen sociedades incluyentes, con mayor justicia y procesos sostenibles. Una de las estrategias viables para alcanzar tal propósito es la formación en HpV.

En el año de 1993, la Organización Mundial de la Salud propuso el enfoque de $\mathrm{HpV}$ integrando tres dimensiones extraídas de los modelos de formación humana más reconocidos en las últimas décadas del siglo XX, fueron estas: las habilidades sociales, cognitivas y control de emociones (Arévalo et al., 2005).

En el caso colombiano, la organización no gubernamental Fe y Alegría implementó programas de habilidades para la vida, trabajando la expresión emocional, el positivismo, el control de sentimientos y el manejo de conflictos para intervenir problemas de violencia, consumo de alcohol y de tabaco (Bravo, 2003; Bravo Hernández, 2015). Por otra parte, la Universidad de Nariño realizó una investigación relacionada con el consumo de tabaco y alcohol, concluyendo que el $85 \%$ de la población universitaria de estudio (360 hombres y 456 mujeres mayores de 18 años), tiene un bajo consumo de sustancias como alcohol y tabaco. Cabe resaltar que en el ámbito universitario se pueden llegar a adquirir comportamientos de riesgo asociados al consumo de sustancias psicoactivas. En la mitigación de dichos riesgos pueden jugar un papel importante las habilidades para la vida, puesto que la empatía, las relaciones interpersonales, la toma de decisiones, el pensamiento crítico, el manejo de tensiones y estrés son algunas de las habilidades que en la cotidianidad fundamentan los roles sociales.

Otro caso que aporta evidencias a favor de las HpV es el programa La Aventura de la Vida implementado en 1989 en el país vasco. Está dirigido a niños, niñas y adolescentes, con inclusión de padres y profesorado, y tiene como propósito la formación en valores. El programa temáticamente aborda los hábitos saludables, la autoestima, la prevención del consumo de sustancias psicoactivas y las habilidades para la vida. Es oportuno mencionar que países como México y Perú también han estado implementando programas con relación a este último tópico (Arévalo et al., 2005).

El enfoque de $\mathrm{HpV}$ es el desarrollo integral de niños, niñas y adolescentes, "así como la prevención de problemas psicosociales, la adquisición de competencias y habilidades específicas en diferentes niveles como el físico, psicológico, social, cognitivo, moral y vocacional" (Mantilla Castellanos, 2001, p. 7). 
Por otra parte, las HpV hacen una clara referencia a las aptitudes que deben tener los seres humanos en la vida para lograr solucionar con éxito dificultades cotidianas, generando comportamientos saludables; para esto se debe realizar un plan organizado en tres dimensiones: social, cognitiva y emocional (OMS, 2001).

La implementación de programas de $\mathrm{HpV}$ requiere de la participación de todos los miembros de la comunidad; en el caso de las instituciones educativas, por ejemplo, se deben diseñar teniendo en cuenta los directivos, los estudiantes, el profesorado y las familias (Villa Urrego et al., 2016).

Las $\mathrm{HpV}$ le permiten al ser humano tener recursos para mejorar la calidad de vida y elaborar diversos tipos de interacción social, logrando el fortalecimiento y el conocimiento de sí mismo, permitiendo la generación de estrategias de creatividad, la consciencia del autocuidado y la autorregulación. El enfoque HpV está compuesto por diez grupos de habilidades:

1. Conocimiento de sí mismo. Habilita reconocer nuestras fortalezas, nuestras debilidades, carácter, gustos y aporta a que podamos generar una comunicación asertiva.

2. Empatía. Capacidad de tener comportamientos solidarios, comprender al otro y colocarnos en su posición, imaginar cómo puede ser la vida de la otra persona y entender lo que le puede suceder.

3. Comunicación asertiva o efectiva. Tiene que ver con la manera apropiada de comunicamos con el otro, de acuerdo con el momento y el contexto, sabiendo dar las respuestas adecuadas.

4. Relaciones interpersonales. Considera un grupo de destrezas que facilitan la interacción de forma efectiva y positiva en sociedad; también indica como iniciar y mantener relaciones e interacciones de manera correcta en el contexto social.

5. Toma de decisiones. Ayuda a manejar de forma acertada la resolución de un problema; puede favorecer una calidad de vida diferente y, además, ayudar a evaluar las consecuencias de los actos.

6. Soluciones y problemas. Con esta habilidad se aprende a superar las adversidades que, si no son resueltas, podrían traer problemas psicológicos, emocionales y físicos. Fortalecer esta área puede ayudarnos a promover una cultura de paz. 
7. Pensamiento creativo. Nos ayuda a encontrar métodos diversos para solucionar o mejorar las circunstancias de nuestra vida. Tiene que ver con la invención de productos y servicios novedosos, conceptos y aspectos del pensamiento, la razón y la iniciativa.

8. Pensamiento crítico. Desarrolla la capacidad de ser objetivos, reconocer la justicia y la violencia e influye en nuestras actitudes y comportamientos; el pensamiento crítico permite filtrar y analizar la información que recibimos.

9. Manejo de sentimientos y emociones. Nos ayuda a reconocer la vida emocional y poder regular lo que sentimos en diferentes contextos y circunstancias, por otro lado, facilita entender la influencia de las emociones en el ámbito social.

10. Manejo de tensiones y estrés, esta es la habilidad que facilita el control y la regulación de la tensión, reconocer los momentos frustrantes, y nos ayuda a aprender a controlar las dificultades generadas en el entorno cotidiano mejorando la interacción social.

\subsection{La aplicabilidad de las HpV}

En Colombia, con respecto a la promoción de las $\mathrm{HpV}$ destacamos el trabajo de $\mathrm{Fe}$ y Alegría, institución que desarrolló un programa con base en este enfoque y reportó logros en los participantes y mayor dominio de las habilidades. Se sugiere que las $\mathrm{HpV}$ son útiles en el entorno social y benefician a niños, niñas, adolescentes, y adultos. Pueden ser utilizadas en contextos comunitarios y educativos facilitando y apoyando el proceso de aprendizaje, el crecimiento personal, el desempeño del ejercicio como ciudadano, el desarrollo social e, incluso, el ejercicio laboral.

La aplicación de habilidades para la vida, según la Organización Panamericana de la Salud (OPS, como se cita en Mangrulkar et al., 2001), puede darse en cualquier tipo de población y cualquier contexto; para su implementación es necesaria la presencia de un facilitador, quien debe previamente tener conocimiento del enfoque, debe saber hacer y saber vivir, para que otros puedan adquirir las destrezas. 
Las $\mathrm{HpV}$ contribuyen al desarrollo de los seres humanos en diferentes ámbitos de la cotidianidad; es por ello relevante tener en cuenta las subjetividades que están permeadas por la cultura antes de su aplicación, bien como herramienta de prevención o con cualquier otro propósito, como bien explican Pérez y Patiño (2018), de formar $\mathrm{y}$ fortalecer aspectos que ayudan a superar las dificultades que se presentan a diario.

¿Por qué implementar las $\mathrm{HpV}$ en la prevención de problemas en la salud mental? Según Mantilla Castellanos (2001, p. 7), las HpV fueron creadas para generar prevención a los problemas psicosociales; así mismo, para que cada persona adquiriera competencias y habilidades en distintas áreas en la vida, igualmente evitar con ello la aparición de trastornos mentales.

Las intervenciones psicosociales pueden ser un escenario válido para aplicar y evaluar los programas de $\mathrm{HpV}$; por ejemplo, podrían implementarse en grupos familiares con violencia intrafamiliar, recibir el entrenamiento y evaluar si se desarrollan las habilidades para reconocer su situación y superarla.

Así mismo podrían ser útiles para el fortalecimiento de la empatía en procesos terapéuticos. En el caso de un grupo de apoyo, cuando un individuo expresa algún hecho doloroso y cualquiera de los asistentes expresa que se sintió de alguna manera identificado con la experiencia vivida por el otro, esto refleja el desarrollo empático dentro de un contexto.

En cuanto, a la toma de decisiones, es evidente que todas las personas debemos aprender a resolver asuntos eficiente y eficazmente. Todos podemos mejorar la forma en que decidimos porque de una $u$ otra manera, nos afecta a nosotros mismos y al entorno social.

Otra de las habilidades desarrolladas por aprendizaje es la solución de problemas; con esta logramos evitar que los conflictos se ahonden y que sean el inicio de episodios negativos sucesivos.

El pensamiento creativo ayuda de manera natural, y sin ningún tipo de imposición, a generar estrategias, invenciones, conceptos, razonamiento e iniciativas de desarrollo, logrando la producción de ideas para la resolver problemas (Moreira Cevallos, 2018). 
El pensamiento crítico desarrolla la pericia de ser objetivos, reconocer la justicia, la violencia, e influye en nuestras actitudes y comportamientos; nos permite el análisis, con la mayor objetividad posible, de la información que nos llega (Reyes Merchán, 2018).

Por lo anterior, se presume que integrar las habilidades en los diferentes ámbitos de la vida cotidiana favorece la salud mental.

Ahora bien, cuando descubrimos, analizamos, conocemos y entendemos nuestras debilidades y fortalezas, que es a lo que se llama el conocimiento de sí mismo, logramos claridad acerca de las herramientas con las que contamos (Hayes \& Fryling, 2013), como podemos utilizarlas e incluso como generamos una comunicación más asertiva, lo que conlleva tanto una mayor interacción entre congéneres, como el desafío de la creación de nuevas ideas y proyectos.

Por cuanto se refiere a la comunicación asertiva, es una habilidad que no se desarrolla con facilidad en todas las personas, por ello es importante formarla no solo en ámbito educativo, sino además en los otros contextos sociales, de manera tal que logre impactar el entorno, en especial, las interacciones que en él se desarrollan (Villalobos \& García, 2016).

Hay que tener en cuenta que la relación interpersonal requiere habilidades que hay que desarrollar correctamente y que son fundamentales en la cotidianidad, incluso, el hecho de no tener buenas relaciones interpersonales puede resultar en la falta de redes de apoyo (Coronado Corrales, 2019), siendo estas las que pueden generar bienestar en momentos de crisis.

Desarrollar la habilidad de tomar decisiones implica no solo aprender a manejar un problema y solucionarlo, sino además saber sortear los impases que se presenten a futuro; evita caer en un círculo vicioso, ser reiterativos o finalmente llegar a ser ineficaces en la resolución de las dificultades cotidianas (Moreno-Mendoza et al., 2019).

Hacen parte del transcurrir cotidiano vivir las dificultades y su superación, y es por ello por lo que no se puede dejar atrás el refuerzo de habilidades para la vida, pues cuando sabemos identificar las causas, las consecuencias y el desenlace de cada inconveniente que se presenta, logramos solucionar la crisis que se presenta y la próxima será resuelta con mayor facilidad. Por el contrario, cuando no se logran desarrollar estas destrezas, se cae en el mismo círculo vicioso, pues el problema estimula el pensamiento (Luy-Montejo, 2019). 
Otro punto de gran relevancia es el pensamiento crítico que, como lo argumentan Frutos \& Pastor (2019), ayuda a reconocer los contextos de violencia, noticias falsas, generando síntesis y análisis, lo que conlleva realmente a un cambio social; en contextos educativos, los alumnos aprenden a diferenciar y a crear sus propias oportunidades.

Por otra parte, el control de las emociones durante las interacciones sociales ayuda a gestionar la experiencia subjetiva; su manejo inadecuado genera problemas y podría llevar a la aparición de trastornos mentales. A modo de ejemplo, en los adolescentes, la falta de manejo de la frustración puede obedecer a la poca gestión emocional (Oramas Viera et al., 2006). De igual modo, la carencia de habilidades sociales en individuos adolescentes en el ámbito escolar aumenta la frecuencia de las agresiones, y los sujetos que son víctimas cuentan con menos herramientas para encontrar salida a esa crisis (Buey \& Varela, 2009).

Morales et al. (2013) sugieren que las habilidades para la vida pueden ser aplicadas en una población de adolescentes en una zona rural; el resultado de su estudio con esta población demostró que las habilidades sociales y de afrontamiento fueron mayores en el grupo entrenado durante un programa de $\mathrm{HpV}$, en comparación con quienes no fueron entrenados.

\section{Conclusión}

Las habilidades para la vida pueden mejorar la salud mental siendo un enfoque que, al desarrollarse en una población, puede tanto evitar la anulación del otro y las agresiones propias y a externos, como aportar a la comprensión del contexto y a la búsqueda de la solución de conflictos.

En cuanto a la presencia de trastornos mentales, las $\mathrm{HpV}$ son generadoras de bienestar, ya que cada una de éstas faculta un aprendizaje para lograr las interacciones apropiadas en diferentes entornos, favoreciendo los intercambios afectivos sanos; a su vez, propenden por el conocimiento de las propias capacidades y limitaciones, aspectos todos que -sin ser los únicos-interactúan conformando una fuerte estrategia de prevención en el desarrollo de enfermedades mentales. 
Por demás, es una obligación moral del Estado colombiano promover que los niños y niñas crezcan con las habilidades necesarias para que nunca más el país vuelva a vivir una guerra absurda que solo deja perdedores. Finalmente, cabe anotar que la implementación de las habilidades para la vida en el contexto colombiano se debe realizar de manera profunda mediante la puesta en marcha de una política de salud mental que propenda por mejorar los entornos de sus habitantes con miras a la obtención de una mejor calidad de vida.

\section{Referencias}

Aggarwal, N. K. (2015). Mental health in the war on terror: culture, science, and statecraft. Columbia University Press.

Arévalo, M. A., Rojas, A. T., \& Mendoza, L. (2005). Habilidades para la vida y su importancia en la salud. Dirección Ejecutiva de Educación para la Salud.

Bravo, A. (2003). Habilidades para la vida: una experiencia de Fe y Alegría en Colombia. Federación Internacional de Fe y Alegría, Movimiento de Educación Popular Integral y Promoción Social. http://centroderecursos.alboan.org/ ebooks/0000/0729/6_FyA_HAB_2003.pdf

Bravo Hernández, A. J. (2015). De habilidades a capacidades y competencias para la vida en la experiencia de Fe y Alegría Colombia. Congreso Reflexionando Las Disciplinas, 263-272. https://www.google.com.co/url?sa=t\&rct=j\&q=\&esrc=s $\&$ source $=$ web\&cd $=1 \&$ cad $=$ rja\&uact $=8 \& v e d=0$ ahUKEwjJ8IaYv63WAhUK6iY KHaUrBK8QFggnMAA\&url=http\%3A\%2F\%2Fwww.umariana.edu.co\%2Fojseditorial\%2Findex.php $\% 2$ Flibroseditorialunimar $\% 2$ Farticle $\% 2 \mathrm{Fview} \% 2 \mathrm{~F} 693 \% 2 \mathrm{~F}$ 616\&usg=AFQjCN

Buey, M., \& Varela, M. (2009). Habilidades sociales y acoso escolar: un estudio en centros de enseñanza secundaria de Madrid. Revista Española de Orientación y Psicopedagogía, 20(1), 39-49. http://dialnet.unirioja.es/servlet/articulo?codigo=2 952124\&orden $=1 \&$ info $=$ link

Compton, M. T., \& Shim, R. S. (2015). The social determinants of mental health. American Psychiatric Association. https://doi.org/10.1176/appi.focus.20150017 
Coronado Corrales, N. E. (2019). Programa de habilidades sociales para desarrollar buenas relaciones interpersonales en los estudiantes del 5to grado de educación primaria de la ie "juan tomis stack"-chiclayo-2017. http://repositorio.unprg.edu.pe/ handle/UNPRG/7268

Dudley, M., Silove, D., \& Gale, F. (2012). Mental health and human rights: Vision, praxis, and courage. Oxford University Press.

Frutos, A. E., Rus, T. I., \& Pastor, B. A. (2019). El absentismo escolar en contextos vulnerables de exclusión. Profesorado, Revista de Currículum y Formación del Profesorado, 23(1), 121-139. https://doi.org/10.30827/profesorado.v23i1.9147

Grey, H., \& Hall-Clark, B. N. (2015). Cultural considerations in Latino American mental health. Oxford University Press. https:/www.oxfordclinicalpsych.com/ view/10.1093/med:psych/9780190243425.001.0001/med-9780190243425

Hayes, L. J., \& Fryling, M. J. (2013). Conocimiento de sí mismo como interconducta. Conductual, 1(1). http://conductual.com/articulos/Conocimiento $\% 20 \mathrm{de} \% 20 \mathrm{si} \% 20$ mismo\%20como\%20interconducta.pdf

Luy-Montejo, C. (2019). El Aprendizaje Basado en Problemas (ABP) en el desarrollo de la inteligencia emocional de estudiantes universitarios. Propósitos y Representaciones, 7(2), 353-383. https://orcid.org/0000-0003-0824-7959

Mangrulkar, L., Whitman, C., \& Posner, M. (2001). Enfoque de habilidades para la vida para un desarrollo saludable de niños y adolescentes. Organización Panamericana de la Salud. http://www.codajic.org/sites/www.codajic.org/files/ Enfoque\%20de\%20Habilidades\%20para\%201a\%20vida\%20OPS_0.pdf

Mantilla Castellanos, L. (2001). Habilidades para la vida: una propuesta educativa para la promoción del desarrollo humanoy la prevención de problemas psicosociales. Fe y Alegría. https://bit.ly/2GRRuQc

MINSALUD. (2015). Encuesta Nacional de Salud Mental, Tomo 1. Ministerio de Salud y Protección Social. https://www.minsalud.gov.co/sites/rid/Lists/BibliotecaDigital/ RIDE/VS/ED/GCFI/doc-metodologia-ensm.pdf 
MINSALUD. (2018). Política Nacional de Salud Mental. https://www.minsalud.gov. $\mathrm{co} /$ sites/rid/Lists/BibliotecaDigital/RIDE/VS/PP/politica-nacional-salud-mental. pdf

Morales, M., Benitez, M., \& Agustín, D. (2013). Habilidades para la vida (cognitivas y sociales) en adolescentes de una zona rural. Revista Electrónica de Investigación Educativa, 15(3), 98-113. http://www.scielo.org.mx/scielo.php?script=sci_arttext\& pid $=$ S1607-40412013000300007

Moreno-Mendoza, I. L., Pérez-Forero, K. Y., Salinas, J. F., Carrillo-Sierra, S. M., \& Bonilla-Cruz, N. J. (2019). Perspectiva de intervención: habilidades para la vida en jóvenes de educación técnica. Archivos Venezolanos de Farmacología y Terapéutica, 38(5), 642- 647. https://hdl.handle.net/20.500.12442/5025

Moreira Cevallos, M. A. (2018). Estrategias metodológicas en el desarrollo del pensamiento creativo en la asignatura de Lengua y Literatura [Trabajo de grado, Universidad de Guayaquil]. http://repositorio.ug.edu.ec/handle/redug/34917

Oramas Viera, A., Santana López, S., \& Vergara Barrenechea, A. (2006). El bienestar psicológico, un indicador positivo de la salud mental. Revista Cubana de Salud y Trabajo, 7(1-2), 6-18. http://roa.ult.edu.cu/bitstream/123456789/1424/1/Bienestar Psicologico...Salud Mental.pdf

Organización Mundial de la Salud. (2001). Informe sobre la salud en el mundo 2001: Salud mental: nuevos conocimientos, nuevas esperanzas. https://www.who.int/ whr/2001/en/whr01_es.pdf?ua=1

Pérez, Y. A. M., \& Patiño, D. F. (2018). Habilidades para la vida y sana convivencia. Boletin Informativo Universidad Mariana, 5(3), 7. http://repository.lasallista.edu. co:8080/ojs/index.php/EN-Clave/article/view/949

Reyes Merchán, K. E. (2018). Importancia del aprendizaje significativo en el desarrollo de habilidades del pensamiento crítico [Trabajo de grado, Universidad de Guayaquil]. http://repositorio.ug.edu.ec/handle/redug/36489 
Suman, F. (2014). Mental health worldwide culture, globalization and development. Palgrave Macmillan. DOI: 10.1057/9781137329608

Villa Urrego, M. A., Castellano Ascencio, M. D., \& Peña Santodomingo, J. M. (2016). Academic reading and writing at the university: Writing centers at a glance. $E N$ Clave Social, 4(1), 36-43. http://repository.lasallista.edu.co:8080/ojs/index.php/ EN-Clave/article/view/949

Villalobos, M. E. U., \& García, A. C. (2016). El liderazgo académico, comunicación asertiva y motivación. Revista Ensayos Pedagógicos, 11(2), 45-61. https://doi. org/10.15359/rep.11-2.2

World Health Organization. (2010). Health topics: mental health. https://www. isdscotland.org/health-topics/mental-health/publications/data-tables.asp 


\section{Capítulo III}

Habilidades cognitivas: Mecanismo para el proceso de aprendizaje y la resolución de problemas 


\section{Introducción}

El pensamiento es considerado una serie abstracta y compleja de procesos determinados por los estímulos y la memoria; su puesta en marcha, como lo afirma Arboleda (2013) conduce al ser humano a reflexionar ante situaciones de su diario vivir, poniendo en práctica sus representaciones y estrategias de orden real, ideal o imaginario a partir de los procesos de la razón, que son acumulados y desarrollados a lo largo del tiempo.

Hablar de pensamiento nos conduce de inmediato al término cognición, que es definido por Verghese (2010) como la capacidad para obtener, interpretar y darle significado a la información del entorno, que es adquirida a través de las tradiciones culturales, las experiencias de la vida, las relaciones sociales, entre otros medios.

Este capítulo aborda el tema de las habilidades cognitivas como el mecanismo y el proceso de aprendizaje con el que cuentan los seres humanos para la solución de los problemas de su vida cotidiana y de la realidad social en la que viven. A continuación, se describirá qué son y cuál es su clasificación, con miras a una conceptualización que aporte a generar futuras propuestas para su uso a nivel educativo, especialmente con los adolescentes.

\section{1. ¿Qué son las habilidades cognitivas?}

El ser humano hace uso de la memoria, la percepción, la atención, el pensamiento abstracto o analógico, la creatividad, la inteligencia, el aprendizaje y la experiencia, para procesar información e interactuar competentemente y de manera simbólica con el entorno en el que se desenvuelve.

Este grupo de actitudes conforman las habilidades cognitivas, que son definidas por Ramos et al. (2010) como las destrezas y técnicas de la mente obligatorias para llevar a cabo una tarea, que además facilitan la adquisición de conocimiento. Su obtención requiere de tres momentos: el reconocimiento, el desarrollo y la capacidad para ser utilizada de manera independiente. 
Otra definición es la de Laorden et al. (2005), quienes consideran que son las operaciones de la mente que el hombre utiliza para aprender de una situación determinada; y la de Meyer et al. (2008), quienes las enuncian como capacidades esenciales de la mente que se utilizan para el razonar.

Siguiendo esta línea, Argudin y Luna (2005) afirman que las habilidades forman una estructura fundamental del ser humano, puesto que le permiten discriminar, identificar y clasificar conceptos para construir y resolver problemas; por demás, "están en la base de los procesos de transferencia que propician una construcción continuada de estructuración de procesos mentales cada vez más complejos, en la dirección de la construcción/reconstrucción de estrategias cognitivas" (p. 133).

Por lo anterior, estas habilidades se encuentran asociadas a la inteligencia y a partir de allí, con base en pruebas y mediciones, han sido clasificadas en dos grupos: inteligencia fluida y cristalizada. El primero reúne las habilidades para detectar patrones y razonar hechos; el segundo grupo se relaciona con los conocimientos adquiridos durante la vida. Esto último pone en evidencia que dichas habilidades pueden ser moldeables con el transcurrir del tiempo y que se adquieren tanto por genética como por la crianza.

\subsection{Clasificación de las habilidades cognitivas}

Las habilidades cognitivas, como indica Raffino (2018), corresponden a un conjunto de actividades intelectuales concretas que están asociadas con la previsión, la planificación, la evaluación y la innovación. Con la primera, se valoran las consecuencias de toda acción antes de realizarla; la segunda es la capacidad de elegir las consecuencias y alcanzar los propósitos; la tercera es la que permite juzgar individualmente la conveniencia o el peligro de una acción; y la última es la facultad de encontrar alternativas o nuevos caminos hacia las metas deseadas.

Como ya se ha dicho, estas habilidades se adquieren a lo largo de la vida y se representan a través del autoconocimiento, la autoeficacia, el afrontamiento, el pensamiento creativo, la toma de decisiones y el pensamiento crítico. A continuación, se describirán cada una de ellas. 


\subsubsection{Autoconocimiento}

Tener conocimiento acerca de nosotros mismos y de quienes somos, hace que nos reconozcamos como seres humanos no solo pensantes, sino con habilidades para entender y aceptar tanto las diferencias como la diversidad.

El autoconocimiento, como lo describe Suanes (2009), es la capacidad de introspección que tiene cada una de las personas para reconocerse como un individuo con una identidad que lo hace único; en dicho proceso, las personas de manera reflexiva adquieren una noción de su yo, con sus cualidades, defectos, limitaciones, necesidades, aficiones y temores. Este debe ser considerado como un tema de transversal no solo en el ámbito cotidiano, sino también en el educativo, ya que la formación en valores no es suficiente cuando se carece de un referente formativo para conocerse y ser mejor.

Figura 3.1. Fases del autoconocimiento

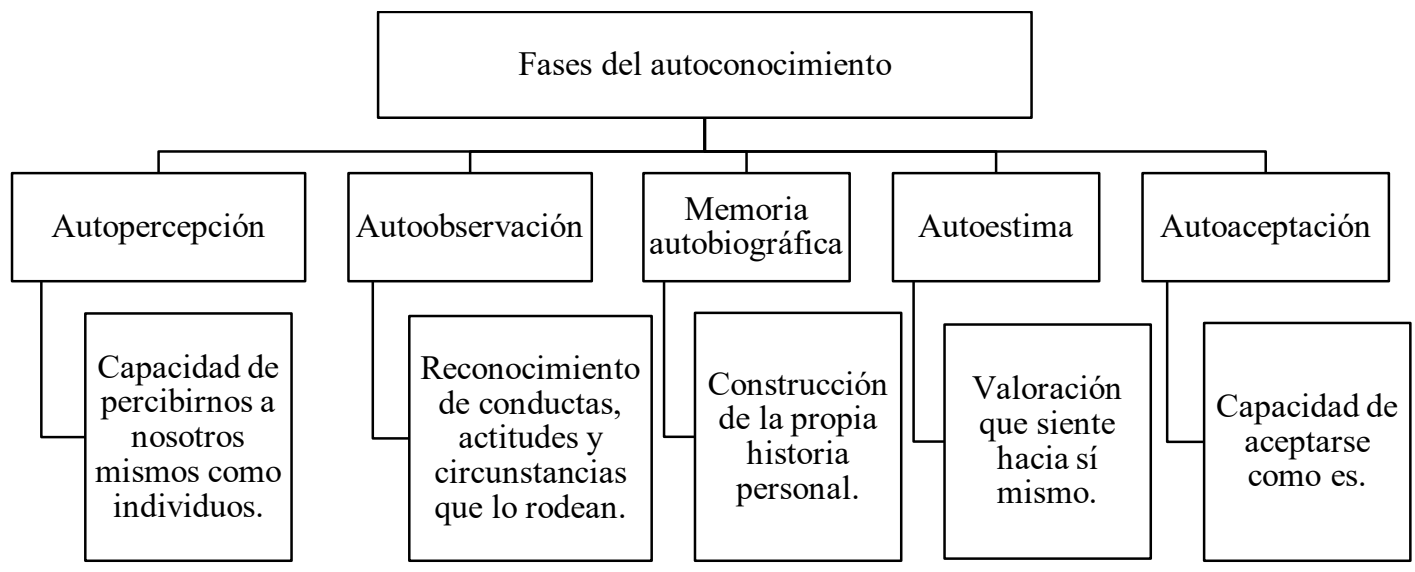

Nota: adaptado de Suanes (2009, p. 3).

Como se describe en la Figura 3.1, el autoconocimiento implica que cada ser humano se observe y se autorreconozca, formando de sí mismo una percepción y aceptando su forma de ser, que sin lugar a duda está permeada por la sociedad a la que pertenece. Las personas entonces deben reconocer y aceptar la realidad propia, para generar crecimiento personal y fomentar buenas relaciones con los otros. 
Durante la etapa de la adolescencia, el fortalecimiento del autoconocimiento aporta al manejo de emociones y a la resolución de problemas derivados de situaciones como las relaciones sentimentales y familiares, el duelo, entre otras; por ello, si se tiene un buen nivel de conocimiento de sí mismo, en palabras de Goleman (2004), se lograría que los jóvenes hablaran abiertamente de sus emociones, de reconocer señales emocionales internas, de identificar sus sentimientos y de tener claros los valores que deben regir su conducta.

Este conocimiento, sin lugar a duda, ayudaría a los adolescentes a identificar, expresar y mantener bajo control sus emociones, impidiendo tanto que sus impulsos emocionales se conviertan en factores de estrés, como que los eventos tensionantes los desmoronen (Bar-On, 1997).

Por lo tanto, el autoconocimiento permite reconocer las propias emociones, evaluar las experiencias y comprender los vínculos entre lo que se piensa, se dice y se hace.

\subsubsection{Autoeficacia}

Los seres humanos están en la capacidad de identificar y plantear sus metas, así como de mejorar los aspectos necesarios para cumplirlas. La habilidad que les permite entonces creer en sus capacidades para poder hacerle frente a diversas situaciones, se denomina autoeficacia.

Dicho concepto fue utilizado por primera vez por Bandura (1995), quien consideraba que el pensamiento regula la motivación y la conducta humana mediante las expectativas de la situación, del resultado y de la autoeficacia. Las primeras son producidas por efectos ambientales, las segundas por la creencia que una conducta producirá un resultado específico, y la tercera por el reconocimiento que una persona tiene de sus capacidades para desempeñar una acción y obtener el efecto deseado.

Sin embargo, la autoeficacia conduce al aumento o reducción de la motivación; al respecto Olivari y Urra (2007) presentan el siguiente ejemplo:

Las personas con alta autoeficacia eligen desempeñar tareas más desafiantes, colocándose metas y objetivos más altos. Una vez que se ha iniciado un curso de acción, las personas con alta autoeficacia invierten más esfuerzo, son más persistentes y mantienen mayor compromiso con sus metas frente a las dificultades, que aquellos que tienen menor autoeficacia. (p. 10) 
Entonces, esta habilidad hace referencia a la efectividad de una persona al afrontar diversas situaciones que están mediadas por el estrés y un contexto específico. Además, debido a que el ser humano establece juicios, puede determinar el éxito o fracaso de su desempeño, transformando las creencias y reflejándolas en decisiones posteriores.

Según Bandura (1997), las creencias de autoeficacia tienen cuatro fuentes principales (ver Figura 3.2).

\section{Figura 3.2. Fuentes de la autoeficacia}

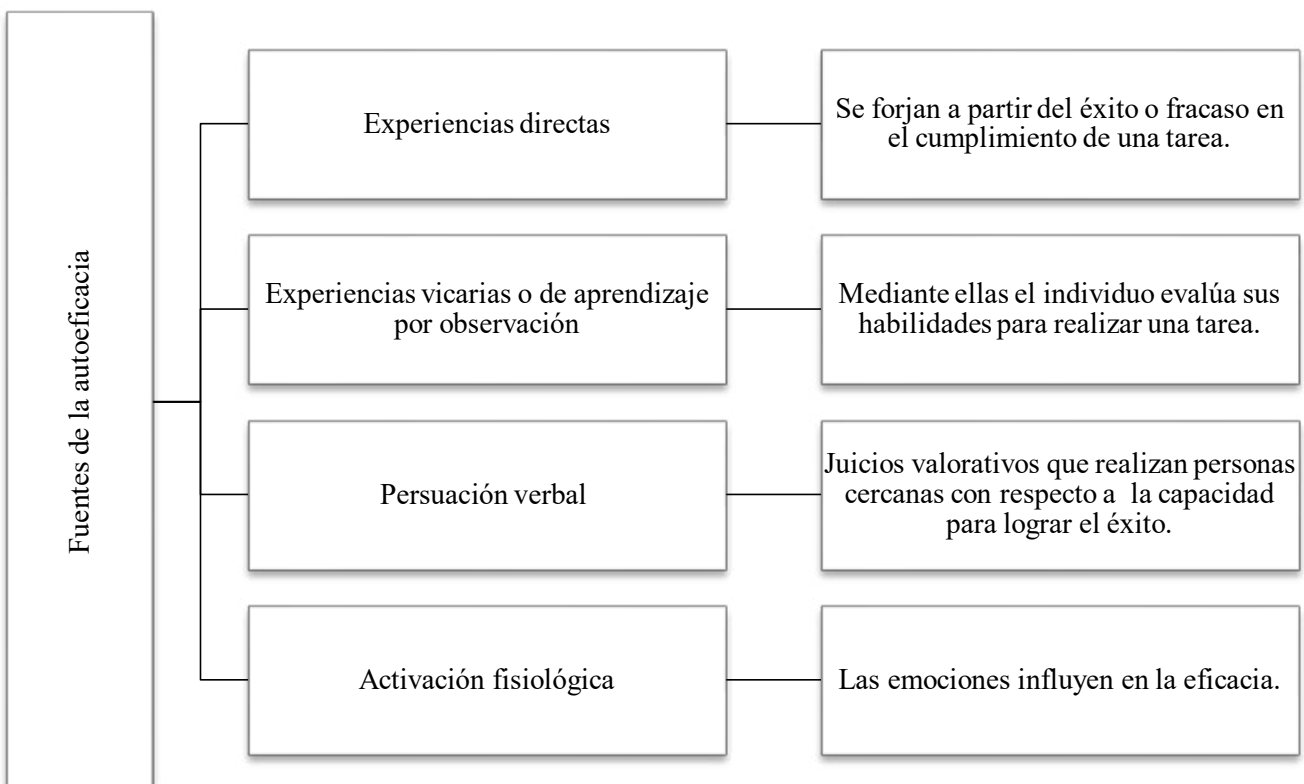

Nota: adaptado de Bandura (1997, p. 158)

En definitiva, teniendo en cuenta las fuentes de la autoeficacia, el ser humano forma creencias acerca de lo que puede hacer y las desarrolla anticipándose a los resultados negativos o positivos que pueda obtener de acuerdo con sus expectativas o metas. 


\subsubsection{Afrontamiento}

Los individuos generan respuestas cognitivas, emocionales y de comportamiento que les permiten resistir y manejar el estrés, en determinadas situaciones de la cotidianidad. Autores como Lazarus y DeLongis (1983) plantean que el afrontamiento es un proceso que se encuentra permeado por los rasgos y patrones temperamentales con los que las personas enfrentan las condiciones en las que se desenvuelven diariamente, por ejemplo, la familia y la sociedad. Las estrategias generalmente utilizadas se centran en la emoción para así evitar el estrés o para afrontar una situación problema.

Dichas estrategias, en primera instancia, se centran en el problema para conocer la orientación que se le debe dar a la tarea, modificarlo o resolverlo; en segunda instancia, se enfocan en las emociones y son utilizadas al detectar un evento incontrolable o que puede ser percibido como peligroso; y en tercera instancia se encuentra la evitación, que se evidencia cuando el individuo aplaza el afrontamiento.

A lo largo de los años, algunos autores se han encaminado a conceptualizar el afrontamiento, tal y como se evidencia en la Tabla 3.1.

\section{Tabla 3.1. Conceptos de afrontamiento}

\begin{tabular}{|c|c|}
\hline Autor & Concepto \\
\hline Mechanic (1962) & Conocimientos que una persona ha obtenido para la resolución de problemas. \\
\hline Lazarus (1966) & Estrategias para tratar las amenazas. \\
\hline Lipowski (1970) & $\begin{array}{l}\text { Procesos cognitivos y actividades motoras que sirven para salvaguardarse o } \\
\text { mejorarse ante una enfermedad. }\end{array}$ \\
\hline Pearlin \& Schooler (1978) & Cualquier respuesta para controlar el estrés ante una tensión o situación. \\
\hline Folkman \& Lazarus (1984) & $\begin{array}{l}\text { Esfuerzos cognitivos y de la conducta que desarrolló el ser humano para manejar } \\
\text { demandas desbordantes. }\end{array}$ \\
\hline $\begin{array}{l}\text { Frydenberg \& Lewis } \\
(2000)\end{array}$ & Interacción dinámica entre las personas y su ambiente. \\
\hline Dwyer (2005) & $\begin{array}{l}\text { Las expectativas y experiencias culturales influyen en que los individuos sientan } \\
\text { más o menos estrés por determinados eventos. }\end{array}$ \\
\hline De Minzi (2006) & $\begin{array}{l}\text { Proceso que implica la conducta y el pensamiento para atender una situación } \\
\text { particular. }\end{array}$ \\
\hline Díaz Martín (2010) & Recurso psicológico de los sujetos para determinar su calidad de vida. \\
\hline
\end{tabular}

El afrontamiento, entonces, implica los procesos cognitivos, conductas, expectativas, experiencias culturales y el pensamiento que cada individuo ha consolidado a lo largo de su existencia y que ha aprendido a través de su cotidianidad. 
Durante la época escolar, ante el ambiente de estrés y las presiones a las que se enfrentan los adolescentes, tales como el trabajo en equipo, la organización de la información, la resolución de problemas, entre otras, el desarrollo del afrontamiento permitirá que se focalicen las emociones y los problemas, a través de la modificación de los eventos que causan tensión disminuyendo su impacto y los sentimientos negativos, como lo plantean Lazarus y DeLongis (1983), permitiendo así que cada sujeto utilice las estrategias que al respecto domina.

Siguiendo esta perspectiva, en 1997, Erika Frydenberg elabora un nuevo modelo de afrontamiento partiendo de que el individuo al valorar determinada situación, tiene en cuenta tanto el impacto de estrés y las posibles consecuencias que este tendrá (pérdida, daño), como los recursos que tiene disponibles para manejarlo; luego se reevalúa el resultado y con base en ello se plantea otra respuesta para afrontarlo. De este modo, el modelo utiliza un mecanismo de retroalimentación que permite al individuo determinar si esta estrategia ingresará a su repertorio de afrontamiento o si será descartada.

Es importante subrayar que los estudios realizados por investigadores como Frydenberg (2000), Casullo y Fernández Liporace (2001), González Barrón et al. (2002), y Figueroa et al. (2005), explican que las mujeres y los hombres emplean diferentes formas de afrontamiento; por ejemplo, para afrontar una situación, las mujeres acuden a buscar el apoyo social, espiritual y reducir la tensión, mientras que los hombres optan por la distracción física e ignorar el problema. Esto evidencia que el perfil de afrontamiento de los hombres es más reducido, por lo que es importante desarrollar y/o fortalecer sus competencias y habilidades para enfrentar cualquier situación en la adolescencia y la adultez.

En síntesis, el afrontamiento es el que permite al ser humano resolver problemas de manera práctica, a través de la gestión de las emociones y el estrés, en un momento o contexto determinado. 


\subsubsection{Pensamiento creativo}

La creatividad debe ser entendida como la capacidad de aplicar y generar en un contexto determinado el cumplimiento de un nuevo objetivo específico, por medio de habilidades tales como la selección y organización de información relevante con nuevos datos, la capacidad de autoorganización, la interdisciplinariedad, la capacidad de reflexión, evaluación y de aprender de los errores.

Csikszentmihalyi (1998) define la creatividad como la capacidad que da sentido a nuestras vidas, ya que las cosas importantes e interesantes son resultado de esta, de ahí que cuando la adoptamos sentimos que estamos viviendo plenamente. Por su parte, para De la Torre (2006), la creatividad es un fenómeno complejo que tiene movimiento, comienza por la conciencia y pone en marcha procesos de aprendizaje, mediante tres planos: la relación entre persona-producto, el proceso de transformación con los efectos que estos implican y la dinámica relacional entre necesidades y condiciones. Entretanto, para Sternberg (1999) es una situación compleja en donde interactúan múltiples procesos vinculados a los ámbitos cognitivos.

El pensamiento creativo exige desarrollar mínimo dos ámbitos: el cognitivo y el socioafectivo; al primero se vincula la inteligencia, el manejo y el procesamiento de la investigación, tal y como lo resume la Figura 3.3.

Figura 3.3. Habilidades del ámbito cognitivo

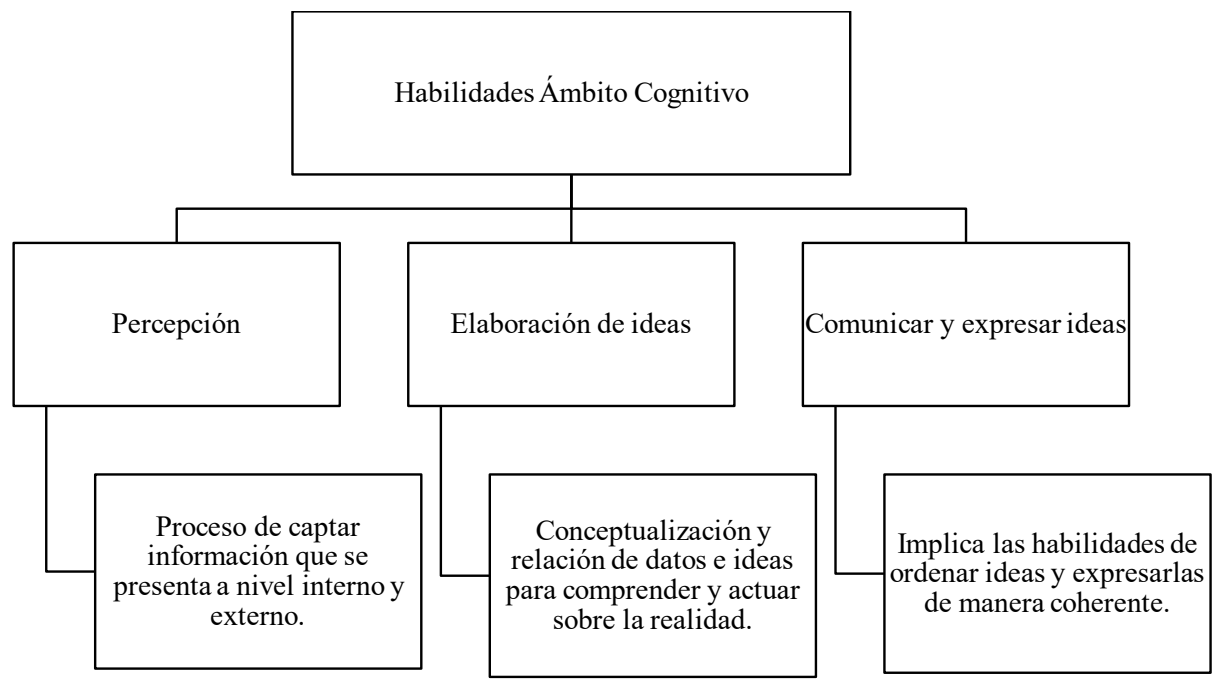

Nota: adaptada de Moromizato (2007, p. 313). 
Al segundo, el ámbito socioafectivo, concierne la apertura a la experiencia, tolerancia a la ambigüedad, autoestima positiva, perseverancia, motivación a crear y habilidades sociales, como lo describe la Figura 3.4.

Figura 3.4. Habilidades del ámbito socioafectivo

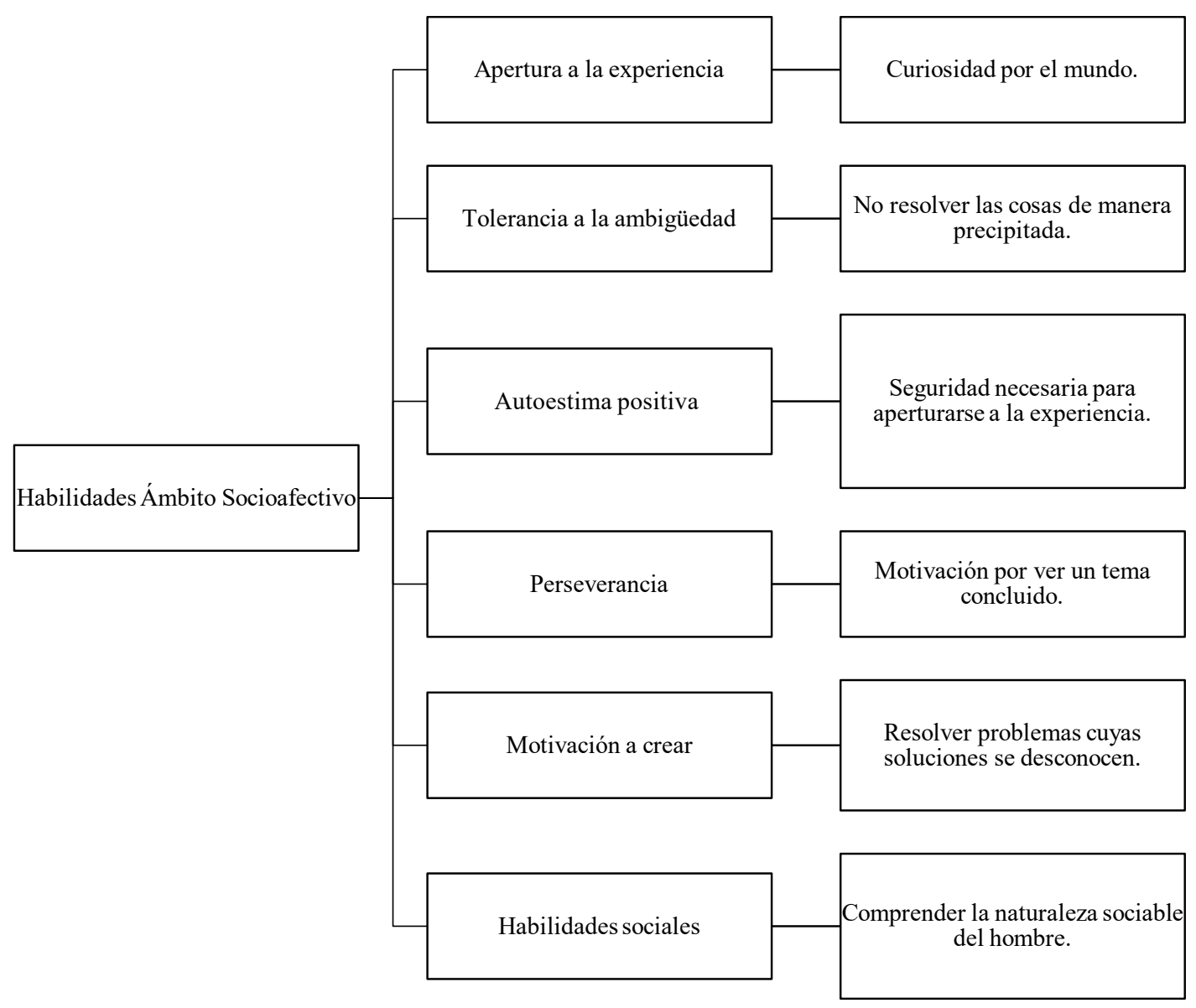

Nota: adaptado de Moromizato (2007, p. 314). 
Lo anterior nos lleva a concluir que el pensamiento creativo implica desarrollar ideas novedosas, respetando el tiempo, los espacios y las opiniones de los otros. Desde esta perspectiva, cabe mencionar que Landau (1987) explica la creatividad como un coloquio en el que se debe aprender a utilizar los sentidos para mirar, escuchar con atención, palpar y sentir.

El desarrollo del pensamiento creativo en los jóvenes, a partir de la motivación, como lo afirman Hausner y Schlosberg (1998), permite mejorar la capacidad de ver las cosas desde diferentes perspectivas y la posibilidad de mantener la mente abierta frente a las nuevas ideas o situaciones; esto contribuirá, además, a que se sientan felices y en un futuro disfruten sus logros personales y profesionales.

Por lo anterior, es importante romper el conformismo, enseñar a preguntar y a dar respuestas, aportar un pensamiento interdisciplinar, estimular lo lúdico y no solo basarse en métodos rigurosos de trabajo.

\subsubsection{Toma de decisiones}

Diariamente nos encontramos con situaciones que nos conducen a elegir entre distintas opciones, este proceso que realiza el ser humano se conoce como toma de decisiones. Entre quienes lo definen podemos mencionar a Hellriegel y Slocum (2004), autores que anotan que faculta definir los problemas y recolectar datos para proponer alternativas y darles un curso de acción; y a Stone et al. (2001) quienes consideran que es el juicio que permite la identificación y la solución de un problema específico.

La toma de decisiones se evidencia en cualquier contexto de la vida cotidiana: el familiar, el laboral, el social y demás, por lo que se debe apelar a la capacidad de análisis o de razonamiento para determinar el mejor camino posible, que le permita a la persona encontrarse con resultados positivos o hallar la solución más adecuada a una problemática. Es importante denotar que probablemente las decisiones estén impregnadas de presiones, de opiniones, de prejuicios morales y hasta de la cultura en la que se ha desarrollado. Por ello, para la toma de decisiones es importante tener en cuenta lo planteado en la Figura 3.5. 
Figura 3.5. Pasos para la toma de decisiones

\begin{tabular}{|c|c|c|c|c|c|}
\hline $\begin{array}{l}\text { Describir el } \\
\text { problema o el } \\
\text { objetivo al que } \\
\text { se quiere } \\
\text { llegar. }\end{array}$ & $\begin{array}{l}\text { Analizar el } \\
\text { problema o la } \\
\text { decisión a } \\
\text { tomar. }\end{array}$ & $\begin{array}{c}\text { Generar } \\
\text { alternativas. }\end{array}$ & $\begin{array}{l}\text { Selección de la } \\
\text { alternativa que } \\
\text { finalmente } \\
\text { llevaremos a } \\
\text { cabo. }\end{array}$ & $\begin{array}{l}\text { Pasar de la } \\
\text { decisión a la } \\
\text { acción. }\end{array}$ & $\begin{array}{l}\text { Valorar las } \\
\text { consecuencias } \\
\text { del éxito y de } \\
\text { la decisión } \\
\text { adoptada. }\end{array}$ \\
\hline
\end{tabular}

Los pasos para la toma de decisiones (Figura 3.5), en algunas ocasiones, se siguen sin ser conscientes de los diversos éxitos y errores que podemos encontrar en el camino, si ello cambia, aporta a que las resoluciones sean más acertadas. La toma de decisiones, afirman De Avalos y Velásquez (2000), pone en juego procesos cognitivos como el pensamiento de los estímulos, recordar experiencias y estimular las posibles consecuencias de cada una de las opciones escogidas.

Otros procesos cognitivos que implica son la observación, la comparación, la codificación, la organización, la clasificación, la resolución, la evaluación y la retroalimentación. La primera es entendida como la aplicación de los sentidos para estudiar una realidad; la segunda es la que determina la relación de semejanza de los asuntos tratados; la tercera busca transformar un código de formulación de un mensaje; la cuarta tiene que ver con la disposición y el orden; la quinta, con el ordenamiento sistemático y la categorización; la sexta, con las conclusiones del problema; la séptima, con los análisis y reflexiones de los razonamientos; y por último, la evaluación, con el proceso de mejora.

Pero sin lugar a duda, las emociones la guían y aceleran o simplifican los procesos, por ello, el ser humano está en la capacidad de tomar decisiones programadas o no. Describe Simon (1984) que las decisiones programadas son aquellas que se toman de manera tan frecuente que se convierten en rutinarias, por ejemplo, el número de horas que se le dedica a una determinada actividad académica, de la que ya se cuenta con un instructivo o protocolo; y las no programadas, son las que se toman ante un problema de poca frecuencia, por ejemplo, la adquisición de un nuevo software para el análisis de datos. 
La toma de decisiones en la adolescencia se encuentra permeada por la incertidumbre, la indecisión y el exceso de confianza en sí mismo; por ello es importante que los jóvenes adquieran herramientas para evaluar las diferentes posibilidades de responder a una situación, estableciendo límites de tiempo para su toma y realizando un refuerzo positivo de su autoestima.

En general, la toma de decisiones permite al ser humano evaluar y elegir por medio de la voluntad una determinada opción, con el objetivo de resolver una situación específica en diversos aspectos de la vida cotidiana.

\subsubsection{Pensamiento crítico}

Actualmente es importante analizar, entender y evaluar la forma como se organizan los conocimientos y la representación de estos en las opiniones que genera el ser humano en su cotidianidad y que están ligados a los arraigos sociales y culturales. Sin embargo, afirma Nickerson (1988), no solo tener conocimiento garantiza el pensamiento crítico.

Por ello, es importante comenzar a hablar de lo que se considera la base del pensamiento crítico: el método socrático. Sócrates (470-399 A.C) creó un método para realizar preguntas de manera racional y analítica, destacando la importancia de buscar evidencias, evaluar premisas y analizar conceptos básicos. Siguiendo esta línea, Santo Tomás de Aquino (1225-1274 D.C.), siglos más tarde, utilizó una técnica que permitía enunciar, analizar y responder las críticas que le hacían a sus propias ideas. Pero fue Descartes (1596-1650 A.C.) quien desarrolló el método de pensamiento crítico que se basaba en la duda sistemática, a través de la construcción de cuatro reglas consignadas en el discurso del método: no recibir como verdadero lo que con toda evidencia no se reconociese como tal; dividir la dificultad en cuantas partes sea necesario para poder resolverla; ordenar los conocimientos por grado de dificultad; y finalmente, realizar enumeraciones generales para no incurrir en ninguna omisión.

Lo anterior evidencia ya unas bases más estructuradas, en donde el pensamiento debe ser organizado para permitir encontrar la verdad, dejando a un lado prejuicios y permitiéndonos no omitir ningún detalle, para no desviarnos de la realidad. 
Posteriormente, Dewey (1989) señala que el pensar humano debe estar enfocado en la solución de los problemas del mundo real, a través de la indagación y la reflexión.

En las últimas décadas podemos encontrar otros conceptos de pensamiento crítico que presentaremos en la Tabla 3.2.

\section{Tabla 3.2. Conceptos de pensamiento crítico}

\begin{tabular}{ll}
\multicolumn{1}{c}{ Autor } & \multicolumn{1}{c}{ Concepto } \\
Informe Delphi (1990) & $\begin{array}{l}\text { Proceso intelectual que busca llegar a un juicio saludable caracterizado por la interpre- } \\
\text { tación, análisis, evaluación y deducción de las evidencias y que puede ser expuesto. }\end{array}$ \\
\hline Kurland (1995) & Darle peso a la razón considerando los puntos de vista sin sesgos ni prejuicios. \\
\hline Paul y Elder (2003) & Manera de pensar acerca de un tema o problema a través del sometimiento intelectual. \\
\hline $\begin{array}{l}\text { González Zamora } \\
\text { (2007) }\end{array}$ & $\begin{array}{l}\text { Forma de pensar de manera responsable emitiendo buenos juicios, y que parte de un } \\
\text { interés en la obtención de conocimiento y verdad. }\end{array}$ \\
\hline Seligman (2005) & $\begin{array}{l}\text { Pensar y analizar las cosas con detenimiento desde varios puntos de vista, antes de } \\
\text { extraer conclusiones. }\end{array}$ \\
\hline Ennis (1985) & $\begin{array}{l}\text { Pensamiento racional y reflexivo que tiene por finalidad reconocer aquello que es } \\
\text { justo y verdadero desde la racionalidad del ser humano orientado hacia la acción; una } \\
\text { acción que debe estar acompañada de herramientas para la resolución de problemas. }\end{array}$ \\
\hline Bisquerra \& Hernán- & $\begin{array}{l}\text { Pensamiento superior centrado en decidir qué pensar, creer, sentir y hacer, que } \\
\text { demanda autodeterminación, reflexión, esfuerzo, autocontrol y metacognición, a } \\
\text { dez (2017) }\end{array}$ \\
\end{tabular}

Los anteriores conceptos evidencian que el pensamiento crítico implica la adquisición y el uso del conocimiento, la evaluación de información y experiencias, y la emisión responsable de juicios de valor para la resolución de las problemáticas del mundo actual.

Ennis (1985) realiza una categorización de las habilidades que conforman el pensamiento crítico, de la manera en que se sintetiza en la Figura 3.6. 
Figura 3.6. Habilidades del pensamiento crítico

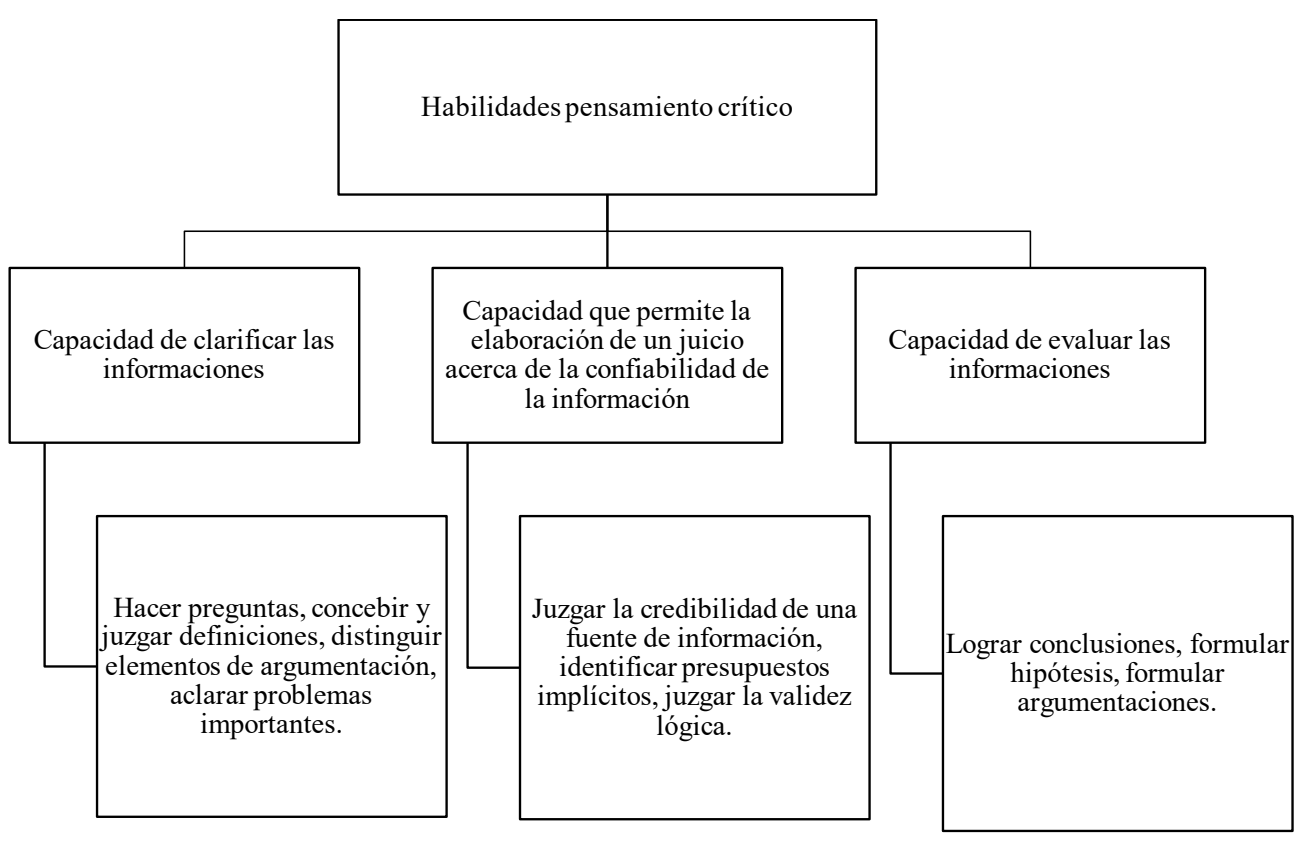

Nota: adaptado de Robert Ennis (1985, p. 45).

Las habilidades entonces se integran para constituir un pensamiento crítico, que conlleve al ser humano a identificar las informaciones que está recibiendo, a elaborar juicios de valor y a evaluar todos los conocimientos que adquiera y los mensajes que le sean suministrados en los diferentes ámbitos en los que se desenvuelve.

Explican Pintrich y García (1993) que, durante la etapa escolar, el pensamiento crítico debe ser entendido como una estrategia cognitiva que permita pensar de un modo más profundo, reflexivo y cuestionador del mundo. Para ello, se debe fomentar en los adolescentes el criterio para la toma de decisiones, la curiosidad, la capacidad de expresar y defender sus ideas y/o creencias, el conocimiento de sus límites, la formación de valores, la importancia del crecimiento intelectual y el justo actuar.

Con lo anterior, se podría afirmar que un pensador crítico es aquel que incluye en su vida cotidiana, tal y como lo afirma Fancione (1990), la curiosidad por una gran variedad de asuntos, la inquietud por estar bien informado, el razonamiento, mente abierta para considerar diversos puntos de vista y opiniones, la valoración de los racionamientos $\mathrm{y}$, finalmente, la honestidad para encarar sus propios prejuicios y estereotipos. 


\section{Conclusión}

Las habilidades cognitivas son las aptitudes que tiene el individuo para procesar la información y que permiten que interactúe con el entorno, por medio de los estímulos que recogen los sentidos y haciendo uso de las habilidades básicas de memoria, percepción, atención, comprensión y lenguaje.

Por ello, están permeadas por la cultura y relacionadas con un grupo de actividades intelectuales que implican planificación, desarrollo y evaluación, lo que permite procesos como la toma de decisiones conscientes y la valoración de sus consecuencias.

Finalmente, es importante potenciar las habilidades cognitivas de autoconocimiento, pensamiento creativo, toma de decisiones y pensamiento crítico, en los programas de formación formal y no formal de adolescentes, para que ellos puedan enfrentarse a situaciones cotidianas siendo capaces de resistirse a la influencia de sus pares y de los medios de comunicación y percibiéndolos de forma crítica.

\section{Referencias}

Arboleda, J.C.(2013). Hacia un nuevo concepto de pensamiento y comprensión. Boletín Redipe, (824), 6-14. https://dialnet.unirioja.es/servlet/articulo?codigo $=4752610$

Asociación Filosófica Americana. (1990). Pensamiento crítico. Una declaración de consenso de expertos con fines de evaluación e instrucción educativa. Informe Delphi. The California Academia Press.

Argudin, Y., \& Luna, M. (2005). Aprende a pensar escribiendo bien: desarrollo de habilidades para escribir. Trillas.

Bandura, A. (Ed.). (1995). Self-efficacy in changing societies. Cambridge university press. https://doi.org/10.1017/CBO9780511527692

Bandura, A. (1997). Self-efficacy: The exercise of control. Freeman. https://doi. org/10.5860/choice.35-1826 
Bar-On, R. (1997). The Emotional quotient inventory: a test of emotional intelligence. Multi-Health Systems. DOI: 10.5772/38875

Bisquerra Alzina, R., \& Hernández Paniello, S. (2017). Psicología positiva, educación emocional y el programa aulas felices. Papeles del Psicólogo, 38(1), 58-65. https:// doi.org/10.23923/pap.psicol2017.2822

Casullo, M., \& Fernández Liporace, M. (2001). Estrategias de afrontamiento en estudiantes adolescentes. Revista del Instituto de Investigaciones de la Facultad de Psicología/ UBA, 6(1), 25-49. DOI: 10.1590/S1984-02922010000100003

Csikszentmihalyi, M. (1998). Creatividad. El fluir y la psicología del descubrimiento y la invención. Paidós. https://doi.org/10.6018/red/resenas/06

De Avalos, M. V., \& Velásquez, M. (2000). Comprensión Lectora: Dificultades estratégicas en resolución de Preguntas Inferenciales. Ediciones Colihue SRL.

De La Torre, S. (2006). Comprender y evaluar la creatividad. (Vol. 4). Ajibe.

De Minzi, M. C. R. (2006). Evaluación del afrontamiento en niños de 8 a 12 años. Revista Mexicana de Psicología, 23(2), 193-201. https://www.redalyc.org/ pdf/2430/243020649005.pdf

Dewey, J. (1989). Como pensamos: Nueva exposición de la relación entre pensamiento y proceso educativo. Editorial Paidos.

Díaz Martín, Y. (2010). Estrés académico y afrontamiento en estudiantes de Medicina. Humanidades Médicas, 10(1). http://scielo.sld.cu/scielo.php?script=sci_ arttext\&pid=S1727-81202010000100007\&lng=es

Dwyer, K. M. (2005). The meaning and measurement of attachment in middle and late childhood.Human Development, 48(3), 155-182.https://doi.org/10.1159/000085519

Ennis, R. (1985). Educational Leadership. A logical basis for measuring critical thinking skills (pp. 44-48). https://pdf4pro.com/view/a-logical-basis-for-measuringcritical-thinking-skills-531c2d.html

Fancione, P. (1990). Critical thinking: A statement of expert consensus for purposes of educational assessment and instruction. The california academic press. 
Figueroa, M. I., Contini, N., Lacunza, A. B., Levín, M., \& Suedan, A. E. (2005). Las estrategias de afrontamiento y su relación con el nivel de bienestar psicológico. Un estudio con adolescentes de nivel socioeconómico bajo de Tucumán (Argentina). Anales de Psicología, 21(1), 66-72. https://www.redalyc.org/ pdf/167/16721108.pdf

Folkman, S., \& Lazarus, R. S. (1984). Stress, appraisal, and coping. New York: Springer Publishing Company.

Goleman, D. (2004). ¿Qué hace a un líder? Harvard Business Review, 82(1), 8291. https://d1wqtxts1xzle7.cloudfront.net/56851155/QUE_HACE_UN_LIDER. pdf? $1529733150=\&$ response-content-disposition=inline $\% 3 \mathrm{~B}+$ filename $\% 3 \mathrm{D}$

Frydenberg, J. (2002). Quality standards in eLearning: A matrix of analysis. The International Review of Research in Open and Distributed Learning, 3(2). https:// doi.org/10.19173/irrodl.v32.109

González Barrón, R., Montoya Castilla, I., Casullo, M., \& Benabéu Verdú, J. (2002). Relación entre estilos y estrategias de afrontamiento y bienestar psicológico en adolescentes. Psicothema, 14(2), 363-368. http://www.psicothema.com/pdf/733. pdf

González Zamora, J. H. (2007). Marco conceptual para la capacidad de pensamiento crítico. Discernimiento: evolución del pensamiento crítico en la educación superior. Universidad ICESI. http://www.eduteka.org/Discernimiento.php

Hausner, L., \& Schlosberg, J. (1998). A Playskool Guide. Teaching your child creativity.

Hellriegel, D., \& Slocum, J. J. (2004). El Cambio Organizacional. El Comportamiento Organizacional. Editorial Thompson.

Kurland, C. (1995). Pensamiento Crítico. Eduketa.

Landau, E. (1987). El vivir creativo: teoría y práctica de la creatividad. Herder. 
Laorden, C., Barriocanal, E. G., \& Sánchez, S. (2005). Integrando descripciones de habilidades cognitivas en los metadatos de los objetos de aprendizaje estandarizados. Revista de Educación a Distancia (RED). https://revistas.um.es/ $\mathrm{red} /$ article/view/24461

Lazarus, R. S. (1966). Psychological stress and the coping process. McGraw-Hill.

Lazarus, R. S., \& DeLongis, A. (1983). Psychological stress and coping in aging. American Psychologist, 38(3), 245-254. https://doi.org/10.1037/0003066X.38.3.245

Lipowski, Z. J. (1970). Physical illness, the individual and the coping processes. Psychiatry in medicine, 1(2), 91-102. https://doi.org/10.2190/19Q39QL8-XYV1-8XC2

Mechanic, D. (1962). Students under stress: A study of the social psychology of adaptation. Free Press Glencoe.

Meyer Hernández, M. L., \& Medrano Torres, N. P. (2008). Habilidades visoespaciales en niños y niñas entre siete y nueve años de edad de los colegios Ateneo Moderno y 20 de octubre de la ciudad de Santa Marta (Bachelor's thesis, Universidad del Magdalena). http://repositorio.unimagdalena.edu.co/jspui/handle/123456789/652

Moromizato, R. (2007). El desarrollo del pensamiento crítico creativo desde los primeros años. El ágora USB, 7(2), 311-321. https://www.redalyc.org/ pdf/4077/407748997010.pdf

Nickerson, R. (1988). On improving thinking through instruction. American Educational Research Association. DOI: 10.3102/0091732X015001003

Olivari Medina, C., \& Urra Medina, E. (2007). Autoeficacia y conductas de salud. Ciencia y enfermería, 13(1), 9-15. http://dx.doi.org/10.4067/S071795532007000100002 .

Paul, R., \& Elder, L. (2003). La mini-guía para el pensamiento crítico, conceptos y herramientas. Fundación para el pensamiento crítico. 
Pearlin, L. I., \& Schooler, C. (1978). The structure of coping. Journal of health and social behavior, 2-21. https://doi.org/10.2307/2136319

Pintrich, P., \& García, T. (1993). Intraindividual differences in students' motivation and selfregulated learning. German journal of educational psichology, 7(3), 99107. https://www.researchgate.net/profile/Teresa-Duncan/publication/232445042 Intraindividual_differences_in_students\%27_motivation_and_self-regulated_ learning/links/55def38908ae79830bb5a94a/Intraindividual-differences-instudents-motivation-and-self-regulated-learning.pdf

Raffino, M. (2018). Habilidades Cognitivas: Concepto, Tipos y Ejemplos. https:// concepto.de/habilidades-cognitivas/

Seligman, M. E. P., Steen, T. A., Park, N., \& Peterson, C. (2005). Positive Psychology Progress: Empirical Validation of Interventions. American Psychologist, 60(5), 410-421. https://doi.org/10.1037/0003-066X.60.5.410

Simon, H. A. (1984). El comportamiento administrativo: estudio de los procesos de adopción de decisiones en la organización administrativa. Aguilar.

Sternberg, R. J. (1999). Estilos de pensamiento. Paidos Iberica, Ediciones.

Stone, D., Maxwell, S., Keating, M. (2001). Bridging research and policy. In: Conference paper from the International Workshop Funded by the U.K. Department for International Development, Radcliffe House, Warwick University, 16-17 July. https://www.researchgate.net/publication/304174780_Bridging_Research_ and_Policy

Suanes, M. N. (2009). Autoconocimiento y autoestima. Temas para la educación, 3. https://www.feandalucia.ccoo.es/andalucia/docu/p5sd6409.pdf

Verghese, J., Mahoney, J., Ambrose, A. F., Wang, C., \& Holtzer, R. (2010). Effect of cognitive remediation on gait in sedentary seniors. Journals of Gerontology Series A: Biomedical Sciences and Medical Sciences, 65(12), 1338-1343. 


\section{Capítulo IV}

¿Cómo educar las emociones?

Perspectivas a partir de la teoría de la construcción emocional 


\section{Introducción}

El desarrollo de habilidades emocionales como la atención, la claridad y la reparación emocional, favorece el ajuste psicosocial, las relaciones interpersonales y el bienestar subjetivo. Aunque este libro presenta como tema principal las habilidades para la vida y la propuesta educativa de la Organización Mundial de la Salud (WHO, 1993), hemos incluido este capítulo dedicado a las emociones, porque consideramos que comprender sus teorías explicativas con mayor evidencia científica, contribuye a los procesos de formación en los programas que tienen como base las habilidades y competencias socioemocionales. Esperamos que este apartado sea ilustrativo sobre la complejidad y la necesidad de conocer los procesos implicados en las emociones.

Inicialmente se ofrece una definición clásica de las emociones, la función y sus causas abordándolas como un sistema de procesos en el que se articulan las experiencias, el comportamiento y los componentes fisiológicos, biológicos, psicológicos, neurológicos y sociales. Se articula el contenido desde los estudios tradicionales que exponen la función de las emociones como un conjunto de procesos selectivos basadas en la motivación; y las causas del mundo emocional se abordan desde el ámbito cognitivo, la estructura biológica y neurobiológica.

El núcleo explicativo de este capítulo es la teoría construccionista de las emociones que propone una nueva forma de entender la vida emocional. Esta teoría, aunque sugiere una perspectiva de análisis diferente a las propuestas clásicas de la emoción, contribuye con el propósito de educar en emociones.

\subsection{Las emociones}

A partir de la década de los noventa, el estudio de las emociones inició un período clave gracias a las investigaciones sobre su efecto en la salud física y mental, además de los hallazgos acerca de su rol en relación con la vida social, familiar y escolar y, en general, con los cambios positivos que pueden desarrollar las personas a través de las emociones y que influyen directamente en el bienestar subjetivo (Fredrickson \& Joiner, 2018). 
Debido al estudio de las emociones desde diversas disciplinas como la psicología, la antropología, las neurociencias y la fisiología, se han propuesto diferentes conceptos, por ende, no se cuenta con una definición unificada; esto no es para nada un problema, es enriquecedor si se tiene en cuenta que las diversas posturas contribuyen a la construcción de la ciencia. Las conceptualizaciones, por tanto, son de diversa índole y pueden presentar rasgos particulares por centrarse en características específicas, en algunas emociones reconocidas en particular o en aspectos de las emociones asociados a patologías (Sloan et al., 2017). Algunos estudios en neurociencias, por ejemplo, han abordado funciones como el procesamiento emocional, la conectividad funcional y los componentes neuronales implicados en el episodio emocional (Kirby \& Robinson, 2017).

Partiremos de una reciente definición integrada de las emociones que surge de las teorías clásicas (Figura 4.1). Las emociones son una coordinación o un conjunto de experiencias (sensaciones, percepciones, pensamientos y recuerdos), expresiones comportamentales (diversas conductas, entre ellas las firmas de expresión facial), y componentes fisiológicos y neurológicos de distinta frecuencia y duración (ritmo de los latidos del corazón, sudoración, frecuencia de la respiración, tensión muscular y activación cerebral), que tienen como función principal la adaptación al ambiente (Vikan, 2017). Esta definición conserva su génesis en los procesos de adaptación y en la teoría evolucionista de Darwin (1872).

Figura 4.1. Definición de las emociones

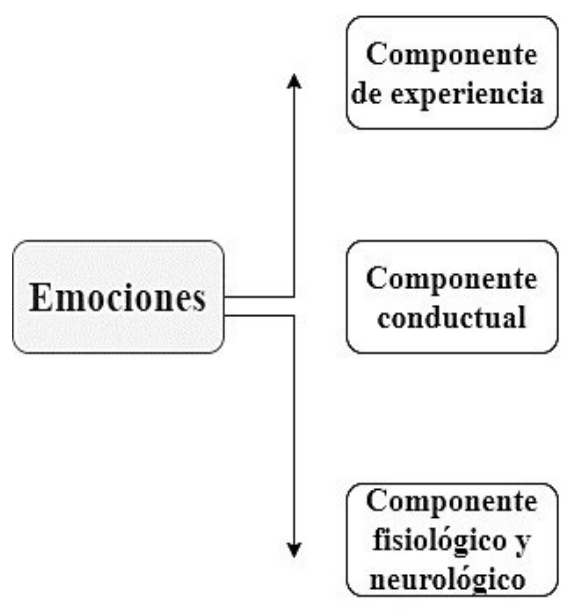

Sensaciones, percepciones, pensamientos y memoria.

Variaciones en el repertorio conductual y la firma de expresión facial.

Respuestas fisiológicas y neurológicas, entre ellas, la activación de los centros cerebrales, la tensión muscular, el ritmo cardiaco, la temperatura corporal y la sudoración. 
Fue Darwin (1872) el primero en atribuir a las emociones una función esencial, la adaptación del organismo al ambiente; mientras Tomkins (2008) las interpretó como un sistema motivacional. Gracias a la integración de estas propuestas se acepta actualmente la selectividad emocional. Esto significa que existe integración entre las emociones y la atención, por medio de este mecanismo, el individuo logra control y predicción sobre su organismo e incluso su comportamiento, en este sentido, las emociones son sistemas motivacionales selectivos.

En la teoría clásica, un aspecto fundamental del estudio de las emociones consistía en distinguirlas de fenómenos afectivos como los estados de ánimo y los sentimientos. Algunos teóricos han propuesto criterios generales para diferenciar las emociones de los sentimientos: desde la duración se considera que las emociones son eventos más cortos y los estados de ánimo experiencias más prolongadas; desde la intensidad se sugiere que las emociones presentan un pico más alto y los estados de ánimo intensidad más baja; desde la presencia y la ausencia de objetivos específicos se alude a que en las emociones estarían presentes, mientras que en los estados de ánimo habría ausencia de estos objetivos (Moors, 2009).

Sobre la clasificación de las emociones, los teóricos no han acordado la mejor forma de estructurarlas internamente. Para algunos investigadores existe un conjunto limitado de emociones llamadas básicas, que componen la gama elemental de la experiencia emocional, estas se combinan y dan origen a otras experiencias. Desde esta perspectiva, se argumenta que las emociones tienen "una estructura y firma neural única, un patrón de valores de evaluación, tendencias a acciones únicas, patrones de respuesta fisiológica única, expresión facial única y calidad experimental única" (Moors, 2009, p. 629). Otros teóricos toman un conjunto de variables subemocionales para establecer los componentes básicos de la vida emocional; en esta perspectiva se incluyen aspectos como la novedad, la valencia emocional, la relevancia de objetivos, la congruencia de objetivos, el potencial de afrontamiento y la agencia (Moors, 2009). Todas estas discusiones se encuentran en los presupuestos investigativos esencialistas de las teorías clásicas de la emoción, que se han ocupado, particularmente, de encontrar las unidades neurológicas, corticales y subcorticales, responsables de las emociones, con el fin explicar las coordenadas emocionales y diferenciar las emociones unas de las otras.

Ekman (2016), encuestó a un amplio número de científicos y les preguntó por la comprensión y la perspectiva con que abordaban el estudio de las emociones; un grupo mayoritario de participantes estuvo de acuerdo con la pertinencia del estudio de 
las emociones desde el enfoque modular y dimensional; por ejemplo, "el módulo de la ira difiere del módulo de miedo, pero la ira varía en lo desagradable que se siente y en su fuerza" (p. 31). Acorde con ello, existen señales universales de las emociones en las expresiones faciales y en la voz; se observan, sin embargo, discrepancias en las evidencias de los factores que desencadenan una emoción, los correlatos fisiológicos y la evaluación emocional.

Ekman (2016) también indagó sobre la taxonomía aceptada de las emociones; el acuerdo fue unánime en cinco emociones: la ira, el miedo, el asco, la tristeza y la felicidad; además, son parcialmente aceptadas la vergüenza y la sorpresa. Otras emociones, que están siendo motivo de investigación, obtuvieron menos apoyo, como la culpa, el amor, el temor, el dolor, la envidia, el orgullo, la gratitud y la compasión. En este mismo estudio, los participantes estuvieron de acuerdo en que las emociones se relacionan con rasgos de personalidad específicos y también con algunos trastornos psicológicos, por ejemplo, el asco se ha relacionado con la anorexia. Esto establece un fondo neurológico para el concepto de las emociones como impulsoras evolutivas selectivas de adaptación que se mueven a partir de motivaciones como la supervivencia y la satisfacción de necesidades. Las reacciones subcorticales pueden, además, confirmar un concepto de emociones como circuitos o programas neurológicos en el ADN.

Al indagar sobre las emociones surgen algunos problemas relacionados que deben ser tenidos en cuenta. Moors (2009) propuso que el análisis de las experiencias de contenido emocional debe tratar cuestiones relativas a la elicitación, la intensidad y la diferenciación emocional. La elicitación se refiere a los estímulos que producen cierta clase de emociones; por ejemplo, descubrir un engaño de una persona amada puede producir ira, indignación o tristeza. Implica también conocer en cuáles circunstancias las emociones son elicitadas, cuáles procesos y bases neurológicas están implicadas y cuáles son los contenidos, mecanismos y representaciones que experimenta el individuo que incitan al desarrollo de dicha activación. Los estudios de elicitación emocional se desarrollan principalmente en laboratorios, a través de mecanismos de simulación y registro (Samson et al., 2016; Visch et al., 2010; Zupan \& Babbage, 2017).

La intensidad se refiere a la debilidad o la fuerza en la emoción y los aspectos que regulan y modulan cada tipo de episodio emocional; de igual manera, se relaciona con las bases neurobiológicas y las condiciones, contenidos, mecanismos y representaciones que impactan la valencia y la activación en la persona en su experiencia emocional. 
Finalmente, en el análisis de la diferenciación emocional se busca determinar la variedad de emociones que experimenta una persona y sus diferentes matices, por ejemplo, la tristeza, la ira, el miedo, el asco o la alegría.

Cada vez es más relevante establecer cuáles son las bases neurobiológicas de la diferenciación emocional, al igual que los contenidos, representaciones, mecanismos e impacto de la cultura en los episodios y experiencias emocionales. El estudio de la diferenciación emocional es uno de los aspectos de las emociones de mayor interés porque facilita otros procesos como la comprensión emocional y la regulación, componentes asociados con el bienestar (Erbas et al., 2014; Israelashvili et al., 2019; Lennarz et al., 2018; Pauw et al., 2019).

La diferenciación de las emociones ha sido sistematizada particularmente por Izard (2007, 2009). Con base en las evidencias disponibles, propuso la clasificación de las emociones que, hasta la fecha, ha sido la más aceptada por los investigadores: alegría, interés, sorpresa, tristeza, ira, miedo, desprecio, vergüenza, culpa, orgullo, envidia y celos. Cada una de las estas emociones, desde la perspectiva de los estudios clásicos, tiene una función, características diversas en la forma como se experimenta y el episodio emocional y cuenta con posibles causas centrales. Determinar cada una de estas variables es precisamente el objeto de los estudios de diferenciación emocional.

De acuerdo con Vikan (2017), las emociones individuales y sociales que han sido objeto de mayor estudio son:

La alegría/felicidad, que tiene como función el establecimiento del disfrute y el contacto social; se caracteriza por la relajación, la sensación de bienestar y el placer. Una de las causas de la alegría es la felicidad que se experimenta a nivel individual y la tendencia a compartir y transmitir sentimientos positivos a otros.

El interés, cuya función principal es generar aprendizaje y construir experiencias; se caracteriza por un estado de alerta, atracción y concentración que surge al atraerse por aprendizajes y vivencias nuevas.

La sorpresa, que tiene como finalidad principal prepararse o recibir con beneplácito experiencias nuevas; genera cambios en el estado anímico, despierta interés y ayuda a crear expectativas. 
La tristeza, que tiene entre sus funciones ayudar al estado de reflexión e introspección y la reevaluación de la experiencia vital; se caracteriza por la sensación de pérdida y pesadez, inactividad y posible desesperanza. Suele experimentarse después de situaciones dolorosas, adversas y en períodos de duelo o de separación.

Por su parte, la ira suele caracterizarse por episodios de excitación, sensaciones corporales de reactividad, desazón y disposición para la defensa y la agresión; facilita la expresión de estados internos de malestar. Puede ser causada por la exposición a injusticias, violación de los derechos, conflictos con otras personas y las instituciones, también surge por diversos eventos adversos.

El miedo es una respuesta a situaciones amenazantes y de peligro, se caracteriza por la sensación de vulnerabilidad, pérdida del control de las situaciones y puede presentarse frente a la amenaza de pérdidas emocionales y riesgo de la integridad física.

El asco tiene funciones de protección frente a materiales, espacios, olores perjudiciales para la salud; se caracteriza por la experiencia de un estado de aversión y deseos de evitación. La causa suele ser la exposición a comidas, materiales y lugares en mal estado.

El desprecio puede caracterizarse por una percepción de superioridad frente a un enemigo, con el fin de disminuir otras emociones o sentimientos como el miedo; tiene como causa central la defensa contra la inseguridad.

La vergüenza tiene como finalidad la reducción de la autoafirmación, se caracteriza por la sensación de debilidad, pérdida de valor y deseo de huida; la causa se ha encontrado principalmente en el fracaso y las experiencias de rechazo social.

La culpa, por su parte, tiene como función el monitoreo, el reconocimiento y la corrección de actos erróneos; se caracteriza por la reflexión y la convicción de haber cometido un acto social o individual moralmente reprochable. La causan los actos, los pensamientos o las actitudes que la persona considera equívocos.

Agrega Vikan (2017) a las emociones más reconocidas el orgullo, la envidia y los celos. 
El orgullo tiene como función principal dar soporte y continuidad a las actividades, las creencias o el aprendizaje; se caracteriza por la satisfacción y la felicidad por los logros. Puede ser causado por la adquisición de logros a nivel personal, social e incluso por superar situaciones adversas o estados emocionales.

La envidia es una emoción que tiene como finalidad la defensa contra la pérdida de competencia; se caracteriza por el deseo de poseer o tener las cualidades o pertenencias de otra persona, se manifiesta especialmente por la creencia, la experiencia, la percepción o consideración de tener menos que los demás.

En el caso de los celos, los investigadores no se han puesto de acuerdo sobre su función específica; suele expresarse de forma más frecuente, aunque no exclusivamente, en las relaciones de pareja y una de sus características es el miedo a la pérdida en la relación con otra persona. La causa es la experiencia real o imaginaria de amenaza.

Aunque estas no son las únicas emociones conocidas, son las que se han establecido actualmente con mayor evidencia en sus correlatos cognitivos, afectivos, motivacionales, somáticos y motores.

\subsection{El episodio emocional}

De acuerdo con Moors (2009), el concepto de episodio emocional tiene mayor potencial que el de emoción. Un episodio emocional implica un componente cognitivo con la función de evaluar un estímulo; un componente de experiencia emocional o sentimiento que le da sentido a la experiencia y se relaciona con el proceso de monitoreo y regulación emocional; un componente motivacional que explica las tendencias a la acción o los estados de preparación para la acción, cuya función es ejecutar acciones relacionadas con el contexto de ocurrencia que provocó el episodio emocional. De igual forma, se encuentran el componente somático, que activa tanto el sistema nervioso central como el periférico, y el componente motor, que se manifiesta particularmente en la expresión emocional y en actos motores que dan cuenta de la emoción experimentada. Los dos últimos componentes, somático y motor, tienen funciones de preparación, apoyo y ejecución de la acción. 
Cuando indagamos sobre las causas nos preguntamos qué factores generan las emociones y nos interesa saber qué ocurre desde el inicio hasta el final del episodio emocional. Los teóricos de la emoción están de acuerdo con que las emociones tienen cantidad y calidad. La cantidad se refiere a la intensidad de la emoción y la calidad a la valencia positiva o negativa de la emoción. La siguiente Figura (4.2) resume los componentes y las funciones del episodio emocional.

\section{Figura 4.2. Funciones y componentes del episodio emocional}

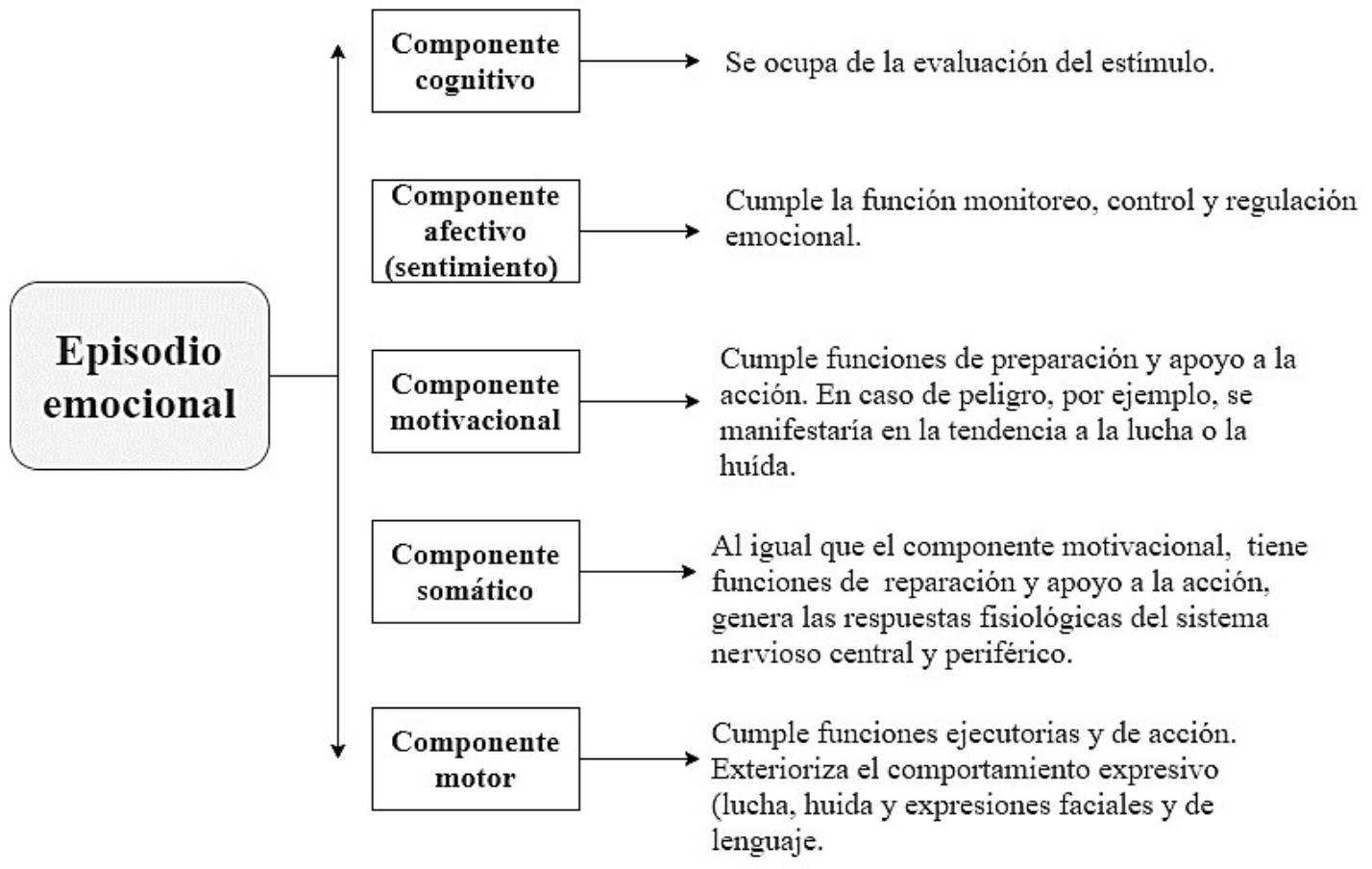

Nota: adaptado de Moors (2009, pp. 626-627).

Como se puede observar, el episodio emocional integra una amplia variedad de componentes que articulan el aprendizaje, las experiencias previas y las diversidades culturales y puede generar variados repertorios emocionales. 


\subsection{Las teorías psicológicas clásicas de las emociones}

La psicología ha propuesto diversas teorías para explicar las emociones, estas aparecen resumidas en la Figura 4.3.

A finales del siglo XIX, William James (1980) propuso la teoría del sentimiento, siguiendo lo que anteriormente había expuesto Descartes en Las pasiones del alma (Descartes, 1644/ 2018). James sostuvo que las respuestas corporales preceden las experiencias emocionales; en su teoría, un estímulo ocasiona una respuesta del cuerpo, de carácter motor, que lleva a la vivencia de la experiencia emocional. En esta teoría incluyó componentes somáticos y motores; sin embargo, la propuesta adolece de explicaciones sobre cómo ocurre cada emoción, cómo se establecen las firmas emocionales y otros factores diferentes a los estímulos externos.

Schachter (1964), en línea con la propuesta de James (1980), postuló una teoría donde las respuestas somáticas preceden la experiencia emocional. La exposición a un estímulo ocasiona un estado indiferenciado de excitación fisiológica, luego el sujeto, a través de procesos cognitivos, hace una interpretación de acuerdo con las características del estímulo. El proceso cognitivo de atribución da valor a la excitación, es decir, otorga valencia positiva o negativa a la causa de la excitación, lo que produce un efecto emocional específico. En este proceso ocurren dos tipos de excitación, una somática, al producirse el estímulo, y otra de intensidad, al ocurrir la valoración cognitiva. En la teoría de Schachter se incorporó el componente cognitivo que tiene funciones de diferenciación emocional; sin embargo, la teoría no especificó cuáles son los estímulos que ocasionan el proceso de excitación. 
Figura 4.3. Teorías psicológicas clásicas de las emociones

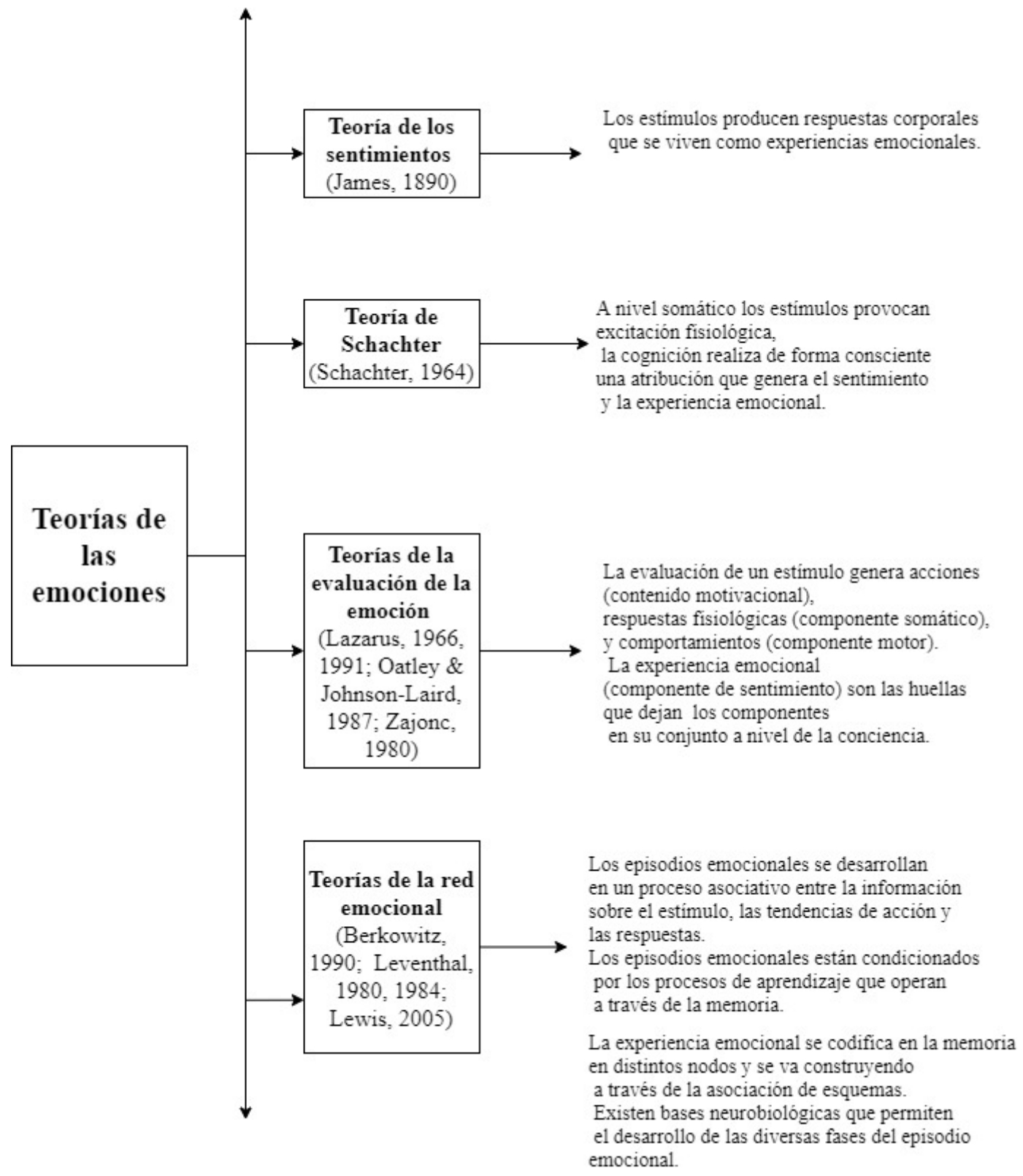

Continua en la página siguiente 


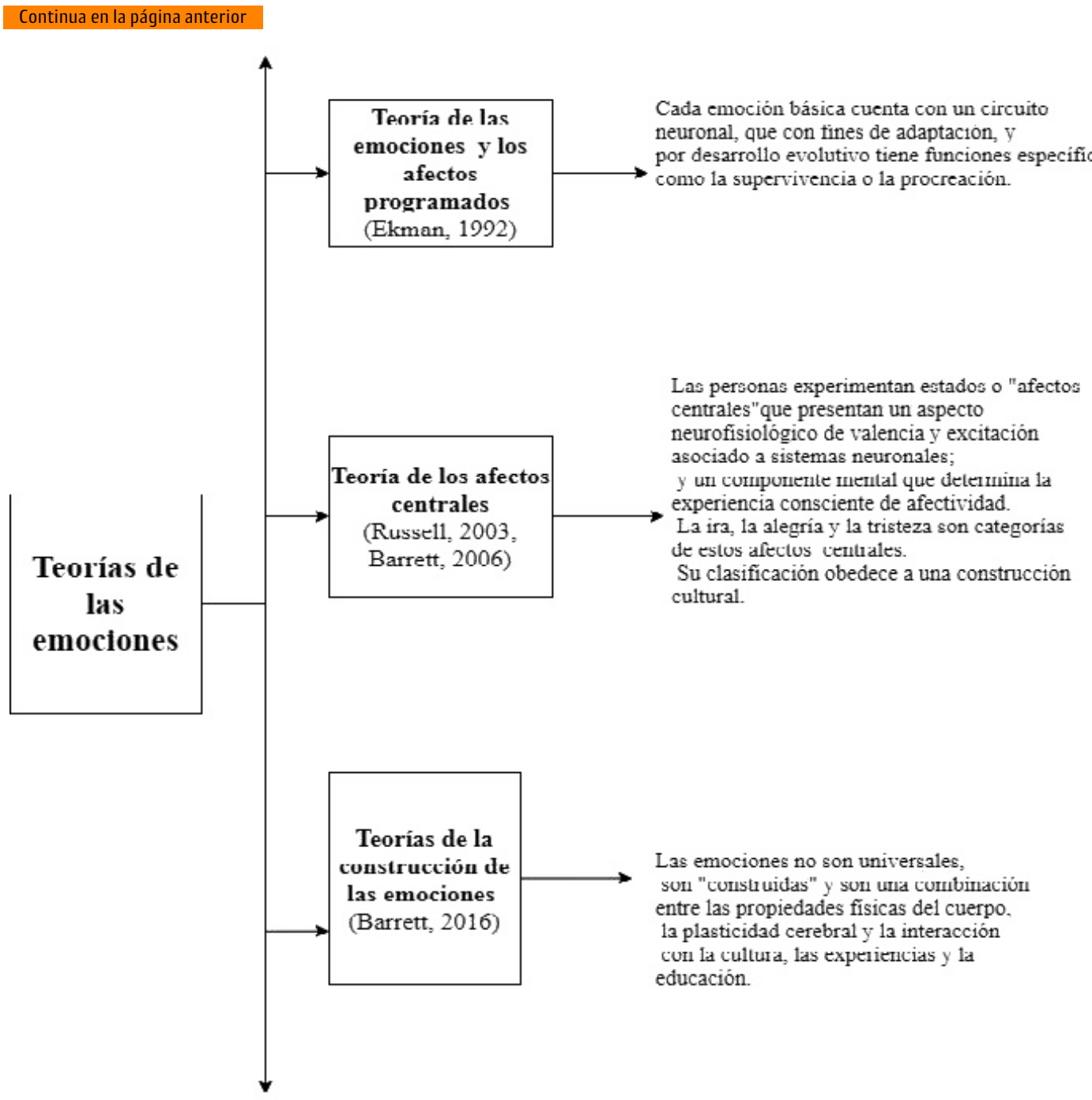

Nota: adaptado de Moors (2009, pp. 635-653).

Estas dos teorías, particularmente la de Schachter (1964), fue cuestionada por la teoría de la evaluación de la emoción desarrollada por varios teóricos, entre ellos, Lazarus (1966, 1991), Oatley y Johnson-Laird (1987) y Zajonc (1980), quienes mantuvieron la idea de que la cognición antecede la emoción, sin embargo, sugirieron que estos procesos no son conscientes. Para esta corriente, la cognición consciente no es necesaria para experimentar emociones y afectos, aunque el proceso cognitivo sí puede presentarse de forma inconsciente (Kunst-Wilson \& Zajonc, 1980). En la teoría de la evaluación emocional, el componente cognitivo se ubica al inicio del epi- 
sodio emocional y determina qué provocó la emoción, es decir, la fuente del estímulo; además, tiene la tarea de diferenciar qué emoción es la que se produce y cuál es la intensidad de la experiencia.

Los teóricos de la evaluación emocional han tratado de explicar si existe una relación causal entre estímulos específicos y las respuestas emocionales; las observaciones al respecto sugieren que es difícil llegar a establecer este tipo de relaciones, la razón principal es que una emoción puede ser causada por estímulos diversos y las mismas emociones, causadas por una misma clase de estímulo, pueden variar en intensidad y significado (Roseman \& Smith, 2001). Los últimos avances en la teoría de la evaluación emocional se han orientado a la formulación de modelos multimodales para explicar la obtención y los procesos del episodio emocional; se ha propuesto que la obtención emocional se puede explicar por mecanismos basados en reglas, por mecanismos asociativos y por la activación de conexiones sensoriales-motoras innatas (Smith \& Neumann, 2005).

Teniendo como base los modelos asociativos, las teorías de redes semánticas y los estudios sobre la memoria, se desarrolló la teoría de la red emocional que cuenta entre sus representantes con Leventhal (1980) y con Berkowitz (1990). En este modelo, los estímulos biológicamente relevantes provocan respuestas emocionales incondicionadas que se van moldeando y cambiando a través de procesos condicionantes. La memoria juega un rol fundamental al ser la encargada del aprendizaje y la recuperación de información a través de mecanismos de asociación. A nivel de la función emocional, los esquemas establecidos se activan cuando se presentan los estímulos, y se produce el episodio emocional cuando se relaciona el evento presente con el esquema aprendido.

En estos modelos clásicos, por tanto, las emociones son generadas a partir de procesos cognitivos con funciones de elicitación, diferenciación, comprensión y asociación de estímulos con la información guardada en los esquemas previos de la memoria.

La teoría de redes emocionales ha tratado de integrar las teorías clásicas con la neurobiología a través del modelado de sistemas dinámicos y ha propuesto diversas fases del episodio emocional; por ejemplo, la activación, autoamplificación y autoestabilización de los estados de evaluación de las emociones, que a nivel neurobiológico, incluyen interacciones de retroalimentación, procesos de neuromodulación, monitoreo de acciones biológicas y plasticidad sináptica, que lleva a describir diversos procesos emocionales en términos de integración funcional y sincronización temporal (Lewis, 2005). 
La teoría de las emociones y los afectos programados propone que cada emoción básica cuenta con un circuito neuronal que, para fines de adaptación y por desarrollo evolutivo, tiene funciones específicas; por ejemplo, un circuito neuronal activa el miedo, que tiene como finalidad la supervivencia. Esta teoría desarrollada principalmente por Ekman (1992), ha encontrado compatibilidad con otras teorías clásicas, entre ellas, los modelos de evaluación, de aprendizaje y con tendencias teóricas modernas que, con los aportes de las neurociencias, buscan estructuras corticales, subcorticales específicas y generales para la explicación de los episodios emocionales.

Russell (2003) propuso la teoría de los afectos centrales, que serían el epicentro (núcleo) de la vida emocional. Las personas experimentan estados que presentan un aspecto neurofisiológico de valencia y excitación asociado a sistemas neuronales; el sujeto cuenta con un componente mental que determina la experiencia consiente de afectividad. Para Russell, en estos procesos influyen los reflejos, la percepción, la cognición y el comportamiento, afectados por causas internas y externas, sin que las personas tengan acceso directo a conexiones causales. Las emociones alteran el afecto central debido a su relación con las propiedades de los estímulos, las motivaciones, la empatía, las experiencias y las habilidades emocionales. En esta teoría, las emociones básicas como la ira, el miedo, la tristeza y la alegría no son emociones en sí mismas sino categorizaciones y construcciones culturales asociadas a los afectos centrales.

\subsection{Anatomía de las emociones}

Las teorías más recientes sobre las emociones han buscado apoyo en las nuevas tecnologías para probar sus hipótesis, esto ha facilitado obtener evidencias y proponer aspectos problemáticos surgidos de los resultados. Algunos ejemplos de las posibilidades que presenta el aporte de las neurociencias se describen a continuación.

La revisión sistemática desarrollada por Machado y Cantilino (2017) buscó identificar los correlatos neuronales con las emociones positivas. Reportó que, hasta el momento, las investigaciones en neurociencias muestran que la formación y la regulación de las emociones positivas, como la felicidad, se asocian con reducciones significativas de la actividad en la corteza prefrontal derecha y bilateralmente en la corteza temporoparietal; además, se ha observado mayor actividad en las regiones 
prefrontales izquierdas. Otras áreas asociadas con mayor actividad son la circunvolución cingulada, las circunvoluciones temporales inferior y media, la amígdala y el cuerpo estriado ventral.

Los estudios de neuroimagen han ayudado a sugerir que el lenguaje emocional se asocia con la experiencia de percepción emocional. Se han observado activaciones en la amígdala y la circunvolución parahipocampal, bilateralmente, cuando en las mediciones de laboratorio no se incluyen palabras de contenido emocional (enojo, asco o desasosiego). Áreas relacionadas con el procesamiento semántico se activan en presencia de las palabras elicitadoras. Estos hallazgos sugieren que el etiquetado de emociones puede favorecer el proceso de regulación emocional (Brooks et al., 2017).

El uso de tecnología como la electroencefalografía (EEG) combinada con protocolos de Interfaz Cerebro Ordenador (BCI) ha ayudado a establecer que el reconocimiento de emociones básicas como asco, enojo, miedo, sorpresa, felicidad, tristeza, calma, se relaciona con la activación de áreas cerebrales específicas en el lóbulo frontal, temporal y parietal derecho (Spezialetti et al., 2018).

Como puede apreciarse, los aportes de las neurociencias han ayudado a las teorías clásicas en la afirmación de sus hipótesis. Sin embargo, este uso de tecnología es reciente y es amplio el campo de las emociones que falta por explorar. Llama la atención uno de los aportes más innovadores de los últimos años, es un paradigma novedoso de las emociones e invita a revisar los modelos clásicos: la teoría construccionista de las emociones.

Los estudios de Barrett y su equipo (2017) han sugerido que el cerebro funciona de forma conjunta, como un sistema de predicciones que cuenta con una red en modo predeterminado dentro de la red interoceptiva. Sin embargo, explica que es un error del esencialismo creer en la existencia dentro de la red predeterminada, de un conjunto de neuronas para cada objetivo o proceso emocional, a modo de "pequeñas esencias". A partir de las evidencias, se deduce que las características, tanto de activación como sensoriales y motoras en las emociones, se distribuyen por todo el cerebro. Los estudios realizados con base en la teoría construccionista de las emociones han llevado a concluir que de ser plausible una activación diferenciada para cada emoción, al ocurrir un episodio emocional, se activaría primero un sitio específico del cerebro, en cada condición experimental, luego las zonas implicadas en procesos lingüísticos y conceptuales y luego las zonas relacionadas con las diferencias motoras y sensoriales, pero esto no se observa tan claramente en los estudios. Se explican a continuación los 
aspectos generales de la teoría que ha puesto en debate la creencia de las emociones universales, la teoría de las "huellas digitales" de la emoción, y se aborda además la teoría localizacionista de las emociones.

\subsection{Las emociones las hace el cerebro: teoría construccionista}

De acuerdo con la teoría construccionista de la emoción, el proceso de construir emociones se perfecciona a lo largo de la vida. En la etapa de recién nacidos, el cerebro adolece del repertorio conceptual que presentan los adultos, esto hace que el cerebro infantil no realice predicciones de forma acertada, pero poco a poco, cada vez que tiene mayor experiencia, se volverán más complejas y adaptativas. Un cerebro adulto modela la experiencia del organismo con el mundo; un cerebro infantil se ocupa de realizar el proceso de aprendizaje. En un bebé, las experiencias sensoriales del mundo exterior, que en un principio son caóticas, novedosas y desenfocadas, se van convirtiendo con el tiempo en "oportunidades para que el cerebro infantil haga predicciones coordinadas que abarquen todos los sentidos" (Barrett, 2017, p. 113). El trabajo del cerebro infantil es enorme y requiere una gran cantidad de energía. Para soportar y resolver el gasto metabólico y la limitación de conexiones, el encéfalo del infante debe transferir la información sensorial que recibe y organizar los marcos conceptuales que le ha proporcionado la experiencia a la menor cantidad de neuronas posibles.

Este proceso de arquitectura cerebral es la optimización que reúne aspectos y características de un concepto por similitud en los datos. El cerebro infantil aprende a organizar datos por patrones de activación neuronal de información que ha recibido por diferentes ángulos y medios sensoriales; por ejemplo, elabora el concepto mamá a partir de las experiencias que ha tenido al ser amamantado, por el olor de la madre, el contacto corporal y la información diversa que ha recibido en varios momentos a través del sistema visual. A medida que el cerebro optimiza el proceso de crear similitudes, se hace progresivamente más eficiente para la comprensión y creación de la información. El objetivo del cerebro es volverse cada vez más eficiente y práctico y esto lo logra progresivamente mediante el aprendizaje que le lleva de la formación de conceptos rudimentarios a estructuras interrelacionadas complejas. Los procesos descritos por la teoría construccionista de las emociones se pueden observar en la Figura 4.4. 
Figura 4.4. ¿Cómo hace el cerebro las emociones?

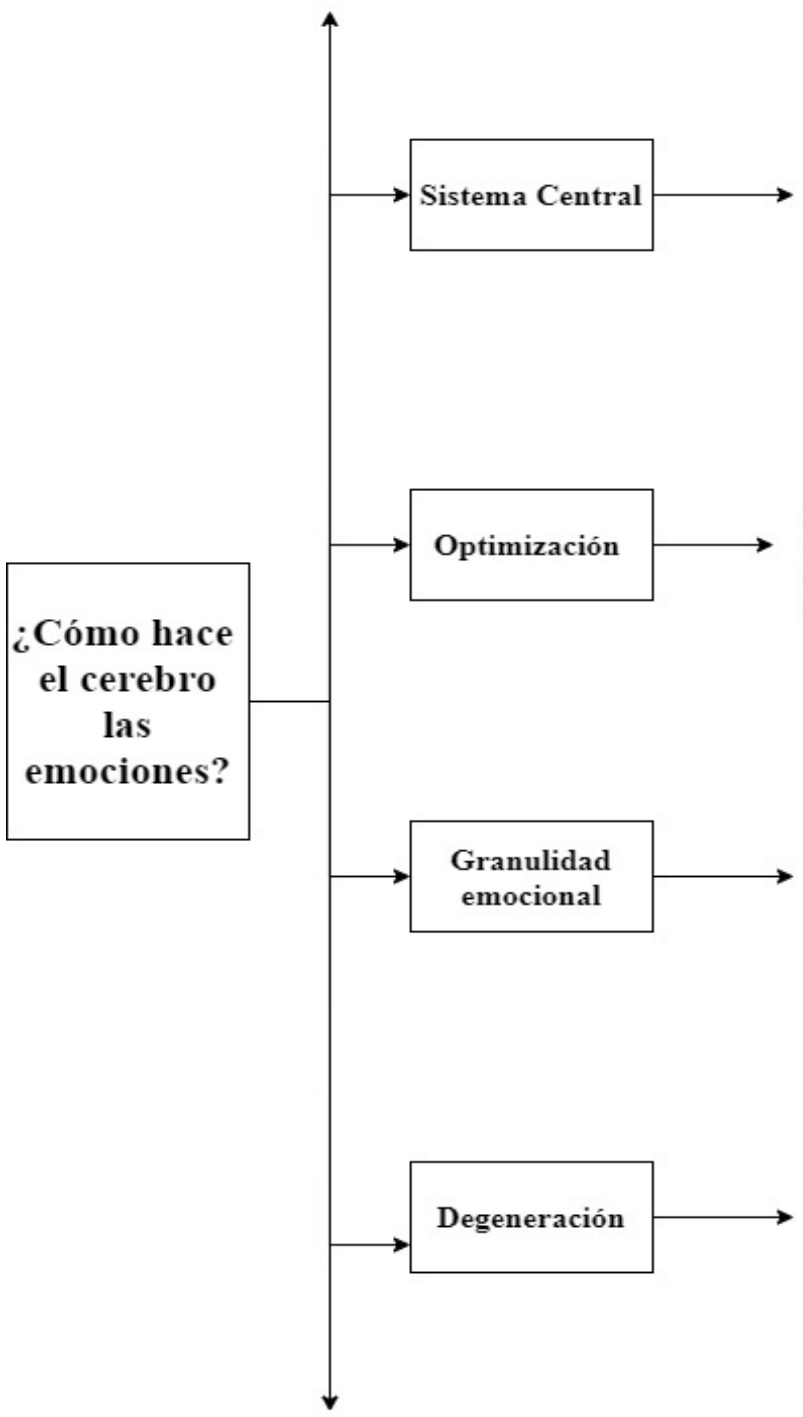

E1 cerebro contiene sistemas centrales con neuronas multipropósito que participan en la creación de una amplia variedad de estados mentales.

Un sistema central único puede desempeñar el papel de pensar, recordar, tomar decisiones, ver, oir, experimentar y percibir diversas emociones.

Un sistema central es "uno a muchos": un área o red cerebral única contribuye a muchos estados mentales diferentes.

Proceso que realiza el cerebro infantil para organizar el aprendizaje en unidades limitadas y diferenciadas, que tiene como función, disminuir el gasto metabólico y la cantidad de conexiones.

La granulidad, es la capacidad cerebral que le permite al sujeto detectar las señales físicas o reacciones para cada emoción, e interpretarlas de forma correcta, en diferentes niveles de precision.

Proceso neurobiológico, en el que varias estructuras cerebrales pueden realizar la misma función, lo cual permite diversificar las posibles respuestas emocionales a partir de los estimulos.

Implica variabilidad de respuesta a nivel somático, sensorial, cognitivo y motor.

La elección entre las posibles respuestas se conoce como instancia ganadora. 


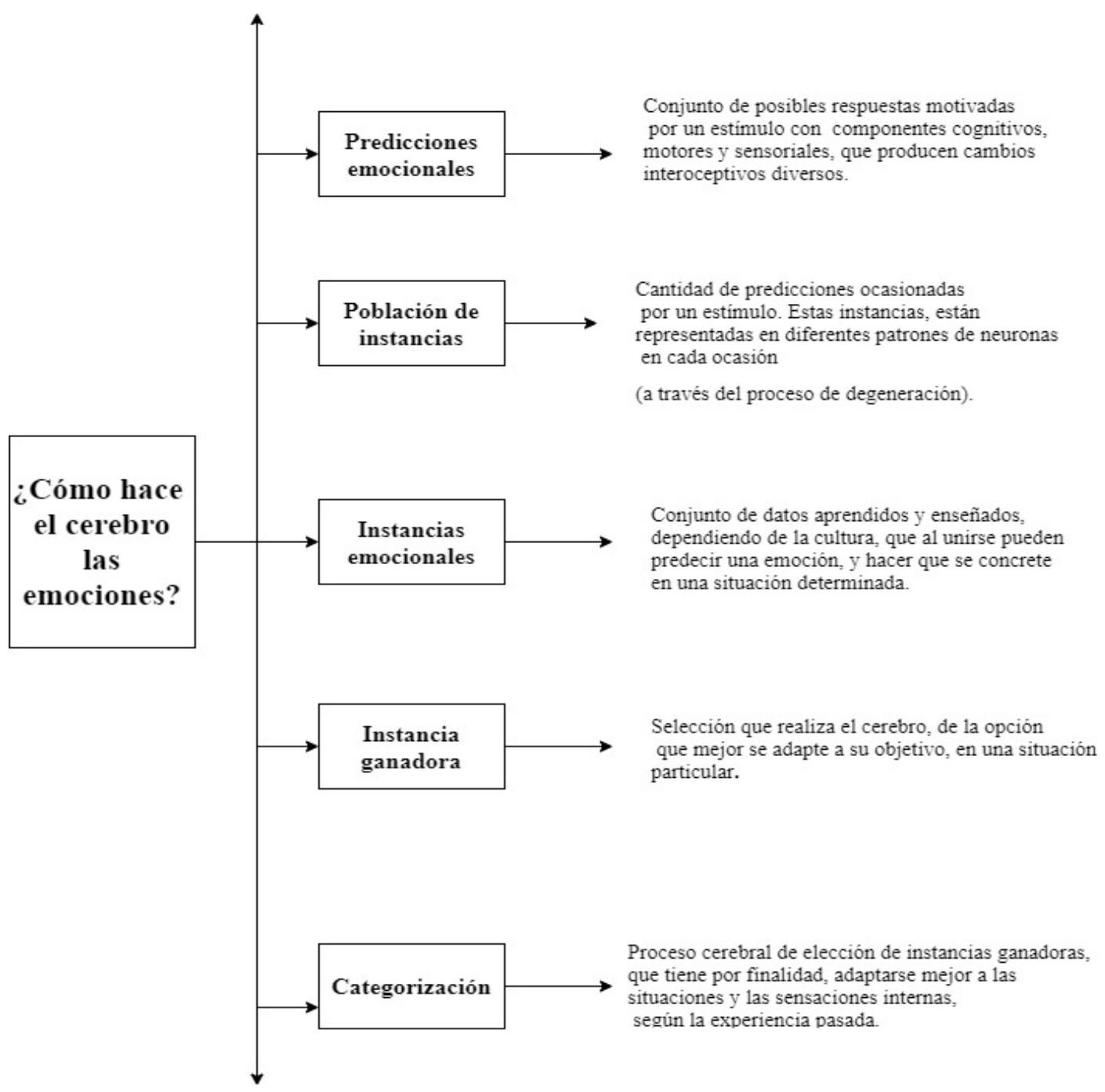

Nota: adaptado de Barrett (2017, pp. 112-127)

En la teoría de la construcción emocional, un episodio emocional como la tristeza o la ira no está representado en un flujo o conjunto único de neuronas, tampoco está almacenado en un lugar específico del entramado cerebral, sino que se encuentra representado por diferentes patrones neuronales en cada ocasión; se construye permanentemente ad hoc dependiendo de la situación. A medida que el cerebro elabora las similitudes por coincidencia de patrones, ocurren diversas opciones de respuestas que involucran diferentes zonas cerebrales, produciendo expresiones o respuestas cogni- 
tivas, sensoriales y motoras; este entramado e instancias diversas, donde la función puede ser realizada por diferentes estructuras cerebrales, se conoce como degeneración.

Existen dos fenómenos inseparables para la experiencia emocional: el "concepto" y la "predicción", ambos son en realidad lo mismo. Cuando el cerebro ha construido el concepto "tristeza" por medio del aprendizaje, por ejemplo, cuando se ha escuchado a alguien expresar que está triste, cuando en una situación adversa ha visto llorar a alguien o cuando al hacer un gesto alguien le pregunta por qué está decaído, el cerebro emite la predicción "tristeza" que seguirá utilizando y creando por similitud frente a eventos relacionados.

Podemos sintetizar lo anterior en la siguiente idea:

\begin{abstract}
Temprano en la vida construyes conceptos a partir de información sensorial detallada (como error de predicción) de tu cuerpo y el mundo. Tu cerebro comprime eficientemente la información sensorial que recibe, al igual que YouTube comprime un video, extrae similitudes de las diferencias y, finalmente, crea un resumen eficiente y multisensorial. Una vez que tu cerebro ha aprendido un concepto de esta manera, puede ejecutar este proceso en reversa, expandiendo las similitudes en diferencias para construir una instancia del concepto, de la misma manera que su computadora o teléfono expande el video entrante de YouTube para mostrarlo. Esta es una predicción. Piense en la predicción como una "aplicación” un concepto, modificando la actividad en sus regiones sensoriales y motoras primarias, y corrigiendo 0 refinando según sea necesario. (Barrett, 2017, p. 118)
\end{abstract}

¿Cómo se llegó a proponer la teoría de la construcción emocional?

En los estudios de la teoría construccionista, inicialmente, se aplicaron los conceptos y procedimientos que ofrece la teoría clásica, por ejemplo, el uso de imágenes donde los participantes reconocen las emociones básicas, también los recursos que ofrecen las nuevas tecnologías de neuroimagen.

Uno de los hallazgos iniciales que distaba de los supuestos de diferenciación emocional es que al preguntarle a las personas por sus estados emocionales no distinguían entre sentirse triste o sentirse deprimido, y al indagar por experiencias emocionales, las personas catalogaban las emociones experimentadas con etiquetas como "enojo", "tristeza", o "miedo", pero no lo hacían para expresar estrictamente lo mismo. 
Luego los investigadores se percataron de la granulidad en la identificación emocional, esto es, que a nivel de la descripción del estado emocional interno existen varios niveles de precisión. La granulidad le permite a la persona detectar señales físicas o reacciones para cada emoción e interpretarlas de forma correcta en diferentes niveles, como en una gama de grises entre el negro y el blanco. Por ejemplo, al tratarse de la interpretación de la alegría, el miedo, el asco, o el asombro, una persona con granulidad emocional baja podría usar la palabra ansioso o deprimido indistintamente ante una situación adversa.

En las revisiones de los estudios clásicos, los científicos construccionistas indagaron sobre los resultados en investigaciones que utilizaron otras técnicas de laboratorio más objetiva, por ejemplo, la llamada electromiografía facial (EMG). Esta se introdujo en los estudios de las emociones para medir el movimiento muscular facial durante la experiencia emocional inducida, con todo lo problemático que puede implicar generar emociones fuera de contexto real, los estudios de los movimientos musculares no han indicado a la fecha, de manera confiable, que cuando alguien experimente alguna emoción particular se pueda definir una huella predecible de la misma.

El equipo de Barrett (2017) analizó los estudios de Camras y sus colegas, quienes mediante experimentos formularon que los bebés difieren en la expresión emocional tal y como está propuesta en la teoría clásica de las emociones en los adultos. Esto significa que las expresiones emocionales pueden tener significados diferentes en bebés, niños y adultos y que es necesario considerar perspectivas alternativas sobre la naturaleza de la emoción y la expresión emocional diferentes a la postura predeterminista (Camras et al., 2002; Camras et al., 2007; Camras \& Shutter, 2010).

A través de experimentos de laboratorio, en la teoría construccionista se ha llegado a la conclusión que las interpretaciones de las emociones en los rostros varían si las imágenes que se les presenta a los participantes van acompañadas de historias que otorgan marco contextual a la expresión emocional. Las indagaciones sobre las reacciones corporales llevaron a revisar las teorías de la retroalimentación facial en las cuales se indica que el sistema nervioso periférico presenta cambios cuando los sujetos imitan expresiones faciales frente a un espejo (Ekman et al., 1983). Muchos experimentos habían seguido las indicaciones de este estudio clásico, pero los hallazgos no han sido concluyentes, los resultados son particularmente diversos de las medidas fisiológicas.

Al analizar los correlatos corporales implicados en las emociones, se ha observado que la variabilidad es la norma y no la excepción, esto significa que las experiencias, los contextos, las diferencias individuales y las características del propio individuo 
generan múltiples respuestas y no huellas emocionales y esto es lo que los datos empíricos están señalando a favor de la teoría de la construcción emocional (Siegel et al., 2018).

Al examinar los estudios de neuroimagen publicados sobre la ira, el asco, la felicidad, el miedo y la tristeza, que podían ser analizados estadísticamente, se diseñó un sistema que permitía dividir el cerebro en celdas y facilitaba una visión tridimensional de las mismas a través de unidades llamadas vóxel (Barret, 2017), se observó que ninguna región del cerebro contenía la huella digital de ninguna emoción (Lindquist et al., 2015; Lindquist et al., 2016).

La teoría constructivista propone que la emoción está influenciada por la cultura, los estereotipos y los símbolos. Por tanto, el mundo emocional se ajusta a tópicos conocidos dentro de una sociedad cultural. Las instituciones sociales como la escuela enseñan estereotipos y modos de expresión emocional a los niños, por ejemplo, las personas que hacen gestos cuando están tristes. Son construcciones culturales y convenciones que se popularizan en la televisión, en los juguetes, los emojis y un sinnúmero de imágenes iconográficas. De igual manera, se utilizan en programas educativos donde se induce a los niños, niñas y adolescentes a reconocer e identificar estos estereotipos (Barrett, 2017). Las bases de la teoría construccionista de las emociones se presentan en la Figura 4.5.

Figura 4.5. Bases de la Teoría Construccionista de las Emociones

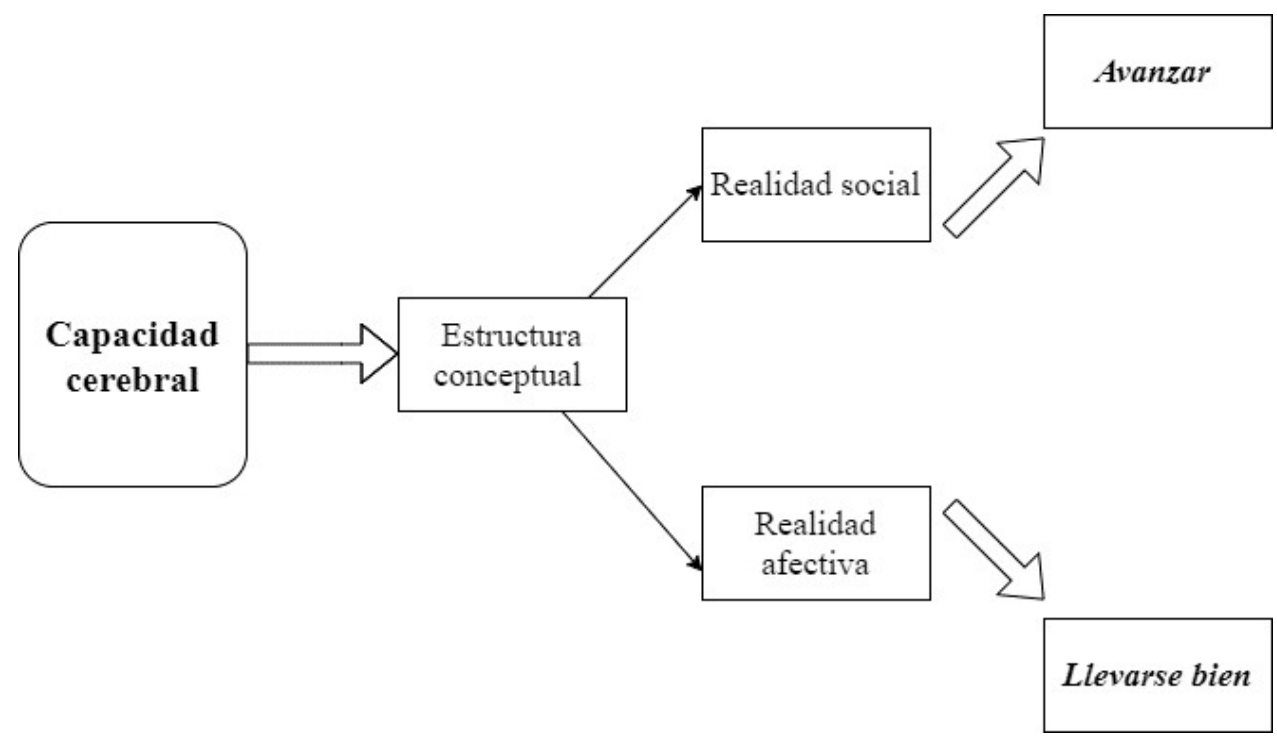


En síntesis, la teoría construccionista (Barrett, 2017) propone que las emociones no están integradas, sino que están hechas de partes más básicas. No son universales, pero varían de una cultura a otra. No se activan; se crean, surgen como una combinación de las capacidades, condiciones y posibilidades del cuerpo físico, un cerebro flexible que se conecta a cualquier entorno en el que se desarrolle, con la cultura y educación propias de cada contexto. Las emociones son reales, pero no en el sentido objetivo en que las moléculas o las neuronas son reales. Son reales en el mismo sentido que el dinero es real, es decir, apenas una ilusión, sino un producto del acuerdo humano (pp. 7-8). El cerebro contiene sistemas centrales que participan en la creación de una amplia variedad de estados mentales. Un sistema central único puede desempeñar un papel en pensar, recordar, tomar decisiones, ver, oír y experimentar y percibir diversas emociones. Un sistema central es "uno a muchos": un área o red cerebral única contribuye a muchos estados mentales diferentes (p. 19).

La teoría construccionista se basa en la premisa de que las emociones son parte de la composición biológica del cerebro y el cuerpo humano es el resultado de la evolución y no el producto de una esencia transmitida por los antepasados.

Las bases de la teoría son tres: el sistema conceptual creado por la sociedad (los seres humanos), la realidad externa y un cerebro potente que no solo se regula a sí mismo, sino que además es capaz de interactuar con otros cerebros para construir la realidad social (Figura 4.5). Pensar desde el innatismo o estructuras especializadas para cada emoción no obedece a la lógica de la complejidad; un cerebro fragmentado tendría baja efectividad y sería poco funcional; un cerebro con alta complejidad, con mecanismos en cascada o a través de la degeneración, es más eficiente, puede crear y trasportar más información, es

\begin{abstract}
más robusto y confiable y con múltiples caminos para llegar al mismo fin, es más resistente a lesiones y enfermedades... la complejidad, no la racionalidad, le permite ser un arquitecto de su experiencia. Sus genes le permiten a usted, y a otros, remodelar su cerebro y, por lo tanto, su mente. (Barret, 2017, p. 282)
\end{abstract}

El cerebro tiene la capacidad de realizar una danza sincronizada entre los conceptos que ayudan a predecir y a generar acciones. Se conecta y es capaz de interactuar con el mundo social y otros cerebros. Existe una conexión sincrónica con los otros organismos, que es la base de la interacción social y la empatía. Son importantes esas relaciones para disfrutar de la vida humana, para generar vínculos y agradarse unos a otros. 
La disyuntiva está en el uso potencial emocional para "avanzar" o para "agradar". Igual que ocurre con la granulidad emocional, los actos van en un margen entre blanco y negro y sus matices, pasar por encima y destruir a los otros para "avanzar" es el límite más negativo de esta gama, encontrar el balance en las relaciones y conseguir autonomía es el equilibrio entre mejorar y "llevarse bien".

\subsection{Avances en el estudio de las emociones}

Debido al interés creciente en el estudio de las emociones, presentamos algunas áreas desde las que se enfoca la investigación actualmente, cuáles son los objetivos y los retos (Tabla 4.1). Sin ser exhaustivos, se ofrece una visión general sobre la comprensión de las emociones que tendremos en los próximos años.

Tal y como lo señala Ekman (2016), son muchos los avances que se han generado en la investigación de las emociones en las dos primeras décadas del siglo XXI; los científicos en este campo se dedican al estudio de los factores fisiológicos, el componente cognitivo y las expresiones faciales, además han surgido numerosas revistas especializadas como, por ejemplo, Emotion, Journal of Experimental Psychology, Journal of Neuroscience, Nature, Nature Reviews Neuroscience, y Nature of Emotion. Hace dos décadas no se diferenciaban los estados de ánimo de las emociones, no se había propuesto el concepto emociones básicas definidas ni se habían establecido asociaciones entre las emociones, la psicopatología y la personalidad. Sin embargo, el abordaje de las emociones, desde las teorías clásicas y propuestas como la constructivista, apenas inicia, y es probable que la comprensión de cada una de las emociones comience a ser cada vez más amplia y se especifiquen con mayor evidencia empírica los factores biológicos, neurobiológicos y neuroquímicos implicados en las emociones; de igual manera, es posible que se integren los aportes y los hallazgos desarrollados a través de metodologías cualitativas y contextuales.

Como ejemplo práctico, las emociones discretas y las implicaciones para la vida práctica están siendo estudiadas en diversos campos, entre ellos, el ámbito laboral. Recientemente un metaanálisis examinó la asociación entre el afecto y las emociones discretas en relación con el desempeño laboral, el desempeño de tareas, el comportamiento organizacional y comportamiento de trabajo contraproducente. Los resultados apoyan la tendencia teórica de congruencia afecto-comportamiento, donde el afecto positivo se asocia positivamente con el comportamiento que beneficia a la organiza- 
ción, y el afecto negativo con el comportamiento dañino. El mismo efecto negativo se consigue en el desempeño de tareas cuando el afecto es negativo (Shockley et al., 2012).

Tabla 4.1. Áreas de interés, objetivos y retos en el estudio de las emociones

\section{Área de investigación de interés} Objetivo Retos

Neurociencias, emociones, dolor Identificar los procesos de inte- Analizar los factores emocionales y y estrés (Al'Absi \& Flaten, 2016) racción entre el estrés, las emo- psicosociales que influyen en el dolor y ciones y la regulación del dolor sugerir cómo traducir este conocimiento en múltiples contextos.

en información y prácticas clínicamente útiles.

Neurociencia, biología y psico- Analizar los procesos biológicos Utilizar las nuevas tecnologías, por logía de las emociones (Adolphs implicados en las emociones y ejemplo, las neuroimágenes para anali\& Anderson, 2018; Buhle et al., profundizar en el ya clásico estu- zar los diversos procesos psicológicos 2014; Fernández-Dols \& Russell, dio entre la emoción y la cogni- y neuropsicológicos en relación con las 2017; Kohn et al., 2014; Lench et ción.

al., 2011) emociones.

Según Adolphs y Anderson (2018), las siguientes son algunas preguntas abiertas que aún no se han respondido en la investigación: ¿La actividad en estructuras subcorticales como la amígdala produce estados de emoción?, ¿las estructuras subcorticales causan estados de emoción global al reclutar e incluir también otras estructuras necesarias?, ¿podemos encontrar estados que satisfagan todas nuestras "propiedades emocionales" y que no consideremos emociones?, ¿podemos derivar propiedades adicionales que son esenciales para las emociones como distintas de otros tipos de estados internos?, ¿existen especies específicas de emociones?, ¿hay emociones únicas para los individuos?, ¿podemos construir un robot que tenga emociones? (pp. 308327). 
Inteligencia artificial

(Bibri, 2015)

Emociones y tecnología (Roeser, 2018; Tettegah, 2016a, 2016b)

Emociones y medios de comunicación (Kappas \& Kramer, 2011;

Liu, 2015)

Cyberemociones (Hołyst, 2017)

Innovación educativa y emocio- Abordar el papel de las emocio- Estudiar las emociones en el ambiente nes (Chemi et al., 2017)
Estudiar el uso y efecto de la tec- Aplicar principios éticos en el uso de la nología en la vida de las personas tecnología.

e identificar su mutua relación,

finalmente estos sistemas se han inspirado y han sido creados por

la inteligencia humana.
Utilizar la tecnología para el estudio de las emociones. nes y la educación desde múlti- escolar: interacciones entre los estudianples perspectivas que permitan tes, procesos de aprendizaje transformadesafiar o facilitar el aprendizaje tivos, aprendizaje estético e innovación para estudiantes y educadores. educativa.

Educación y desarrollo de com- Contribuir al diseño y evaluación Generar evidencias sobre la efectivipetencias socioemocionales de programas de intervención e dad de los programas de competencias (Devis-Rozental, 2018; Düringer, investigación en el campo de las socioemocionales y los modelos que los 2014; Keefer et al., 2018; Malti, competencias socioemocionales. orientan.

2013).

Diversificar las poblaciones objetivo.

Sexualidad, género y emociones Analizar aspectos emocionales Abordar desde diversas perspectivas, (De Boise, 2015; Latu et al., 2013; relacionados con el sexo y el biológicas, neuropsicológicas, históriSteenbergh \& Ruberg, 2011) género, tanto desde el punto de cas, literarias, psicológicas y sociales las vista fisiológico como antropoló- emociones por género y sexo. gico y cultural.

Estudiar los factores biológicos, psicológicos, neurológicos y sociales implicados en la sexualidad y las emociones. 


\section{Continua en la página anterior}

Emociones, salud mental y bien- Avanzar en la comprensión de Fomentar el trabajo interdisciplinar y estar la experiencia humana de las transdisciplinar de áreas como la neu-

(Cabrita et al., 2017; Panksepp \& emociones y cómo las diversas robiología, la genética, la biología, la Biven, 2012). disciplinas contribuyen con el neurociencia, la antropología y la psicobienestar y la salud mental. logía, para ofrecer a los profesionales de la salud mental aportes científicos relevantes para el acompañamiento en temas de salud física y mental.

Emociones, salud física y servi- Avanzar en la comprensión de Contribuiral bienestar físico y emocional cios de salud. las emociones en relación con la de las personas en el sistema de salud.

(Allan \& Arber, 2018; Dragojlovic salud física.

\& Broom, 2018; Kleres, 2018)

Emociones y política (Clément \& Analizar el aporte de las emocio- Proponer modelos explicativos de las Sangar, 2018; Hunter, 2015; Kon- nes a los procesos sociales y polí- emociones políticas y cómo afectan la zelmann \& Schmid, 2014; Wolff, ticos y a la construcción social. construcción de las sociedades.

2019)

Emociones, trabajo y productivi- Contribuir al estudio de las emo- Brindar aportes multidisciplinares para dad ciones y el rol que cumplen en los la comprensión de las emociones y su

(Furnham, 2008; Payne \& Cooprocesos productivos y las organi- importancia en las instituciones y orgazaciones sociales. $\quad$ nizaciones productivas. per, 2007)

Analizar la base psicológica, fun- Brindar aportes y evidencias sobre las

Emociones y cuerpo

(De Gelder, 2016) cional y neuronal de las emociones en el cuerpo. emociones y cómo se expresan en el cuerpo.

Emociones y grupos minoritarios Estudiar desde diversas disci- Aportar en la comprensión de las emo(Nguyet Erni, 2017) plinas las emociones y cómo se ciones desde la interdisciplinariedad presentan en las diversas culturas, teniendo en cuenta las diferencias cultusobre todo en los grupos minori- rales.

tarios.

Emociones, violencia y sistema Contribuir al estudio de las emo- Aportar evidencias para la comprensión legal (Finkel Parrott, 2006) ciones y la violencia y cómo del rol de las emociones en la violencia deben comprenderse las emocio- y cómo aplicarse a los sistemas legales. nes en el sistema legal. 


\section{Conclusión}

Desde la psicología se han propuesto diversas teorías para explicar las emociones en los seres humanos. Las teorías clásicas son, en general, esencialistas y buscan establecer los correlatos, los procesos y las estructuras neurobiológicas implicadas.

La definición clásica integra expresiones comportamentales, experiencias y componentes fisiológicos y neurológicos, con base en la motivación y la adaptación. Los investigadores están de acuerdo en que su estudio se debe realizar con enfoque modular y dimensional, y las nuevas tecnologías han contribuido a la revisión de las teorías a partir de las evidencias empíricas. Son las teorías clásicas las que han dado forma a los programas y prácticas que se utilizan para educar y formar las competencias socioemocionales.

Se ha expuesto de manera sucinta la teoría construccionista de las emociones que ha brindado una visión nueva para comprender la forma en que el cerebro crea la experiencia emocional, si bien es reciente, aporta aspectos fundamentales útiles para el desarrollo y la construcción de propuestas en el campo de la formación socioemocional.

\section{Referencias}

Adolphs, R., \& Anderson, D. J. (2018). The neuroscience of emotion: A new synthesis. Princeton University Press.

Al'Absi, M., \& Flaten, M. A. (2016). The neuroscience of pain, stress and emotión: Psychological and clinical implications. Academic Press.

Allan, H. T., \& Arber, A. (2018). Emotions and reflexivity in health and social care field research. Palgrave Macmillan.

Barrett, L. F. (2006). Solving the emotion paradox: Categorization and the experience of emotion. Personality and Social Psychology Review, 10(1), 20-46. https://doi. org/10.1207/s15327957pspr1001_2 
Barrett, L. (2017). How the emotions are made, the secret life of the brain. Houghton Mifflin Harcourt.

Berkowitz, L. (1990). On the formation and regulation of anger and aggression: A cognitive neoassociationistic analysis. American Psychologist, 45(4), 494-503. https://doi.org/10.1037/0003-066X.45.4.494

Bibri, S. E. (2015). The human face of ambient intelligence cognitive, emotional, affective, behavioral, and conversational aspects (Volume 9). Atlantis Press.

Brooks, J. A., Shablack, H., Gendron, M., Satpute, A. B., Parrish, M. H., \& Lindquist, K. A. (2017). The role of language in the experience and perception of emotion: a neuroimaging meta-analysis. Social Cognitive and Affective Neuroscience, 12(2), 169-183. https://doi.org/10.1093/scan/nsw121

Buhle, J. T., Silvers, J. A., Wage, T. D., Lopez, R., Onyemekwu, C., Kober, H., Weber, J., \& Ochsner, K. N. (2014). Cognitive reappraisal of emotion: A meta-analysis of human neuroimaging studies. Cerebral Cortex, 24(11), 2981-2990. https://doi. org/10.1093/cercor/bht154

Cabrita, M., Lamers, S. M. A., Trompetter, H. R., Tabak, M., \& Vollenbroek-Hutten, M. M. R. (2017). Exploring the relation between positive emotions and the functional status of older adults living independently: a systematic review. Aging and Mental Health, 21(11), 1121-1128. https://doi.org/10.1080/13607863.2016.1204982

Camras, L. A., Meng, Z., Ujiie, T., Dharamsi, S., Miyake, K., Oster, H., Wang, L., Cruz, J., Murdoch, A., \& Campos, J. (2002). Observing emotion in infants. facial expression, body behavior, and rater judgments of responses to an expectancyviolating event. Emotion, 2(2), 179-193. https://doi.org/10.1037/1528-3542.2.2.179

Camras, L. A., Oster, H., Bakeman, R., Meng, Z., Ujie, T., \& Campos, J. J. (2007). Do infants show distinct negative facial expressions for fear and anger? Emotional expression in 11-month-old European American, Chinese, and Japanese infants. Infancy, 11(2), 131-155. https://doi.org/10.1111/j.1532-7078.2007.tb00219.x

Camras, L. A., \& Shutter, J. M. (2010). Emotional facial expressions in infancy. Emotion Review, 2(2), 120-129. https://doi.org/10.1177/1754073909352529 
Chemi, T., Grams Davy, S., \& Lund, B. (2017). Innovative pedagogy a recognition of emotions and creativity in education. Sense Publishers.

Clément, M., \& Sangar, E. (2018). Researching emotions in international relations: Methodological perspectives on the emotional turn. Palgrave Macmillan.

Darwin, C. (1872). The expression of the emotions in man and animals. Albemarle.

De Boise, S. (2015). Men, masculinity, music, and emotions. Palgrave Macmillan.

De Gelder, B. (2016). Emotions and the body. Oxford University Press.

Descartes, R. (2018). As Paixões da Alma. KTTK Editora.

Devis-Rozental, C. (2018). Developing socio- emotional intelligence in higher education scholars. Palgrave Macmillan.

Dragojlovic, A., \& Broom, A. (2018). Bodies and suffering emotions and relations of care. Routledge/Taylor y Francis Group.

Düringer, E.-M. (2014). Evaluating emotions. Palgrave Macmillan.

Ekman, P. (1992). An argument for basic emotions. Cognition y Emotion, 6(3/4), 169200. http:/www.paulekman.com/wp-content/uploads/2013/07/AnArgument-ForBasic-Emotions.pdf

Ekman, P. (2016). What scientists who study emotion agree about. Perspectives on Psychological Science, 11(1), 31-34. https://doi.org/10.1177/1745691615596992

Ekman, P., Levenson, R. W., \& Friesen, W. V. (1983). Autonomic nervous system activity distinguishes among emotions. Science, 221(4616), 1208-1210. https://doi. org/10.1126/science.6612338

Erbas, Y., Ceulemans, E., Lee Pe, M., Koval, P., \& Kuppens, P. (2014). Negative emotion differentiation: Its personality and well-being correlates and a comparison of different assessment methods. Cognition and Emotion, 28(7), 1196-1213. https:// doi.org/10.1080/02699931.2013.875890 
Fernández-Dols, J.-M., \& A. Russell, J. A. (2017). The science of facial expression. Oxford University Press.

Finkel, N. J., \& Parrott, W. G. (2006). Emotions and culpability: How the law is at odds whith psychology, jurors, and itself. American Psychological Association (APA).

Fredrickson, B. L., \& Joiner, T. (2018). Reflections on positive emotions and upward spirals. Perspectives on Psychological Science, 13(2), 194-199. https://doi. org/10.1177/1745691617692106

Furnham, A. (2008). Head y heart management: Managing attitudes, beliefs, behaviors, and emotions at work. Palgrave Macmillan.

Hołyst, J. A. (Ed). (2017). Cyberemotions Collective Emotions in Cyberspace. Springer International Publishing.

Hunter, S. (2015). Power, politics, and the emotions: Impossible Governance? Routledge/Taylor y Francis Group.

Israelashvili, J., Oosterwijk, S., Sauter, D., \& Fischer, A. (2019). Knowing me, knowing you: emotion differentiation in oneself is associated with recognition of others' emotions. Cognition and Emotion, 33(7), 1461-1471. https://doi.org/10.108 0/02699931.2019.1577221

Izard, C. E. (2007). Basic emotions, natural kinds, emotion schemas, and a new paradigm. Perspectives on Phychological Science, 2(3), 260-280. https://doi. org/10.1111/j.17456916.2007.00044.x

Izard, C. E. (2009). Emotion theory and research: Highlights, unanswered questions, and emerging issues. Annual Review of Psychology, 60(1), 1-25. https://doi. org/10.1146/annurev.psych.60.110707.163539

James, W. (1890). The principles of psychology. Dover.

Kappas, A., \& Kramer, N. C. (2011). Face-to-Face communication over the internet emotions in a web of culture, language, and technology. Cambridge University Press. 
Keefer, K. V., Parker, J. D. A., \& Saklofske, D. H. (2018). Emotional intelligence in education integrating research with practice. Springer International Publishing.

Kirby, L. A. J., \& Robinson, J. L. (2017). Affective mapping: An activation likelihood estimation (ALE) meta-analysis. Brain and Cognition, 118, 137-148. https://doi. org/10.1016/j.bandc.2015.04.006

Kleres, J. (2018). The social organization of disease: Emotions and civic action. Routledge/Taylor y Francis Group.

Kohn, N., Eickhoff, S. B., Scheller, M., Laird, A. R., Fox, P. T., \& Habel, U. (2014). Neural network of cognitive emotion regulation-An ALE meta-analysis and MACM analysis. NeuroImage, 87, 345-355. https://doi.org/10.1016/j. neuroimage.2013.11.001

Konzelmann Ziv, A., \& Schmid, H. B. (2014). Institutions, emotions, and group agents' contributions to social ontology. Springer.

Kunst-Wilson, W. R., \& Zajonc, R. B. (1980). Affective discrimination of stimuli that cannot be recognized. Science, 207, 557-558. https://science.sciencemag.org/ content/sci/207/4430/557.full.pdf

Latu, I., Mast, M. S., \& Kaiser, S. (2013). Gender and emotion: An Interdisciplinary perspective. Peter Lang.

Lazarus, R. S. (1966). Psychological stress and the coping process. McGraw-Hill.

Lazarus, R. S. (1991). Emotion and adaptation. Oxford University Press.

Lench, H. C., Flores, S. A., \& Bench, S. W. (2011). Discrete emotions predict changes in cognition, judgment, experience, behavior, and physiology: A meta-analysis of experimental emotion elicitations. Psychological Bulletin, 137(5), 834-855. https:// doi.org/10.1037/a0024244

Lennarz, H. K., Lichtwarck-Aschoff, A., Timmerman, M. E., \& Granic, I. (2018). Emotion differentiation and its relation with emotional well-being in adolescents. Cognition and Emotion, 32(3), 651-657. https://doi.org/10.1080/02699931.2017.1 338177 
Leventhal, H. (1980). Toward a comprehensive theory of emotion. In L. Berkowitz (Ed.), Advance in Experimental Social Psychology (Vol. 13, pp. 139-207). Academic Press.

Lewis, M. D. (2005). Bridging emotion theory and neurobiology through dynamic systems modeling. Behavioral and Brain Sciences, 28(2), 169-194. https://doi. org/10.1017/S0140525X0500004X

Lindquist, K. A., Wager, T. D., Kober, H., Bliss-Moreau, E., \& Barrett, L. F. (2015). The brain basis of emotion: A meta-analytic review. Behavior Brain Science, 35(3), 121-143. https://doi.org/10.1017/S0140525X11000446.

Lindquist, K. A., Satpute, A. B., Wager, T. D., Weber, J., y Barrett, L. F. (2016). The brain basis of positive and negative affect: Evidence from a meta-analysis of the human neuroimaging literature. Cerebral Cortex, 26(5), 1910-1922. https://doi. org/10.1093/cercor/bhv001

Liu, B. (2015). Sentiment analysis mining opinions, sentiments, and emotions. Cambridge University Press.

Machado, L., \& Cantilino, A. (2017). A systematic review of the neural correlates of positive emotions. Revista Brasileira de Psiquiatria, 39(2), 172-179. https://doi. org/10.1590/1516-4446-2016-1988

Malti, T. (2013). Adolescent emotions development, morality, and adaptation. Wiley Online Library.

Moors, A. (2009). Theories of emotion causation: A review. Cognition and Emotion 23(4), 625-662. https://doi.org/10.1080/02699930802645739

Nguyet Erni, J. (2017). Visuality, emotions and minority culture feeling ethnic. Springer-Verlag GmbH Germany.

Oatley, K., \& Johnson-laird, P. (1987). Towards a cognitive theory of emotions. Cognition y Emotion, 1(1), 29-50. http://dx.doi.org/10.1080/02699938708408362

Panksepp, J., \& Biven, L. (2012). The archaeology of mind: Neuroevolutionary origins of human emotions. Norton y Company. 
Pauw, L. S., Sauter, D. A., van Kleef, G. A., \& Fischer, A. H. (2019). Stop crying! The impact of situational demands on interpersonal emotion regulation. Cognition and Emotion, 33(8), 1587-1598. https://doi.org/10.1080/02699931.2019.1585330

Payne, R. L., \& Cooper, C. L. (2007). Emotions at work: Theory, research and applications for management. Wiley-Interscience.

Roeser, S. (2018). Risk, technology, and moral emotion. Routledge/Taylor y Francis Group.

Roseman, I. J., \& Smith, C. A. (2001). Appraisal theory: Overview, assumptions, varieties, controversies. In K. R. Scherer, A. Schorr, \& T. Johnstone (Eds.), Appraisal processes in emotion (pp. 3-34). Oxford University Press.

Russell, J. A. (2003). Core affect and the psychological construction of emotion. Psychological Review, 110(1), 145-172. https://doi.org/10.1037/0033295X.110.1.145

Samson, A. C., Kreibig, S. D., Soderstrom, B., Wade, A. A., \& Gross, J. J. (2016). Eliciting positive, negative, and mixed emotional states: A film library for affective scientists. Cognition and Emotion, 30(5), 827-856. https://doi.org/10.1080/026999 31.2015.1031089

Schachter, S. (1964). The interaction of cognitive and physiological determinants of emotional state. In L. Berkowitz (Ed.), Advances in experimental social psychology (pp. 49-80). Academic Press.

Shockley, K. M., Ispas, D., Rossi, M. E., \& Levine, E. L. (2012). A meta-analytic investigation of the relationship between state affect, discrete emotions, and job performance. Human Performance, 25(5), 377-411. https://doi.org/10.1080/08959 285.2012.721832

Siegel, E. H., Sands, M. K., Van den Noortgate, W., Condon, P., Chang, Y., Dy, J., Quigley, K. S., \& Barrett, L. F. (2018). Emotion fingerprints or emotion populations? A meta-analytic investigation of autonomic features of emotion categories. Psychological Bulletin, 144(4), 343-393. https://doi.org/10.1037/bul0000128 
Sloan, E., Hall, K., Moulding, R., Bryce, S., Mildred, H., \& Staiger, P. K. (2017). Emotion regulation as a transdiagnostic treatment construct across anxiety, depression, substance, eating and borderline personality disorders: A systematic review. Clinical Psychology Review, 57, 141-163. https://doi.org/10.1016/j. cpr.2017.09.002

Smith, E. R., \& Neumann, R. (2005). Emotion processes considered from the perspective of dual-process models. In L. Feldman Barrett, P. M. Niedenthal, \& P. Winkelman (Eds.), Emotion and Consciousness (pp. 212-334). The Guilford Press.

Spezialetti, M., Cinque, L., Tavares, J. M. R. S., \& Placidi, G. (2018). Towards EEGbased BCI driven by emotions for addressing BCI-Illiteracy: a meta-analytic review. Behaviour and Information Technology, 37(8), 855-871. https://doi.org/10.1080/01 44929X.2018.1485745

Steenbergh, W., \& Ruberg, K. (2011). Sexed sentiments interdisciplinary perspectives on gender and emotion. Rodopi.

Tettegah, S. Y. (2016a). Emotions, technology, and behaviors. Academic Press.

Tettegah, S. Y. (2016b). Emotions, technology, and social media. Academic Press.

Tomkins, S. S. (2008). Affect, imagery, consciousness. The negative affects. Springer Publishing Company, LLC.

Vikan, A. (2017). A fast road to the study of emotions: An introduction. Springer.

Visch, V. T., Tan, E. S., \& Molenaar, D. (2010). The emotional and cognitive effect of immersion in film viewing. Cognition and Emotion, 24(8), 1439-1445. https://doi. org/10.1080/02699930903498186

World Health Organization (WHO). (1993). Life skills education for children and adolescents in schools: Introduction and guidelines to facilitate the development and implementation of life skills programmes. Division of Metal Health and Prevention of Substance Abuse. 
Wolff, N. (2019). Not quite hope and other political emotions in the gilded age. Oxford University Press.

Zajonc, R. B. (1980). Feeling and thinking: Preferences need no inferences. American Psychologist, 35(2), 151-175. https://doi.org/10.1037/0003-066X.35.2.151

Zupan, B., \& Babbage, D. R. (2017). Film clips and narrative text as subjective emotion elicitation techniques. Journal of Social Psychology, 157(2), 194-210. https://doi.or g/10.1080/00224545.2016.1208138 


\section{Capítulo V}

\section{Habilidades sociales:}

Dimensión esencial de las

habilidades para la vida

Arcadio de Jesús Cardona Isaza, Margarita Morales y Gloria Inés De Salvador 


\section{Introducción}

Las habilidades para la vida son un enfoque de intervención comunitario propuesto por la Organización Mundial de la Salud (WHO, 1993), conformado por un conjunto de diez habilidades divididas en tres dimensiones: habilidades cognitivas, emocionales y sociales. En este capítulo se plantean aspectos generales sobre la importancia de la enseñanza de las habilidades sociales y su rol en los modelos y programas de competencia social y socioemocional.

Se propone que las habilidades para la vida $(\mathrm{HpV})$ son un enfoque viable, además de pertinente, por la originalidad de sus fines, entre ellos, la prevención, la intervención psicosocial en comunidades y la tarea de disminuir riesgos asociados a problemas de salud. Este enfoque es importante porque sus propósitos contribuyen al bienestar, que es el objetivo central de los modelos recientes de competencia socioemocional.

Las habilidades para la vida son aplicables a diversos contextos y, sobre todo, a aquellos que presentan situaciones de vulnerabilidad social. Se observa, sin embargo, que es fundamental aportar evidencias de la efectividad de las intervenciones que se realizan con base en este enfoque, y fortalecer y actualizar las bases teóricas que justifiquen las habilidades sociales. Las $\mathrm{HpV}$ son importantes en todas las etapas del desarrollo, y educar en ellas durante la adolescencia puede contribuir a la respuesta de las personas a las exigencias del mundo actual, a que puedan gestionar sus problemas y ayudar a conseguir un comportamiento socialmente deseado (Prajapati et al., 2017).

\subsection{El enfoque de habilidades para la vida}

Desde que el enfoque de las habilidades para la vida fue propuesto en 1993 por la Organización Mundial de la Salud (WHO, 1993), han surgido muchas propuestas educativas, sobre todo para contextos escolares, que tienen el objetivo común de potenciar el desarrollo humano más allá de la instrucción académica; estos modelos tienen que ver principalmente con la inteligencia emocional, la competencia social y la competencia socioemocional (Bisquerra Alzina \& Pérez Escoda, 2007; Mayer \& Salovey, 1997). 
Las $\mathrm{HpV}$ ciertamente gozan de un nombre bastante potente, sin embargo, la literatura sobre este enfoque es escasa. Una de las grandes debilidades que encontramos es que, si bien cuenta con un marco teórico en sus inicios sólido y multidisciplinario, no ha alcanzado, recientemente, las evidencias suficientes para inferir que sea una propuesta competente en relación con otras en las que los teóricos y científicos sociales han mostrado mayor interés por demostrar su efectividad mediante la evaluación de sus resultados. Para contribuir en este sentido, los investigadores han iniciado la evaluación de los programas de habilidades para la vida (Bancin \& Ambarita, 2019).

Aunque estamos cerca de una treintena de años desde que fue propuesto el enfoque $\mathrm{HpV}$ (WHO, 1993), sus objetivos continúan siendo novedosos y prácticos:

\footnotetext{
1. Fomentar el conocimiento, los valores y las actitudes prosociales;

2. Favorecer la competencia social, la orientación de la conducta al cambio, el comportamiento prosocial; $y$,

3. Contribuir a la prevención en problemas de salud, entre otros (p. 4).
}

En los contextos actuales, hablar de actitudes, prosocialidad, prevención de problemas de salud pública (por ejemplo, evitando el uso de drogas), y el cambio en la conducta, no podría ser más pertinente. En sociedades empobrecidas como las de América Latina se requieren discursos realistas de desarrollo comunitario; el colectivo de la región no comparte las condiciones de otras sociedades donde el bienestar subjetivo es un propósito fundamental de los programas de competencia socioemocional. La solidaridad, la prosocialidad, la construcción de la identidad, el respeto, la igualdad social, el desarrollo sostenible, la cooperación y la superación de la violencia, son preocupaciones y urgencias mucho más cercanas. El eje de habilidades sociales en las habilidades para la vida es un recurso educativo que puede aportar a los objetivos del enfoque, si se tienen en cuenta los niveles de conflicto, la falta de asertividad y otros comportamientos y actitudes que pueden abordarse, prevenirse y modificarse en la cotidianidad.

Los programas de habilidades sociales se han desarrollado particularmente en población escolar y, en general, la falta de consenso sobre los objetivos en la enseñanza de las habilidades sociales y las limitaciones de los procesos evaluativos dificulta concluir qué tan efectivos son para promover el cambio en los niños, niñas y los adolescentes (January et al., 2011).

Las habilidades sociales se han descrito en diversos modelos de intervención para adolescentes, entre los más reconocidos se encuentra el modelo SEL (por sus siglas en inglés, Social and Emotional Learning), que es un conjunto de estrategias para 
desarrollar competencias a nivel social, emocional y de conducta que son aplicables en el ámbito escolar, laboral y comunitario (Frey et al., 2019). Programas como SEL son potencialmente efectivos porque integran diversas dimensiones y se adaptan a las diferentes necesidades del contexto; este es un reto para los programas que utilicen el enfoque de habilidades para la vida (WHO, 1993).

El enfoque de $\mathrm{HpV}$ tiene de base propuestas pertinentes y originales como resolver problemas relacionados con la salud, entre ellos, el uso de drogas y diversas conductas de riesgo; ello es particularmente notable ya que no se trata solo de favorecer el comportamiento adaptativo y socialmente correcto y el bienestar subjetivo, sino que contribuye con la prevención, el cuidado de la vida, del entorno y de la comunidad. Este es el talante inicial de la propuesta, fortalecer las habilidades emocionales, sociales y cognitivas, para favorecer el desarrollo y la competencia social individual y para resolver problemas y riesgos en contexto. El modelo integrado de $\mathrm{HpV}$ (Figura 5.1) muestra la articulación del enfoque entre el conocimiento, las actitudes, los valores, la conducta prosocial y la prevención de problemas de salud.

Figura 5.1. Modelo integrado de las habilidades para la vida

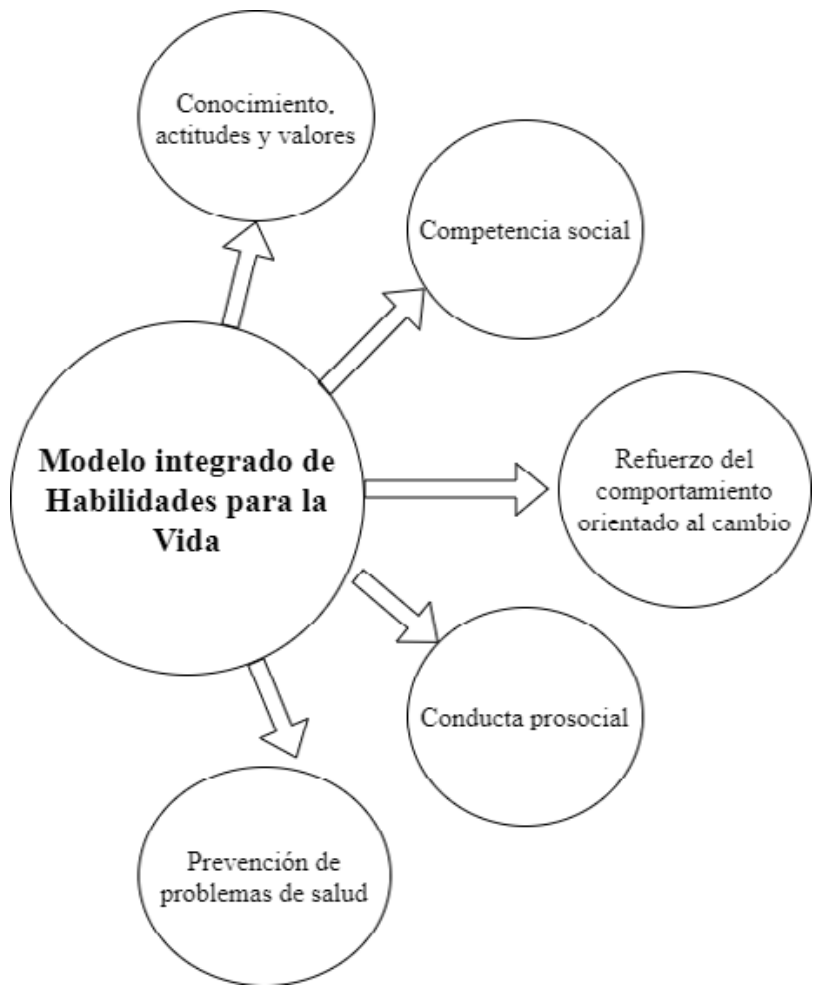




\section{2. ¿Qué son las habilidades sociales?}

Definir las habilidades sociales es una tarea problemática, particularmente porque al hablar de una habilidad social las personas pueden darle una variabilidad compleja. La falta de acuerdo también ha sido una constante entre teóricos y académicos. Libet y Lewinsohn (1973) las definieron como "conductas interpersonales que mejoran la efectividad de un individuo como miembro de una organización" (p. 304). Desde esta perspectiva, la persona tiene la capacidad de asumir y aceptar la responsabilidad por su comportamiento, la opción de estar constantemente abierto a nuevas experiencias, la posibilidad de experimentar con factores más allá de la realidad presente, y la competencia para resolver problemas.

Para Gresham y Elliot (1990), refiriéndose a los adolescentes, las habilidades sociales se dividen en cinco grupos principales de acciones:

"La cooperación: se entiende como un conjunto de comportamientos de ayuda a otros, compartir cosas materiales o tiempo en proyectos con los pares, y cumplir las reglas sociales.

"La afirmación: se refiere a asumir comportamientos por la indicación de otras personas, ajustarse a las normas del grupo y compartir información sobre las reglas de conducta social.

" Responsabilidad: se aplica a los comportamientos de los adolescentes que demuestran la habilidad para comunicarse con los adultos, mantener y defender sus ideas como propias y asumir las consecuencias.

" Empatía: se define como la habilidad de ponerse en el lugar de otros, se manifiesta en comportamientos que revelan la preocupación por los sentimientos de un compañero o un adulto significativo.

"Autocontrol: se refiere a la capacidad de tener comportamientos de respuesta en un momento de conflicto o dificultad con los pares o frente a correctivos de los adultos.

Desde esta postura teórica, las habilidades sociales son la parte más maleable de competencia social, la cual reúne una gama más amplia y compleja de comportamientos y habilidades (Elliott \& Busse, 1991). 
Para Cook et al. (2008), las habilidades sociales son conductas aprendidas de iniciación y de respuesta que favorecen la interacción con los otros; estas se retroalimentan y se refuerzan socialmente e implican para cada sujeto la habilidad de comportarse en contexto, es decir, dan cuenta de la competencia de la persona para adaptarse y ser efectiva en tareas sociales.

Las habilidades sociales se pueden considerar como parte de la competencia social, que es el grado en que los niños, niñas y los adolescentes establecen y mantienen relaciones interpersonales, los límites y relaciones de cooperación y aceptación con sus pares, la capacidad de construir y mantener relaciones con otros chicos y chicas de su edad y la suficiencia para evitar o romper relaciones perjudiciales.

Las habilidades sociales se consideran necesarias, pero no suficientes, para determinar la competencia y el ajuste sociales. El desempeño social integra otros componentes, principalmente emocionales y cognitivos, que estructuran la complejidad de la conducta. El otro, el ajuste social, no se puede considerar un producto directo del desempeño social, esto porque está afectado por una amplia gama de factores, entre ellos, las expectativas de respuesta, las creencias, las normas y los rituales que, en general, son determinados por la cultura (Nangle, Hansen et al., 2010). El ajuste social hace referencia a los procesos de adaptación o inadaptación social; teóricamente, una persona que asuma los valores y las costumbres positivas de su cultura tendrá mayor acceso a los bienes sociales, mayor bienestar y riqueza en sus relaciones sociales (Madariaga et al., 2017; Salguero et al., 2011; Snyder, 2014).

\subsection{La competencia social}

Una persona (socialmente) competente es aquella que es capaz de utilizar los recursos personales y ambientales para llevar a cabo sus tareas. Una definición clásica indica que la competencia social es la habilidad para movilizar y coordinar opciones, de tal manera que las oportunidades son creadas aprovechando los potenciales o recursos del ambiente, lo que mejora las posibilidades para un buen resultado de desarrollo (Waters \& Sroufe, 1983).

La competencia social se ejecuta en el marco cultural, las relaciones, el tiempo, la percepción (codificación), integración y los comportamientos involucrados en relaciones sociales, y se asocia con la motivación, el conocimiento y la capacidad de 
interactuar. Las habilidades sociales son construcciones importantes para comprender la comunicación social. Además, "la competencia emocional hace parte de la competencia social y ambas se integran; no es posible tener competencia emocional sin competencia social y viceversa" (Semrud-Clikeman, 2007, p. 9).

La competencia social también hace referencia a las habilidades y las capacidades específicas de las personas con respecto a realidades particulares. Por ejemplo, una persona con condiciones médicas graves deberá gestionar habilidades que le permitan interactuar con el sistema social y las personas que trabajan en los servicios de atención (Lamerichs et al., 2019). De igual manera, por ser un concepto amplio y dinámico se aplica a las competencias que desarrollan niños, niñas y adolescentes con problemas en salud mental y diversidad funcional (Semrud-Clikeman, 2007). En la Tabla 5.1 se resume qué son las habilidades sociales, a qué constructo teórico pertenecen y cómo se enseñan.

Tabla 5.1. Habilidades sociales en el contexto de la educación en competencia social y las competencias socioemocionales

Conductas aprendidas de iniciación y de respuesta que favorecen la interacción con los otros; se retroalimentan y se refuerzan socialmente e implican para cada

Las habilidades sociales son sujeto la habilidad de comportarse en contexto, es decir, dan cuenta de la competencia de la persona para comportarse y de ser competente en tareas sociales (Cook et al., 2008).

La competencia social se desarrolla en el marco cultural, las relaciones, el tiempo, la percepción (codificación), integración y los comportamientos involucrados en relaciones sociales. También la motivación, el conocimiento y la capacidad de interactuar (Semrud-Clikeman, 2007, p. 9). Pueden ser muy específicas para poblaciones clínicas o en mayor vulnerabilidad (Lamerichs et al., 2019).

Hacen parte de Las competencias socioemocionales son habilidades de autoconocimiento, atención, comprensión, gestión y regulación emocional, habilidades sociales y empatía. Son competencias mediante las cuales se autorregula el comportamiento para iniciar y mantener de manera efectiva las interacciones sociales, teniendo en cuenta tanto las necesidades personales como las del grupo social (Mayer \& Salovey, 1997).

Programas de entrenamiento en habilidades sociales (Goldstein et al., 1989).

Programas de competencia social (Felner et al., 1990).

Se enseñan a través de

Programas de competencias socioemocionales (Mayer \& Salovey, 1997; Mayer et al., 2016; Bisquerra Alzina \& Pérez Escoda, 2007). 


\subsection{Modelos de habilidad social}

Los modelos de habilidades sociales se orientan a explicar la capacidad y habilidad social a partir de procesos cognitivos y de aprendizaje que tienen influencia directa sobre la conducta; por ello, las evidencias en el campo de la psicología y la educación favorecen los modelos orientados al aprendizaje socioemocional y social-cognitivo. Los modelos de base social y cognitiva se respaldan en teorías de procesamiento de información y en medidas de evaluaciones de las formas de atribución social y de faltas y dificultades en la interacción social. También se han desarrollado métodos y estrategias para evaluar la cognición y la habilidad social en relación con las metas, las estrategias, la percepción de autoeficacia y las expectativas de respuestas comportamentales. El análisis del procesamiento de información y las estrategias conductuales y cognitivas de la interacción social, han permitido evaluar diversos fenómenos asociados a las habilidades sociales, entre ellos, la legitimación y las creencias en torno a la agresión (Nangle, Hansen et al., 2010).

El modelo de procesamiento de información (Crick \& Dodge, 1994) propone que las personas se acercan a situaciones sociales con conocimientos sociales previos, como esquemas y recuerdos. La habilidad social es una respuesta al procesamiento de información, que implica:

1. La codificación interna y externa de las señales.

2. La interpretación de las señales.

3. La selección de los objetivos de la conducta.

4. Decisiones de respuesta.

5. Manifestación externa de la conducta.

Las respuestas comportamentales son construidas con base en el procesamiento de información y obedecen a procesos decisionales. Estas decisiones están afectadas por evaluaciones basadas en las reglas, la moral y los valores, las expectativas de respuesta, la percepción y la evaluación de autoeficacia. Incluyen procesos de codificación e interpretación, atribuciones causales y expresión de la conducta en función de la clarificación de metas individuales y sociales. 
La teoría del aprendizaje social (Bandura, 1977) explica que las percepciones de autoeficacia y las expectativas de resultado afectan la habilidad de las personas y las formas de comportarse socialmente; también, que las atribuciones negativas, los objetivos sociales, el manejo de técnicas y herramientas de comunicación, las percepciones de autoeficacia, las creencias sobre la legitimidad de los actos, pueden ser determinantes en la agresión, la prosocialidad y el trato con otras personas.

Otra propuesta teórica enunciada con base en el procesamiento de información es el modelo reformulado de habilidad social (McFall, 1982), desde el que se explica que dicha habilidad opera con el siguiente procedimiento: en primer lugar, se produce una codificación de las habilidades con varios pasos: recepción, percepción e interpretación de la información; en segundo lugar, se decide sobre el tipo de habilidad a utilizar, estas pueden ser de búsqueda, selección de opciones, utilidad o evaluación; y en tercer lugar, se codifica el repertorio de habilidades.

El modelo de estrategias de negociación interpersonal (Selman et al., 1986), que también hace parte de los modelos sociocognitivos de procesamiento de información, centró su interés en las relaciones interpersonales y las estrategias de resolución de conflictos. Este modelo consta de cuatro procesos:

" Definir el problema: analiza las relaciones entre el contexto, las expectativas del sujeto y los problemas específicos.

" Toma de decisiones: una vez definido el problema, se plantean las acciones que se llevarán a cabo para solucionarlo.

" Justificación y estrategias de la estrategia: se refiere a la consideración de las soluciones propuestas. Incluye los significados de la solución para las personas involucradas.

"Complejidad de los sentimientos expresados: los sentimientos en las relaciones sociales pueden ser complejos, múltiples y diferentes en cada uno de los implicados.

Por su parte, el modelo de atribuciones hostiles (Crick \& Dodge, 1994; Hiemstra et al., 2019) indica que la habilidad social se afecta cuando falla el proceso de codificación de la información. De acuerdo con Crick y Dodge (1994), el procesamiento erróneo durante cualquiera de sus pasos puede conducir a un comportamiento agresivo; estos son: 
1. La información debe estar codificada con precisión.

2. La información codificada debe representarse correctamente.

3. Se debe especificar un objetivo de interacción.

4. Se deben generar alternativas de respuesta.

5. Estas alternativas de respuesta deben evaluarse y, a partir de estas respuestas, se puede seleccionar una expresión conductual óptima.

6. Se debe promulgar la respuesta seleccionada (Orobio de Castro et al., 2002).

\subsection{Los aportes de la teoría del aprendizaje social}

La teoría del aprendizaje social ha aportado en forma considerable a la conceptualización actual de las habilidades sociales, en su cuerpo teórico explica una gama significativa de habilidades cognitivas, emocionales y de comportamiento, objeto del aprendizaje social, entre ellas, la motivación y las expectativas (DuBois \& Felner, 1996).

Esta teoría indicó que el ambiente es un determinante del comportamiento, al igual que las formas como las personas interpretan la información procedente del entorno. También aportó las bases para entender el aprendizaje conductual indirecto, la comunicación simbólica, la mediación cognitiva y el determinismo recíproco entre el ambiente, la cognición y la conducta, que permite el cambio, pero también el mantenimiento de esta última. En el ámbito de lo práctico "aportó las bases de los procedimientos de intervención de aprendizaje social, que incluyen el refuerzo, la retroalimentación, el ensayo de comportamiento, el modelado, y el entrenamiento, así como capacitación en resolución de problemas y las conductas de autoinstrucción" (Nangle, Erdley et al., 2010, p. 38).

Desde la teoría del aprendizaje social, las habilidades sociales son comportamientos aprendidos que resultan del refuerzo positivo de las mismas habilidades, las experiencias de aprendizaje -que pueden ser directas o indirectas, los procesos de modelamiento y retroalimentación en el proceso de instrucción, y las expectativas y motivaciones del sujeto frente al aprendizaje o las relaciones interpersonales (Nangle, Erdley et al., 2010). Los reforzadores cumplen una función de potenciación o extinción en el aprendizaje de la habilidad social, las conductas que son reforzadas 
positivamente se inclinan a repetirse y aquellas que son sancionadas, probablemente disminuyan. De igual manera, la consistencia y permanencia de los reforzadores contribuyen al mantenimiento de la conducta; las habilidades sociales que se enseñan, pero no se refuerzan consistentemente, en especial en las primeras etapas de aprendizaje, tenderán a declinar porque el sujeto no las domina por completo (Kelly, 1982; Trower, 2014).

Otra importante contribución de la teoría del aprendizaje social a las habilidades sociales es la noción de consecuencia anticipada. El proceso de aprendizaje de la habilidad social se puede realizar a través del modelado y la observación de la ejecución de la habilidad; inicialmente, no es necesaria una exposición directa para aprender una conducta (Bandura, 1977; Kelly, 1982).

La mediación cognitiva en la formación de las habilidades sociales es fundamental en el aprendizaje social, debido a que, según Bandura (1978, 1993), las personas pueden ejercer cierto grado de control sobre su propio comportamiento. Agrega el autor que, a través de la regulación, los individuos, pueden alterar sus entornos inmediatos, crear autoincentivos cognitivos y generar consecuencias para su propio comportamiento. También mediante las cogniciones de autoeficacia y su nivel de desarrollo, las personas pueden establecer metas para sí mismos, estar firmes en el compromiso de lograrlas y atribuir fracasos al esfuerzo insuficiente; a mayor sentido de autoeficacia, mayor será la dificultad de la meta y la responsabilidad que asuma frente a esta.

En general, las habilidades sociales en el marco de la teoría del aprendizaje social son conductas aprendidas, susceptibles de ser modificadas, mediadas por procesos cognitivos, sobre las cuales las personas pueden ejercer cierto grado de control y tienen la capacidad para aplicarlas sobre su propio comportamiento. El aprendizaje de las habilidades sociales contribuye a procesos de autorregulación por medio de los cuales los individuos pueden alterar los entornos inmediatos, modificar procesos cognitivos y direccionar la conducta.

Las habilidades sociales se aprenden de forma similar a otros comportamientos; se adquieren por interacciones entre el individuo y el medio ambiente. El proceso de aprendizaje, como lo indican Nangle, Erdley et al. (2010), puede ser directo -involucrando exposición real a las contingencias- o indirecto -involucrando la observación de otros-; ambos también pueden ocurrir a través de medios más simbólicos, como el lenguaje hablado o escrito, y permiten ser aplicados en el contexto cotidiano y en el terapéutico. En la Tabla 5.2 se presentan enfoques de intervención en habilidades 
en la práctica terapéutica, discriminados por foco de atención, procedimientos de intervención, condiciones de intervención, control de rendimiento y evaluación de los resultados.

Tabla 5.2. Comparación de los diferentes enfoques de intervención en habilidades sociales

\section{Características básicas}

Foco de intervención

\section{Operante}

Aprendizaje social

Cognitivo conductual

Observar los comportamien- Observación de la con- Habilidades para resolver

tos, los antecedentes y las ducta y procesos media- problemas y su relación

consecuencias de los eventos cionales con la conducta observada
Procedimientos de inter- Reforzamiento vención
Modelado, juegos de rol Entrenamiento; resolución $\mathrm{y}$ autoinstrucciones de problemas y autoinstrucciones

Condiciones de la inter- Individual o en grupo; Individual o en grupos Individual y en pequeños vención directo y en entorno natural pequeños; directo o grupos; directo o análogo mediado por pares; análogo o en el ambiente natural

\begin{tabular}{llll}
\hline Control de rendimiento & Externo & Interno y externo & Interno \\
\hline Evaluación de resultados & Cambio en el rendimiento de & Cambio en las respues- Cambio en los pensamien- \\
& las conductas objetivo & tas aprendidas y rendi- tos acerca de la conducta y \\
& & miento en las respuestas & habilidad para exteriorizar \\
& & & conductas apropiadas \\
\hline
\end{tabular}

\section{6. ¿Por qué enseñar habilidades sociales?}

Son numerosas las razones por las cuales es conveniente formar a los niños, niñas y adolescentes en habilidades sociales, entre ellas que las deficiencias en dichas habilidades aumentan la vulnerabilidad a los problemas de salud mental, por ejemplo, la depresión, la soledad y la ansiedad social (Segrin \& Flora, 2000). 
Educar a los niños, niñas y adolescentes ayuda a mejorar el rendimiento académico y disminuir problemas de comportamiento (Mcclelland et al., 2000); aquellos que participan en programas de entrenamiento en habilidades sociales presentan menos problemas internalizantes y externalizantes y mayor conducta prosocial (Henricsson \& Rydell, 2006).

De acuerdo con Le Messurier y Parker (2011), en los adolescentes que han participado en programas de habilidades sociales se han observado mejoras en las diversas áreas, y en aquellos que presentan retraso social mejora la adaptación, la integración y el conocimiento social. En un meta análisis que incluía 27.064 participantes y 84 estudios, se observó que los objetivos de los programas buscan mejorar los niveles de adecuación social y la resolución de problemas sociales mediante el desarrollo de habilidades interpersonales, autocontrol o capacitación en perspectiva social; los resultados sugieren que los adolescentes que reciben capacitación en habilidades sociales pueden beneficiarse en cuanto a la reducción de ansiedad, mayor comodidad en situaciones sociales o mayor motivación en las actividades que realizan (Cook et al., 2008; Hattie, 2009).

Actualmente se desarrollan programas de habilidades sociales aplicados a diversas problemáticas de salud mental y a otras que requieren atención clínica como la ira, la agresión, la ansiedad social, diversidad intelectual, trastornos del espectro autista, esquizofrenia y trastornos asociados al uso de drogas y las adicciones (Nangle, Hansen et al., 2010).

\section{7. ¿Cuáles son los programas de entrenamiento en habilidades sociales más efectivos?}

Un metaanálisis sobre la efectividad de los programas de entrenamiento en habilidades sociales, dirigidos a adolescentes con problemas de comportamiento y emocionales, buscó establecer si enseñar habilidades sociales era una estrategia de intervención efectiva para estudiantes de secundaria; también exploró si los enfoques teóricos particulares como el conductual, el aprendizaje social, el cognitivo y el cognitivo conductual mostraban ser más efectivos unos que otros. Los resultados indicaron que las intervenciones en habilidades sociales, cuando se usan solas o en grupos pequeños, no son muy efectivas para aumentar la competencia social de los estudiantes; pero en general, los programas de habilidades sociales registran mejoras en el colectivo y los 
participantes se ven beneficiados de las intervenciones. Acerca de las diferencias en los enfoques, los resultados no fueron concluyentes; sin embargo, se estableció que el uso de uno u otro enfoque sí ocasiona resultados diferenciales en el proceso de aprendizaje de las habilidades; por ejemplo, en los primeros años de la adolescencia, los entrenamientos con aprendizaje operante produjeron resultados significativamente mayores que los producidos por enfoques de orientación social y cognitivo conductual, mientras en los adolescentes, los programas que incluían tácticas de aprendizaje social como el modelado y el entrenamiento por roles, produjeron mejores resultados que los programas de entrenamiento operante o cognitivo (Cook et al., 2008).

Los hallazgos del metaanálisis indican que los programas de habilidades sociales que lograron cambios en los estudiantes tuvieron ganancias principalmente a corto plazo, lo que señala la necesidad de proporcionar entrenamiento de habilidades de manera regular y sostenida. Los participantes más beneficiados con estos programas, de acuerdo con los datos, son los niños, niñas y adolescentes en riesgo (Cook et al., 2008). Tales programas, en especial los de resolución de problemas interpersonales, pueden hacer una diferencia positiva en los resultados sociales. Los programas más efectivos fueron aquellos que "utilizaron estrategias de consejería, retroalimentación de la conducta y modelado, particularmente cuando se enfoca en temas individuales de relación de pares" (Hattie, 2009, p. 151).

\subsection{Medidas de habilidad social}

La investigación en habilidades sociales ha permitido el diseño y validación de instrumentos de observación, registro, autoinformes, reportes de terceros y experimentos que permiten evaluar la habilidad social. Nangle, Hansen et al. (2010) realizaron una compilación de instrumentos para evaluar las habilidades sociales en niños, niñas, adolescentes y adultos. El reporte incluye el nombre del instrumento, la citación original, el propósito, la población objetivo, la descripción, las variables de evaluación, los puntajes, las propiedades psicométricas, la fuente (sitio de compra) y el costo. La evaluación debe hacerse siempre con instrumentos validados, por lo que son recomendadas las traducciones y adaptaciones.

Se anexa en este capítulo el cuestionario de habilidades del aprendizaje estructurado (Goldstein et al., 1989) adaptado por Tomas (1995). Este instrumento evalúa el desarrollo de habilidades sociales que puede aplicarse a niños, niñas y adolescen- 
tes, a partir de los 12 años. Cuenta con 50 ítems, contiene los siguientes seis grupos diferentes de habilidades sociales: habilidades sociales básicas; habilidades sociales avanzadas; habilidades relacionadas con los sentimientos; habilidades alternativas a la agresión; habilidades para hacer frente al estrés; habilidades de planificación.

\section{Conclusión}

Las habilidades para la vida son un enfoque propuesto por la Organización Mundial de la Salud (WHO, 1993) que incluye tres dimensiones: las habilidades cognitivas, las habilidades emocionales y las habilidades sociales. Si bien es una propuesta viable, además de pertinente, por la originalidad de sus fines (la prevención, la intervención psicosocial en comunidades y la tarea de disminuir riesgos asociados a problemas de salud, el desarrollo individual y comunitario, y el bienestar) y también por su aplicabilidad a diversos contextos (incluidos aquellos que presentan situaciones de vulnerabilidad social), se ha observado que, en comparación con otros modelos (los de competencia socioemocional, inteligencia emocional y aprendizaje socioemocional), el enfoque de las habilidades para la vida adolece de evidencia reportada en los medios científicos. Se considera que las dimensiones que la componen, entre ellas las habilidades sociales, hacen de este enfoque un candidato a modelo de competencia socioemocional, sin embargo, debe evidenciar que cumple con los objetivos para los que fue diseñado, establecer los contenidos de cada dimensión y unificar el uso del modelo en diferentes contextos. Se han aportado consideraciones teóricas que sustentan la importancia de la enseñanza de habilidades sociales.

\section{Referencias}

Bancin, A., \& Ambarita, B. (2019). Education model based on life skill (a metasynthesis). In 4th Annual International Seminar on Transformative Education and Educational Leadership (AISTEEL 2019), 384, 319-324. https://doi.org/10.2991/ aisteel-19.2019.69

Bandura, A. (1977). Social learning theory. General Learning Press. 
Bandura,A. (1978). The self-system in reciprocal determinism. American Psychologist, 33(4), 344-358. https://doi.org/10.1037/0003-066X.33.4.344

Bandura, A. (1993). Perceived self-efficacy in cognitive development and functioning. Educational Psychologist, 28(2), 117-148. https://doi.org/10.1207/ s15326985ep2802_3

Bisquerra Alzina, R., \& Pérez Escoda, N. (2007). Las competencias emocionales. Educación XXI, 10, 61-82. https://doi.org/10.1109/PESGM.2012.6344804

Cook, C. R., Gresham, F. M., Kern, L., Barreras, R. B., Thornton, S., \& Crews, S. D. (2008). Social skills training for secondary students with emotional and/ or behavioral disorders: A review and analysis of the meta-analytic literature. Journal of Emotional and Behavioral Disorders, 16(3), 131-144. https://doi. org/10.1177/1063426608314541

Henricsson, L., \& Rydell, A.-M. (2006). Children with Behaviour Problems: The Influence of Social Competence and Social Relations on Problem Stability, School Achievement and Peer Acceptance Across the First Six Years of School. Infant and Child Development, 15, 347-366. https://doi.org/10.1002/icd.448

Crick, N. R., \& Dodge, K. A. (1994). A review and reformulation of social informationprocessing mechanisms in children's social adjustment. Psychological Bulletin, 115(1), 74-101. https://doi.org/10.1037/0033-2909.115.1.74

DuBois, D. L., \& Felner, R. D. (1996). The quadripartite model of social competence: Theory and applications to clinical intervention. In M. A. Reinecke, F. M. Dattilio, $\&$ A. Freeman (Eds.), Cognitive therapy with children and adolescents: A casebook for clinical practice (pp. 124-152). Guilford Press.

Elliott, S. N., \& Busse, R. T. (1991). Social skills assessment and intervention with children and adolescents: Guidelines for assessment and training procedures. School Psychology International, 12, 63-83. https://doi.org/10.1177/0143034391121006

Felner, R. D., Lease, A. M., \& Phillips, R. S. C. (1990). Social competence and the language of adequacy as a subject matter for psychology: A quadripartite tri-level framework. In T. P. Gullota, G. R. Adams, \& R. Montemayor (Eds). The development of social competence in adolescence (pp. 245-264). Sage. 
Frey, N., Fisher, D., \& Smith, D. (2019). All learning is social and emotional helping students develop essential skills for the classroom and beyond. ASCD.

Goldstein, A. P., Sprafkin, R. P., Gershaw, N. J., \& Klein, P. (1989). Habilidades sociales y autocontrol en la adolescencia: un programa de enseñanza. Ediciones Martínez Roca.

Gresham, F. M., \& Elliot, S. N. (1990). Social skills rating system. American Guidance Service.

Hattie, J. (2009). Visible learning: A synthesis of over 800 meta-analyses relating to achievement. Routledge.

Hiemstra, W., De Castro, B. O., \& Thomaes, S. (2019). Reducing aggressive children's hostile attributions: A cognitive bias modification procedure. Cognitive Therapy and Research, 43(2), 387-398. https://doi.org/10.1007/s10608-018-9958-x

January, A. M., Casey, R. J., \& Paulson, D. (2011). A meta-analysis of classroomwide interventions to build social skills: Do they work? School Psychology Review, 40(2), 242-256. https://doi.org/0279-6015

Kelly, J.A. (1982). Social-skills training: A practical guide for interventions. Springer.

Lamerichs, J., Danby, S. J., Bateman, A., \& Ekberg, S. (2019). Children and mental health talk: Perspectives on social competence. Palgrave Macmillan.

Le Messurier, M., \& Parker, M. D. (2011). What's the Buzz? A social skills enrichment programme for primary students. Routledge.

Libet, J. M., \& Lewinsohn, P. M. (1973). Concept of social skill with special reference to the behavior of depressed persons. Journal of Consulting and Clinical Psychology, 40(2), 304-312. https://doi.org/10.1037/h0034530

Madariaga, J. M., Arribiliaga, A., \& Zulaika, L. M. (2017). Componentes y relaciones de un modelo estructural del ajuste psicosocial en la adolescencia. International Journal of Developmental and Educational Psychology. Revista INFAD de Psicología, 6(1), 303. https://doi.org/10.17060/ijodaep.2014.n1.v6.748 
Mayer, J. D., Caruso, D. R., \& Salovey, P. (2016). The ability model of emotional intelligence: Principles and updates. Emotion Review, 8(4), 290-300. https://doi. org/10.1177/1754073916639667

Mayer, J. D., \& Salovey, P. (1997). What is emotional intelligence? In D. J. Sluyter (Ed.), Emotional development and emotional intelligence: Educational implications (pp. 3-34). Basic Books.

Mcclelland, M. M., Morrison, F. J., \& Holmes, D. L. (2000). Children at risk for early academic problems: The role of learning-related social skills. Early Childhood Research Quarterly, 15(3), 307-329. https://doi.org/10.1016/S08852006(00)00069-7

McFall, R. M. (1982). A review and reformulation of the concept of social skills. Behavioral Assessment, 4(1), 1-33. https://doi.org/10.1007/BF01321377

Nangle, D. W., Erdley, C. A., Adrian, M., \& Fales, J. (2010). A conceptual basis in social learning theory. In D. W. Nangle, D. J. Hansen, C. A. Erdley, \& P. J. Norton (Eds.), Practitioner's guide to empirically based measures of social skills (3a. ed., pp. 37-49). Guilford Press.

Nangle, D. W., Hansen, D. J., Erdley, C. A., \& Norton, P. J. (Eds.). (2010). Practitioner's Guide to Empirically Based Measures of Social Skills. Springer-Verlag.

Orobio de Castro, B., Veerman, J. W., Koops, W., Bosch, J. D., \& Monshouwer, H. J. (2002). Hostile attribution of intent and aggressive behavior: A meta-analysis. Child Development, 73(3), 916-934. https://doi.org/10.1111/1467-8624.00447

Prajapati, R., Sharma, B., \& Sharma, D. (2017). Significance of life skills education. Contemporary Issues in Education Research (CIER), 10(1), 1-6. https://doi. org/10.19030/cier.v10i1.9875

Salguero, J. M., Fernández-Berrocal, P., Ruiz-Aranda, D., Castillo, R., \& Palomera, R. (2011). Inteligencia emocional y ajuste psicosocial en la adolescencia: el papel de la percepción emocional. European Journal of Education and Psychology, 4(2), 143-152. http://www.redalyc.org/articulo.oa?id=129322659005 
Segrin, C., \& Flora, J. (2000). Poor social skills are a vulnerability factor in the development of psychosocial problems. Human Communication Research, 26(3), 489-514. https://doi.org/10.1111/j.1468-2958.2000.tb00766.x

Selman, R. L., Beardslee, W., Schultz, L. H., Krupa, M., \& Podorefsky, D. (1986). Assessing adolescent interpersonal negotiation strategies. Toward the integration of structural and functional models. Developmental Psychology, 22(4), 450-459. https://doi.org/10.1037/0012-1649.22.4.450

Semrud-Clikeman, M. (2007). Social competence in children. Springer.

Snyder, F. J. (2014). Socio-emotional and character development: A theoretical orientation. Journal of Character Education, 10(2), 107-127. https://www.ncbi. nlm.nih.gov/pmc/articles/PMC4605220/

Tomas, A. (1995). Conducta Tipo A y habilidades sociales en estudiantes del primer al quinto año de Psicología de una Universidad Nacional de Lima (Tesis). Universidad Federico Villarreal, Lima.

Trower, P. (2014). Radical approaches to social skills training. Routledge.

Waters, E., \& Sroufe, L. A. (1983). Social competence as a developmental construct. Developmental Review, 3(1), 79-97. https://doi.org/10.1016/0273-2297(83)90010-2

World Health Organization. (1993). Life skills education for children and adolescents in schools: Introduction and guidelines to facilitate the development and implementation of life skills programmes. Division of Metal Health and Prevention of Substance Abuse. 


\section{Anexo}

\section{Ficha técnica cuestionario de habilidades del aprendizaje}

\section{estructurado}

Nombre: cuestionario de habilidades del aprendizaje estructurado

Autor: Arnold Goldstein et al. (1989)

Aplicación: Individual y colectivo

Tiempo: 15 a 20 minutos aproximadamente

Edad: 12 años en adelante

Significación: Indica habilidades sociales en déficit en población adolescente, pudiéndose ampliar a grupos de mayor edad.

Traducción y adaptación: Ambrosio Tomás Rojas (1995)

\section{Objetivos}

Determinar las deficiencias y competencias que tiene una persona en sus habilidades sociales.

Identificar el uso de la variedad de habilidades sociales, personales e interpersonales. Evaluar en qué tipo de situaciones las personas son competentes o deficientes en el empleo de una habilidad social.

Este instrumento permite obtener información precisa y específica sobre el nivel de habilidades sociales.

\section{Calificación}

La calificación es un procedimiento simple y directo que se ve facilitado por la estimación que hace el sujeto de su grado competente o deficiente en el que utiliza las habilidades sociales.

La puntuación máxima que obtener en un ítem es 5 y el valor mínimo es 1 . 
Las puntuaciones 1 y 2 indican, en general, un déficit en la habilidad.

El puntaje por áreas, el cual indica las deficiencias o logros del sujeto en un área específica, se obtiene sumando los puntajes obtenidos en los ítems comprendidos en cada área del instrumento.

El puntaje total, que varía en función al número de ítems que responde el sujeto en cada valor de 1 a 5 , como mínimo es 50 y como máximo es de 250 puntos. Este tipo de puntaje es útil como indicador. También es útil para evaluar el aprendizaje estructurado, al aplicarse la prueba a manera de re-test luego del tratamiento.

El cuestionario permite diseñar estrategias de aprendizaje estructurado con uso de técnicas de modelamiento, juegos de rol, retroalimentación del rendimiento y reforzamiento. El programa propuesto por Goldstein et al. (1989), cuenta con sesiones de entrenamiento para cada una de las habilidades.

\section{Cuestionario de habilidades del aprendizaje estructurado}

\section{Tomado de Goldstein et al. (1989)}

Instructor:

Nombre:

Clase:

Edad: 
Apreciado(a),

Más abajo usted encontrará la lista de las habilidades en cuyo empleo los adolescentes son competentes. Este cuestionario le ayudará a evaluar el uso que usted hace de las distintas habilidades. Luego se utilizará esta información para desarrollar el aprendizaje estructurado. Asimismo, la información se empleará para decidir qué habilidades se deben potenciar. Al contestar, valore la utilización de la habilidad, basada en una observación de la conducta en distintas situaciones.

Marque (N) si nunca utiliza bien la habilidad

Marque (PV) si muy pocas veces utiliza bien la habilidad

Marque (AV) si algunas veces utiliza bien la habilidad

Marque (AM) si a menudo utiliza bien la habilidad

Marque (S) si siempre utiliza bien la habilidad

Por favor valore todas las aptitudes que figuran en la lista. Si hay una situación en la cual usted tiene dificultades para emplear bien la aptitud, apúntelo brevemente en el espacio señalado como "Situación problema".

\begin{tabular}{|c|c|c|c|c|c|c|}
\hline \multicolumn{2}{|r|}{ Grupos de habilidades } & $\mathbf{N}$ & PV & $\mathbf{A V}$ & $\mathbf{A M}$ & $\mathbf{S}$ \\
\hline \multicolumn{7}{|c|}{ I. $\quad$ Habilidades sociales básicas } \\
\hline 1 & $\begin{array}{l}\text { Escuchar: ¿Presta atención a la persona que le está hablando y hace } \\
\text { un esfuerzo para comprender lo que están diciendo? }\end{array}$ & $\mathrm{O}$ & $\mathrm{O}$ & $\mathrm{O}$ & $\mathrm{O}$ & $\mathrm{O}$ \\
\hline 2 & $\begin{array}{l}\text { Iniciar una conversación: ¿Habla con los demás de temas poco } \\
\text { importantes para pasar luego a los más importantes? }\end{array}$ & $\mathrm{O}$ & $\mathrm{O}$ & $\mathrm{O}$ & $\mathrm{O}$ & $\mathrm{O}$ \\
\hline 3 & $\begin{array}{l}\text { Mantener una pregunta: ¿Determina la información que necesita, } \\
\text { pregunta a quién le puede responder hasta quedar satisfecho(a) con } \\
\text { la respuesta? }\end{array}$ & $\mathrm{O}$ & $\mathrm{O}$ & $\mathrm{O}$ & $\mathrm{O}$ & $\mathrm{O}$ \\
\hline 4 & $\begin{array}{l}\text { Formular una pregunta: ¿Determina la información que necesita y } \\
\text { se la pide a la persona adecuada? }\end{array}$ & $\mathrm{O}$ & $\mathrm{O}$ & $\mathrm{O}$ & $\mathrm{O}$ & $\mathrm{O}$ \\
\hline 5 & $\begin{array}{l}\text { Dar las "gracias”: ¿Permite que los demás sepan que le agradece } \\
\text { los favores, la ayuda, algún servicio, etc.? }\end{array}$ & $\mathrm{O}$ & $\mathrm{O}$ & $\mathrm{O}$ & $\mathrm{O}$ & $\mathrm{O}$ \\
\hline 6 & Presentarse: ¿Se da a conocer a los demás por propia iniciativa? & $\mathrm{O}$ & $\mathrm{O}$ & $\mathrm{O}$ & $\mathrm{O}$ & $\mathrm{O}$ \\
\hline 7 & $\begin{array}{l}\text { Presentar a otras personas: ¿Ayuda a que los demás se } \\
\text { conozcan entre sí? }\end{array}$ & $\mathrm{O}$ & $\mathrm{O}$ & $\mathrm{O}$ & $\mathrm{O}$ & $\mathrm{O}$ \\
\hline 8 & $\begin{array}{l}\text { Hacer un cumplido: ¿Expresa lo que le gusta de algún aspecto de la } \\
\text { otra persona o alguna de las actividades que realiza? }\end{array}$ & $\mathrm{O}$ & $\mathrm{O}$ & $\mathrm{O}$ & \multirow[t]{2}{*}{$\mathrm{O}$} & $\mathrm{O}$ \\
\hline & Situaciones problema: & & & & & \\
\hline & Habilidades sociales avanzad & & & & & \\
\hline 9 & Pedir ayuda: ¿Pide que le ayuden cuando tiene alguna dificultad? & $\mathrm{O}$ & $\mathrm{O}$ & $\mathrm{O}$ & $\mathrm{O}$ & $\mathrm{O}$ \\
\hline 10 & $\begin{array}{l}\text { Participar: ¿Elige la mejor forma para integrarse en un grupo o para } \\
\text { participar en una determinada actividad? }\end{array}$ & $\mathrm{O}$ & $\mathrm{O}$ & $\mathrm{O}$ & $\mathrm{O}$ & $\mathrm{O}$ \\
\hline 11 & $\begin{array}{l}\text { Dar instrucciones: ¿Explica con claridad a los demás cómo hacer } \\
\text { una tarea específica? }\end{array}$ & $\mathrm{O}$ & $\mathrm{O}$ & $\mathrm{O}$ & $\mathrm{O}$ & $\mathrm{O}$ \\
\hline 12 & $\begin{array}{l}\text { Seguir instrucciones: ¿Presta atención a las instrucciones, pide } \\
\text { explicaciones, lleva adelante las instrucciones correctamente? }\end{array}$ & $\mathrm{O}$ & $\mathrm{O}$ & $\mathrm{O}$ & $\mathrm{O}$ & $\mathrm{O}$ \\
\hline 13 & Disculparse: ¿Pide disculpas a los demás por haber hecho algo mal? & $\mathrm{O}$ & $\mathrm{O}$ & $\mathrm{O}$ & $\mathrm{O}$ & $\mathrm{O}$ \\
\hline 14 & $\begin{array}{l}\text { Convencer a los demás: ¿Intenta persuadir a los demás de que sus } \\
\text { ideas son mejores y que serán de mayor utilidad que las de la otra } \\
\text { persona? }\end{array}$ & $\mathrm{O}$ & $\mathrm{O}$ & $\mathrm{O}$ & $\mathrm{O}$ & $\mathrm{O}$ \\
\hline
\end{tabular}




\begin{tabular}{|c|c|c|c|c|c|c|}
\hline \multicolumn{7}{|c|}{ Situaciones problema: } \\
\hline \multicolumn{7}{|c|}{ Habilidades relacionadas con los s } \\
\hline 15 & $\begin{array}{l}\text { Conocer los propios sentimientos: } \\
\text { ¿Intenta reconocer las emociones que experimenta? }\end{array}$ & $\mathrm{O}$ & & $\mathrm{O}$ & $\mathrm{O}$ & $\mathrm{O}$ \\
\hline 16 & $\begin{array}{l}\text { Expresar los sentimientos: ¿Permite que los demás conozcan lo que } \\
\text { siente? }\end{array}$ & $\mathrm{O}$ & $\mathrm{O}$ & $\mathrm{O}$ & $\mathrm{O}$ & $\mathrm{O}$ \\
\hline 17 & $\begin{array}{l}\text { Comprender los sentimientos de los demás: } \\
\text { ¿Intenta comprender lo que sienten los demás? }\end{array}$ & $\mathrm{O}$ & $\mathrm{O}$ & $\mathrm{O}$ & $\mathrm{O}$ & $\mathrm{O}$ \\
\hline 18 & $\begin{array}{l}\text { Enfrentarse con el enfado de otro: } \\
\text { ¿Intenta comprender el enfado de la otra persona? }\end{array}$ & $\mathrm{O}$ & $\mathrm{O}$ & $\mathrm{O}$ & $\mathrm{O}$ & $\mathrm{O}$ \\
\hline 19 & $\begin{array}{l}\text { Expresar afecto: ¿Permite que los demás sepan que se interesa o se } \\
\text { preocupa por ellos? }\end{array}$ & $\mathrm{O}$ & $\mathrm{O}$ & $\mathrm{O}$ & $\mathrm{O}$ & $\mathrm{O}$ \\
\hline 20 & $\begin{array}{l}\text { Resolver el miedo: ¿Piensa por qué está asustado(a) y hace algo para } \\
\text { disminuir su miedo? }\end{array}$ & $\mathrm{O}$ & $\mathrm{O}$ & $\mathrm{O}$ & $\mathrm{O}$ & $\mathrm{O}$ \\
\hline 21 & $\begin{array}{l}\text { Autorrecompensarse: ¿Se dice a sí mismo(a) cosas positivas o hace } \\
\text { cosas agradables cuando se merece una recompensa? }\end{array}$ & $\mathrm{O}$ & $\mathrm{O}$ & $\mathrm{O}$ & $\mathrm{O}$ & $\mathrm{O}$ \\
\hline \multicolumn{7}{|c|}{ Situaciones problema: } \\
\hline \multicolumn{7}{|c|}{$\begin{array}{lll}\text { IV. } & \text { Habilidades alternativas a la agresión } \\
\end{array}$} \\
\hline 22 & $\begin{array}{l}\text { Pedir permiso: ¿Reconoce cuando es necesario pedir permiso para } \\
\text { hacer algo y luego lo pide a la persona indicada? }\end{array}$ & $\mathrm{O}$ & $\mathrm{O}$ & $\mathrm{O}$ & $\mathrm{O}$ & $\mathrm{O}$ \\
\hline 23 & $\begin{array}{l}\text { Compartir algo: ¿Se ofrece para compartir algo que es apreciado por } \\
\text { los demás? }\end{array}$ & $\mathrm{O}$ & $\mathrm{O}$ & $\mathrm{O}$ & $\mathrm{O}$ & $\mathrm{O}$ \\
\hline 24 & Ayudar a los demás: ¿Ayuda a quien lo necesita? & $\mathrm{O}$ & $\mathrm{O}$ & $\mathrm{O}$ & $\mathrm{O}$ & $\mathrm{O}$ \\
\hline 25 & $\begin{array}{l}\text { Negociar: ¿Llega a establecer un sistema que satisfaga tanto a usted } \\
\text { mismo(a) como a quienes sostienen posturas diferentes? }\end{array}$ & $\mathrm{O}$ & $\mathrm{O}$ & $\mathrm{O}$ & $\mathrm{O}$ & $\mathrm{O}$ \\
\hline 26 & $\begin{array}{l}\text { Emplear el autocontrol: ¿Controla su carácter de modo que no se le } \\
\text { «escapan las cosas de la mano»? }\end{array}$ & $\mathrm{O}$ & $\mathrm{O}$ & $\mathrm{O}$ & $\mathrm{O}$ & $\mathrm{O}$ \\
\hline 27 & $\begin{array}{l}\text { Defender los propios derechos: ¿Defiende sus derechos dando a } \\
\text { conocer a los demás cuál es su postura? }\end{array}$ & $\mathrm{O}$ & $\mathrm{O}$ & $\mathrm{O}$ & $\mathrm{O}$ & $\mathrm{O}$ \\
\hline 28 & $\begin{array}{l}\text { Responder a las bromas: ¿Se las arregla sin perder el control cuando } \\
\text { los demás le hacen bromas? }\end{array}$ & $\mathrm{O}$ & $\mathrm{O}$ & $\mathrm{O}$ & $\mathrm{O}$ & $\mathrm{O}$ \\
\hline 23 & $\begin{array}{l}\text { Compartir algo: ¿Se ofrece para compartir algo que es apreciado por } \\
\text { los demás? }\end{array}$ & $\mathrm{O}$ & $\mathrm{O}$ & $\mathrm{O}$ & $\mathrm{O}$ & $\mathrm{O}$ \\
\hline 24 & Ayudar a los demás: ¿Ayuda a quien lo necesita? & $\mathrm{O}$ & $\mathrm{O}$ & $\mathrm{O}$ & $\mathrm{O}$ & $\mathrm{O}$ \\
\hline 25 & $\begin{array}{l}\text { Negociar: ¿Llega a establecer un sistema que satisfaga tanto a usted } \\
\text { mismo (a) como a quienes sostienen posturas diferentes? }\end{array}$ & $\mathrm{O}$ & $\mathrm{O}$ & $\mathrm{O}$ & $\mathrm{O}$ & $\mathrm{O}$ \\
\hline 26 & $\begin{array}{l}\text { Emplear el autocontrol: ¿Controla su carácter de modo que no se le } \\
\text { «escapan las cosas de la mano»? }\end{array}$ & $\mathrm{O}$ & $\mathrm{O}$ & $\mathrm{O}$ & $\mathrm{O}$ & $\mathrm{O}$ \\
\hline 27 & $\begin{array}{l}\text { Defender los propios derechos: ¿Defiende sus derechos dando a } \\
\text { conocer a los demás cuál es su postura? }\end{array}$ & $\mathrm{O}$ & $\mathrm{O}$ & $\mathrm{O}$ & $\mathrm{O}$ & $\mathrm{O}$ \\
\hline 28 & $\begin{array}{l}\text { Responder a las bromas: ¿Se las arregla sin perder el control cuando } \\
\text { los demás le hacen bromas? }\end{array}$ & $\mathrm{O}$ & $\mathrm{O}$ & $\mathrm{O}$ & $\mathrm{O}$ & $\mathrm{O}$ \\
\hline 29 & $\begin{array}{l}\text { Evitar los problemas con los demás: ¿Se mantiene al margen de } \\
\text { situaciones que le pueden ocasionar problemas? }\end{array}$ & $\mathrm{O}$ & $\mathrm{O}$ & $\mathrm{O}$ & $\mathrm{O}$ & $\mathrm{O}$ \\
\hline 30 & $\begin{array}{l}\text { No entrar en peleas: ¿Encuentra otras formas para resolver } \\
\text { situaciones difíciles sin tener que pelearse? }\end{array}$ & $\mathrm{O}$ & $\mathrm{O}$ & $\mathrm{O}$ & $\mathrm{O}$ & $\mathrm{O}$ \\
\hline
\end{tabular}




\begin{tabular}{|c|c|c|c|c|c|c|}
\hline \multicolumn{7}{|c|}{ Situaciones problema: } \\
\hline \multicolumn{7}{|c|}{ V. Habilidades para hacer frente al estrés } \\
\hline 31 & $\begin{array}{l}\text { Formular una queja: ¿Les dice a los demás cuando han sido ellos los } \\
\text { responsables de originar un determinado problema e intenta } \\
\text { encontrar una solución? }\end{array}$ & $\mathrm{O}$ & & $\mathrm{O}$ & $\mathrm{O}$ & $\mathrm{O}$ \\
\hline 32 & $\begin{array}{l}\text { Responder a una queja: ¿Intenta llegar a una solución justa ante la } \\
\text { queja justificada de alguien? }\end{array}$ & $\mathrm{O}$ & $\mathrm{O}$ & $\mathrm{O}$ & $\mathrm{O}$ & $\mathrm{O}$ \\
\hline 33 & $\begin{array}{l}\text { Demostrar deportividad después de un juego: ¿Expresa un cumplido } \\
\text { sincero a los demás por la forma en que han jugado? }\end{array}$ & $\mathrm{O}$ & $\mathrm{O}$ & $\mathrm{O}$ & $\mathrm{O}$ & $\mathrm{O}$ \\
\hline 34 & $\begin{array}{l}\text { Resolver la vergüenza: ¿Hace algo que le ayude a sentir menos } \\
\text { vergüenza o a estar menos cohibido(a)? }\end{array}$ & $\mathrm{O}$ & $\mathrm{O}$ & $\mathrm{O}$ & $\mathrm{O}$ & $\mathrm{O}$ \\
\hline 35 & $\begin{array}{l}\text { Arreglárselas cuando le dejan de lado: ¿Determina si le han dejado } \\
\text { de lado en alguna actividad y, luego, hace algo para sentirse mejor } \\
\text { en esa situación? }\end{array}$ & $\mathrm{O}$ & $\mathrm{O}$ & $\mathrm{O}$ & $\mathrm{O}$ & $\mathrm{O}$ \\
\hline 36 & $\begin{array}{l}\text { Defender a un(a) amigo }(a) \text { : ¿Manifiesta a los demás que han tratado } \\
\text { injustamente a un amigo(a)? }\end{array}$ & \multirow{2}{*}{$\mathrm{O}$} & $\mathrm{O}$ & $\mathrm{O}$ & $\mathrm{O}$ & $\mathrm{O}$ \\
\hline 37 & $\begin{array}{l}\text { Responder a la persuasión: ¿Considera con cuidado la posición de la } \\
\text { otra persona, comparándola con la propia, antes de decidir lo que } \\
\text { hará? }\end{array}$ & & $\mathrm{O}$ & $\mathrm{O}$ & $\mathrm{O}$ & $\mathrm{O}$ \\
\hline 38 & $\begin{array}{l}\text { Responder al fracaso: ¿Comprende la razón por la cual ha fracasado } \\
\text { en una determinada situación y qué puede hacer para tener más éxito } \\
\text { en el futuro? }\end{array}$ & $\mathrm{O}$ & $\mathrm{O}$ & $\mathrm{O}$ & $\mathrm{O}$ & $\mathrm{O}$ \\
\hline 39 & $\begin{array}{l}\text { Enfrentarse a los mensajes contradictorios: ¿Reconoce y resuelve la } \\
\text { confusión que se produce cuando los demás le explican una cosa, } \\
\text { pero dicen o hacen otras que se contradicen? }\end{array}$ & $\mathrm{O}$ & $\mathrm{O}$ & $\mathrm{O}$ & $\mathrm{O}$ & $\mathrm{O}$ \\
\hline 40 & $\begin{array}{l}\text { Responder a una acusación: ¿Comprende lo que significa la } \\
\text { acusación y por qué se la han hecho y, luego, piensa en la mejor } \\
\text { forma de relacionarse con la persona que le ha hecho la acusación? }\end{array}$ & $\mathrm{O}$ & $\mathrm{O}$ & $\mathrm{O}$ & $\mathrm{O}$ & $\mathrm{O}$ \\
\hline 41 & $\begin{array}{l}\text { Prepararse para una conversación dificil: ¿Planifica la mejor forma } \\
\text { para exponer su punto de vista antes de una conversación } \\
\text { problemática? }\end{array}$ & $\mathrm{O}$ & $\mathrm{O}$ & $\mathrm{O}$ & $\mathrm{O}$ & $\mathrm{O}$ \\
\hline 42 & $\begin{array}{l}\text { Hacer frente a las presiones del grupo: ¿Decide lo que quiere hacer } \\
\text { cuando los demás quieren que haga otra cosa distinta? }\end{array}$ & $\mathrm{O}$ & $\mathrm{O}$ & $\mathrm{O}$ & $\mathrm{O}$ & $\mathrm{O}$ \\
\hline 43 & $\begin{array}{l}\text { Tomar iniciativas: ¿Resuelve la sensación de aburrimiento iniciando } \\
\text { una nueva actividad interesante? }\end{array}$ & $\mathrm{O}$ & $\mathrm{O}$ & $\mathrm{O}$ & $\mathrm{O}$ & $\mathrm{O}$ \\
\hline 44 & $\begin{array}{l}\text { Discernir sobre la causa de un problema: ¿Reconoce si la causa de } \\
\text { algún acontecimiento es consecuencia de alguna situación bajo su } \\
\text { control? }\end{array}$ & $\mathrm{O}$ & $\mathrm{O}$ & $\mathrm{O}$ & $\mathrm{O}$ & $\mathrm{O}$ \\
\hline 45 & $\begin{array}{l}\text { Establecer un objetivo: ¿Toma decisiones realistas sobre lo que es } \\
\text { capaz de realizar antes de comenzar una tarea? }\end{array}$ & $\mathrm{O}$ & $\mathrm{O}$ & $\mathrm{O}$ & $\mathrm{O}$ & $\mathrm{O}$ \\
\hline 46 & $\begin{array}{l}\text { Determinar las propias habilidades: ¿Es realista cuando debe } \\
\text { dilucidar (determinar) cómo puede desenvolverse en una } \\
\text { determinada tarea? }\end{array}$ & $\mathrm{O}$ & $\mathrm{O}$ & $\mathrm{O}$ & $\mathrm{O}$ & $\mathrm{O}$ \\
\hline 47 & $\begin{array}{l}\text { Recoger información: ¿Resuelve qué necesita saber y cómo } \\
\text { conseguir la información? }\end{array}$ & $\mathrm{O}$ & $\mathrm{O}$ & $\mathrm{O}$ & $\mathrm{O}$ & $\mathrm{O}$ \\
\hline 48 & $\begin{array}{l}\text { Resolver los problemas según su importancia: ¿Determina de forma } \\
\text { realista cuál de los numerosos problemas es el más importante y el } \\
\text { que debería solucionar primero? }\end{array}$ & $\mathrm{O}$ & $\mathrm{O}$ & $\mathrm{O}$ & $\mathrm{O}$ & $\mathrm{O}$ \\
\hline 49 & $\begin{array}{l}\text { Tomar una decisión: ¿Considera las posibilidades y elige la que le } \\
\text { hará sentirse mejor? }\end{array}$ & $\mathrm{O}$ & $\mathrm{O}$ & $\mathrm{O}$ & $\mathrm{O}$ & $\mathrm{O}$ \\
\hline 50 & $\begin{array}{l}\text { Concentrarse en una tarea: ¿Se organiza y se prepara para facilitar } \\
\text { la ejecución de su trabajo? }\end{array}$ & $\mathrm{O}$ & $\mathrm{O}$ & $\mathrm{O}$ & $\mathrm{O}$ & $\mathrm{O}$ \\
\hline
\end{tabular}

Situaciones problema: 


\section{Resumen del cuestionario de actividades}

Instrucciones: Escriba la valoración (del cuestionario de habilidades) además de la fecha en la que se ha realizado el postest. Después de haber completado este último, registre la diferencia entre las puntuaciones del pre y postest en la última columna con un $+\mathrm{o}$ un - para indicar los cambios de rendimiento en cada habilidad. Como las habilidades no tienen el mismo grado de dificultad, no haga una media con la puntuación de distintas habilidades.

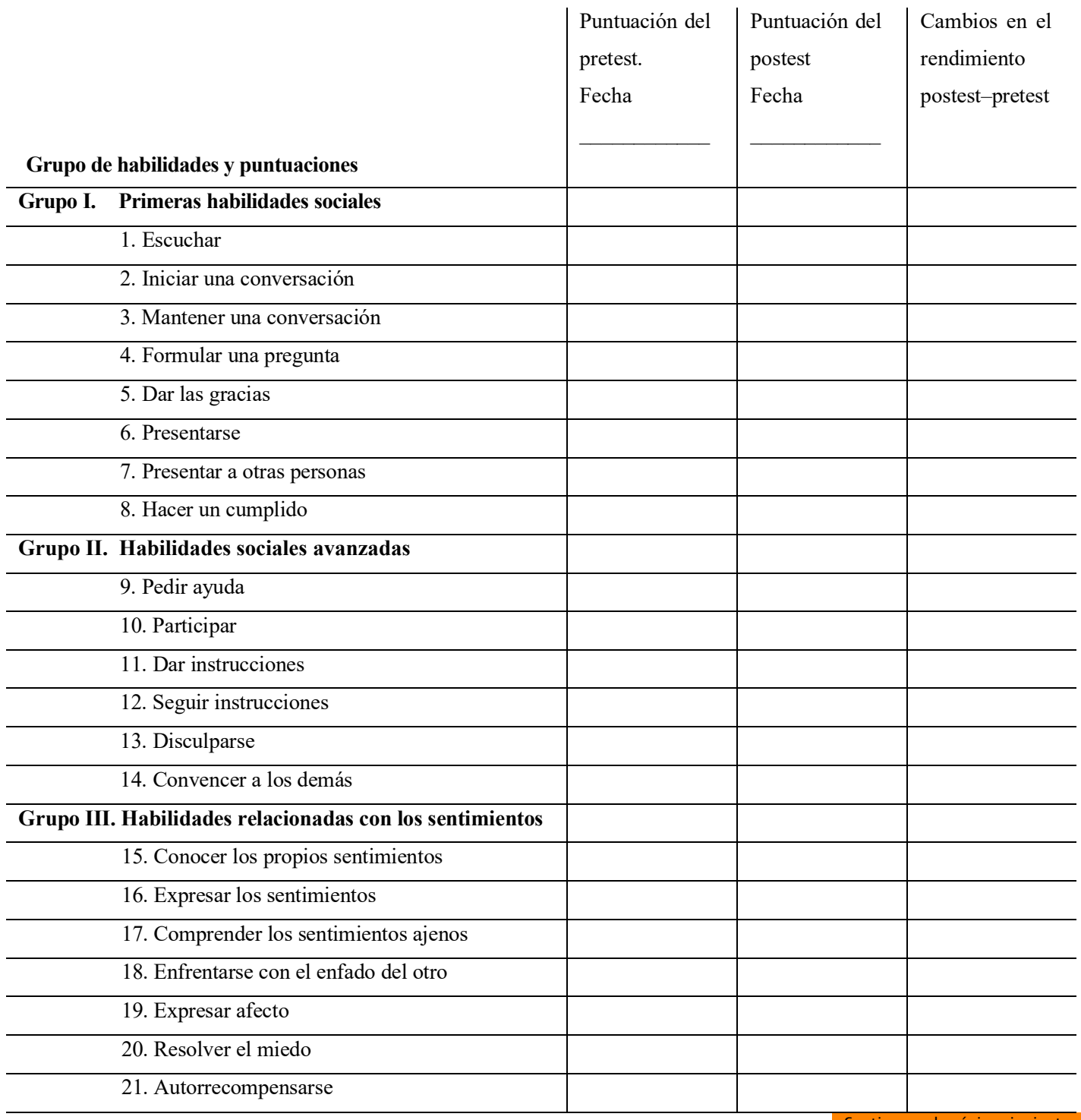


Continua en la página anterior

Grupo IV. Habilidades alternativas a la agresión

22. Pedir permiso

23. Compartir algo

24. Ayudar a los demás

25. Negociar

26. Emplear el autocontrol

27. Defender los propios derechos

28. Responder a las bromas

29. Evitar los problemas con los demás

30. No entrar en peleas

\section{Grupo V. Habilidades para hacer frente al estrés}

31. Formular una queja

32. Responder a una queja

33. Demostrar deportividad

34. Resolver la vergüenza

35. Arreglárselas cuando le dejan de lado

36. Defender a un amigo

37. Responder a la persuasión

38. Responder al fracaso

39. Enfrentarse a mensajes contradictorios

40. Responder a una acusación

41. Prepararse para controversia difícil

42. Hacer frente a las presiones de grupo

\section{Grupo VI. Habilidades de planificación}

43. Tomar iniciativas

44. Discernir la causa de un problema

45. Establecer un objetivo

46. Determinar las propias habilidades

47. Recoger información

48. Resolver problemas prioritarios

49. Tomar una decisión

50. Concentrarse en una tarea 


\section{Tabla de resultados}

\begin{tabular}{c|c|c|c|c|c|c}
\cline { 2 - 7 } & $\begin{array}{c}\text { GRUPO I } \\
\text { (de 1 a 8) }\end{array}$ & $\begin{array}{c}\text { GRUPO II } \\
\text { (de 9 a 14) }\end{array}$ & $\begin{array}{c}\text { GRUPO III } \\
\text { (de 15 a 21) }\end{array}$ & $\begin{array}{c}\text { GRUPO IV } \\
\text { (de 22 a 30) }\end{array}$ & $\begin{array}{c}\text { GRUPO V } \\
\text { (de 31 a 42) }\end{array}$ & $\begin{array}{c}\text { GRUPO VI } \\
\text { (de 43 a 50) }\end{array}$ \\
\hline PDO & & & & & & \\
\hline PDM & 32 & 24 & 28 & 36 & 48 & 32 \\
\hline PDP (\%) & & & & & & \\
\hline
\end{tabular}

Cálculo de la puntuación directa ponderada (PDP \%) a reflejar en la

$$
\text { gráfica }
$$

$\frac{\text { Puntuación directa obtenida (PDO) }}{\text { Puntuación directa máxima (PDM) }} \quad \mathrm{X}=100$

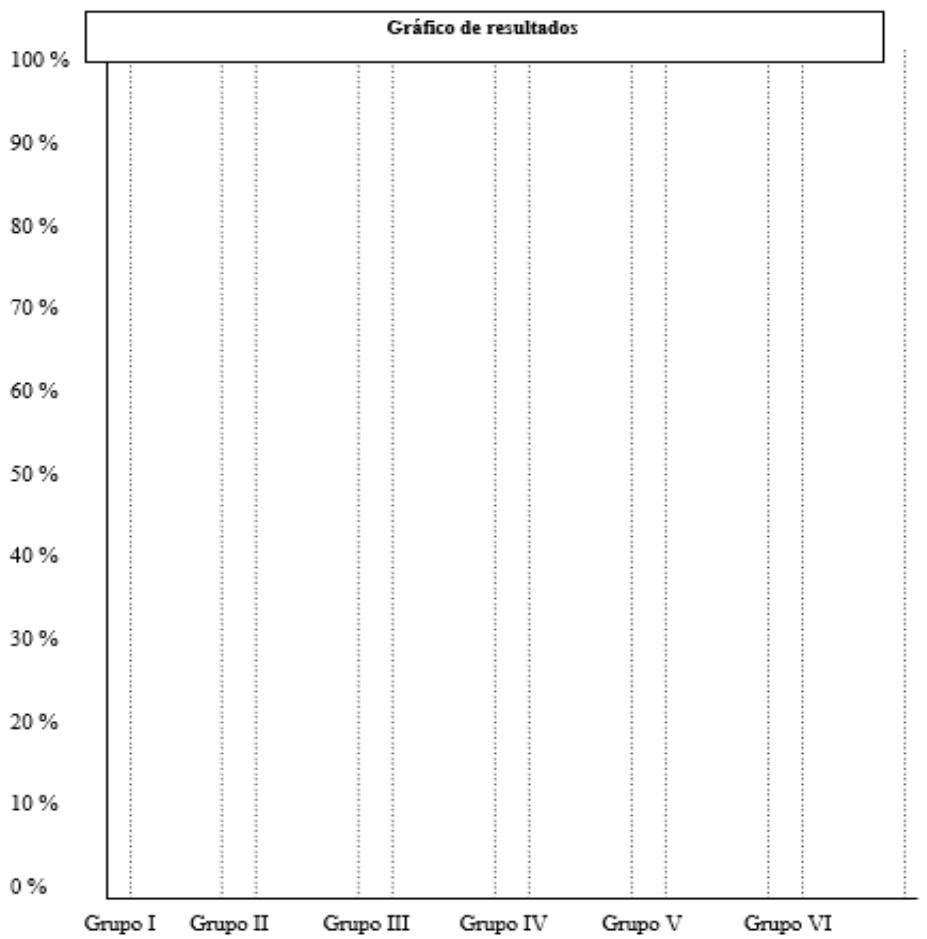




\section{Capítulo VI}

Promover el desarrollo

humano: El reto para las nuevas

generaciones de jóvenes

Germán Andrés Torres Escobar 


\section{Introducción}

El presente apartado tiene como objetivo caracterizar el concepto de desarrollo humano, de tal manera que permita comprender al lector el contexto laboral y económico en el que están insertos los jóvenes actualmente.

En los capítulos previos se ha planteado la importancia del concepto de las habilidades para la vida y como pueden ayudar a los jóvenes a prevenir que se involucren en conductas de riesgo, a que tomen mejores decisiones y participen de manera asertiva en diferentes ámbitos sociales (Choque-Larrauri \& Chirinos-Cáceres, 2009).

Sin embargo, las condiciones económicas y laborales del contexto mundial actual, enfocado primordialmente en el crecimiento económico e industrial por encima del bienestar de las personas, limita en buena medida el acceso de los jóvenes de escasos recursos a mejores oportunidades de vida y, a su vez, está dañando el medio ambiente por la sobreexplotación de recursos naturales (Suárez \& Molina, 2014).

Desde esta perspectiva, el capítulo hace un recorrido por la definición del concepto de desarrollo, los principales enfoques que aborda el desarrollo desde la economía y, finalmente, plantea una propuesta pedagógica que le permita a los jóvenes aprender a ser "hábiles" para insertarse con éxito en el mundo laboral, a partir de un emprendimiento sostenible, en el cual puedan ser artífices de su propio empleo y, desde este último, promuevan acciones que beneficien tanto a otras personas como al medio ambiente (González \& Figueroa, 2009).

De igual manera, en este capítulo se busca generar conciencia sobre la importancia de enseñar a los jóvenes algunas lecciones como: que el ser humano debe usar racionalmente los recursos naturales para no agotarlos; que debe compartir de manera equitativa los recursos, de tal manera que muchas personas puedan acceder a estos; y debe cuidar y proteger el planeta, de lo contrario terminará destruyéndolo y de paso se destruirá a sí mismo (González \& Figueroa, 2009).

En síntesis, no se trata solamente de que el joven de hoy sea hábil socialmente para "adaptarse" a la comunidad en la que vive, sino que también sea hábil para transformarla tanto en beneficio del ser humano como de la naturaleza, cuya coexistencia es simbiótica o mutuamente dependiente (Portillo-Torres, 2017). 


\subsection{El concepto de desarrollo humano}

El concepto de desarrollo a escala humana surgió originalmente en economía (Flores \& Rodríguez, 2011) y hace referencia al grado de bienestar que pueden alcanzar las personas de una determinada nación, a partir del acceso a un empleo que les permita comprar bienes y servicios necesarios para vivir y hacer realidad sus metas profesionales, de estatus y materiales.

Debido al progreso constante del conocimiento, la formación de las personas ha ido volviéndose cada vez más calificada y especializada, por ende, las actividades laborales son más tecnificadas y conducen a una mayor productividad (Rodríguez \& Mendoza, 2007); es decir, un aumento en la creación de nuevos bienes y servicios que generan un mayor crecimiento económico, lo que se traduce en altos niveles de ganancias económicas.

Sin embargo, debido a su costo elevado, no todas las personas pueden acceder a una educación altamente especializada (Juarros, 2006), esto restringe su acceso a un trabajo que les ayude a cubrir sus requerimientos y limita indirectamente tanto su crecimiento económico personal como el de sus países.

Por ende, aunque existen países con un alto crecimiento económico que se traduce en un fuerte Producto Interno Bruto (PIB), la riqueza que generan les pertenece solo a unas pocas personas con educación altamente especializada, que controlan la forma como se invierte esa riqueza y se distribuye entre la gran mayoría de trabajadores de las naciones (Guardiola \& Bernal, 2010), quienes dependen de esa minoría.

Dado que aquellos que controlan el capital no siempre consideran las necesidades de los trabajadores, sino que priorizan las propias o los bienes materiales, la forma como se distribuye la riqueza se hace de manera poco equitativa, aumentando así las condiciones de pobreza, el desempleo y de empeoramiento de la situación vital de las personas (Sánchez, 2006).

Otra gran problemática relacionada con el tema del desarrollo humano ha sido el daño que le han causado al medio ambiente quienes controlan la riqueza de las naciones buscando un crecimiento económico desmesurado (Binder, 2002) que les brinde el liderazgo económico mundial, sin importar la explotación desmedida de recursos naturales, actividad que está acabando con el equilibrio en el funcionamiento del pla- 
neta, en la medida en que genera el exterminio de muchos seres vivos, contamina las reservas hídricas y eólicas, a la vez que destruye los ecosistemas en los que vive el ser humano.

Pese a que en el ámbito mundial existe conciencia sobre estas dos problemáticas antes enunciadas: la desigualdad en el acceso de los recursos económicos y sobreexplotación de los recursos, muchas naciones "desarrolladas", persisten en su búsqueda del crecimiento económico para ganar el liderazgo mundial y político frente a las demás - tal es el caso de países como Estados Unidos, China, Reino Unido o Japón-, y esta situación a largo plazo podría llevar a una crisis social y económica que deterioraría el bienestar del ser humano y de otros organismos vivientes (Estenssoro, 2010).

Teniendo en cuenta estas condiciones, se han desarrollado dos nuevas perspectivas del desarrollo humano diferentes a la postura tradicional vinculada al crecimiento económico, que han asociado el desarrollo al bienestar y la instalación de capacidades en las personas, así como una producción limpia o sustentable (Haro-Martínez \& Taddei-Bringas, 2014) que haga un aprovechamiento adecuado de los recursos y ayude a su preservación a largo plazo.

A continuación, se describen: la evolución histórica del concepto de desarrollo humano tradicional, el desarrollo humano fundamentado en la instalación de capacidades y el desarrollo humano sustentable, a partir de autores destacados que han abordado cada una de estas corrientes de pensamiento y que aportan a la comprensión de lo que ocurre en el ámbito internacional, con sus implicaciones a corto y largo plazo para la humanidad.

\subsection{Enfoques del desarrollo humano}

El concepto de desarrollo humano se originó a la par de la economía como ciencia social, entre los siglos XVI y XVII, luego de que los monarcas europeos se percataron de los hallazgos de los primeros exploradores como Cristóbal Colón, Marco Polo o James Cook, quienes viajaron desde el siglo XV hacia sitios lejanos de Europa en busca de nuevas tierras, y encontraron abundancia de recursos como el oro, la plata, alimentos desconocidos y tierras fértiles, y vieron en esos recursos potencialmente explotables, la posibilidad de generar riqueza y expansión para sus naciones (Nieto, 2009). 
Esta forma de pensamiento económico se denominó mercantilismo y fue rebatida posteriormente por una élite de pensadores europeos como Adam Smith, David Ricardo y Fraçois Quesnay, quienes fueron influidos por un pensamiento liberalista y fisiocrático que planteaba que el bienestar de las naciones no dependía solo del acaparamiento de riquezas como los metales preciosos y la regulación de la misma por parte del Estado, sino de la libertad de las personas para comerciar productos y servicios (Ricoy, 2005).

Fue entonces, con los aportes de estos autores, que los gobernantes y los comerciantes europeos vieron en esas tierras lejanas la posibilidad de incrementar su riqueza personal y la de sus naciones, así que comenzaron a realizar más viajes comerciales que les permitieran aprovechar los recursos descubiertos, y al darse cuenta de que las personas residentes en esas latitudes carecían de un poder bélico amenazante, optaron por colonizar esas tierras, dominar a sus gentes y convertir sus territorios en su fuente de extracción de recursos (Granados, 2010).

Este fue el caso de varios países europeos como España, Portugal, Reino Unido y otros, que desde el siglo XVIII constituyeron colonias que comenzaron a explotar de manera cada vez más eficiente, con ayuda de las máquinas creadas durante la Revolución Industrial (Chaves, 2004). Algunas de estas máquinas que les permitieron tener un mayor control de los territorios fueron la locomotora -que permitió transportar mercancías a largas distancias-y las armas -utilizadas para someter a los colonos-.

La prosperidad derivada de este desarrollo humano europeo basado en el crecimiento económico alcanzó su cúspide a comienzos de 1900, época en que se vieron enfrentadas diversas naciones por el dominio colonial y entraron en la Primera y Segunda Guerra Mundial (Bosenberg, 2006).

Si bien ambas guerras trajeron la devastación del continente europeo, por otra parte impulsaron el crecimiento económico y el liderazgo de dos países que hasta entonces habían estado al margen del panorama internacional, Estados Unidos y Rusia (Almandoz, 2010), debido a que ambos financiaron económicamente a los involucrados en el conflicto, detuvieron las aspiraciones de dominación mundial de países como Alemania, Italia y Japón, y asumieron nuevas formas de pensamiento económico que lideraron el panorama económico posterior a 1950.

Estados Unidos, apoyado en los ideales de la democracia francesa y del liberalismo económico, buscó implantar en América Latina, Europa Occidental y Corea del Sur, una forma de desarrollo humano basado en la defensa de las libertades individuales, el 
libre intercambio económico y la acumulación de capital, a partir del movimiento capitalista; mientras que Rusia, basada en los ideales del pensamiento marxista, impulsó un desarrollo humano que promulgaba el crecimiento económico de las masas, el control estatal de las relaciones comerciales y la restricción de las libertades individuales en favor del nacionalismo, mediante una forma de pensamiento denominada comunismo (Hevia, 2015).

De esta manera, se dividió el orden mundial entre estas dos grandes potencias al lado de las naciones aliadas, las cuales crecieron y pasaron a convertirse en países del primer y segundo mundo; pero las colonias, que aportaban recursos para tales naciones, quedaron rezagadas económicamente porque siguieron estando sometidas para aportarles materias y trabajo humano (Mallorquín, 2005), hasta que en la década de 1960, comenzaron a emanciparse, así lo hicieron la India, Sudáfrica, y algunas de las Antillas, que han pasado a conformar parte de las naciones del tercer mundo.

Hacia 1990 cayó la hegemonía económica y militar de las naciones lideradas por Rusia, debido a que muchos de sus países miembros buscaron tener mayor independencia y fortalecer sus economías, y la misma Rusia tuvo que hacer reformas con la "Perestroika" para adaptarse a una economía de mercado cada vez más competida, pero conservando un modelo socialista. Tan solo China, con un sólido nacionalismo y una fuerte producción industrial, ha mantenido vigente su modelo comunista hasta la actualidad (Benz, 2005).

Las demás naciones del globo entraron, en la década de 1990, en un modelo de desarrollo humano conocido como globalización (Chonchol, 1998), en el que la aparición de la Internet como tecnología de la información permitió crear un mercado más abierto, cercano y de carácter internacional, caracterizado por el surgimiento de rápidos avances en economía, impulsados por las innovaciones tecnológicas de la computación y la robótica que han ido transformando gradualmente la industria mecánica, para hacerla más eficiente. 


\subsection{Concepto de desarrollo humano a partir del}

\section{bienestar y la equidad}

Entre las décadas de 1970 y 1980, varios teóricos, al percatarse de que naciones de América Latina, África y del Asia (Domínguez y Caria, 2018) estaban en desventaja frente a otras naciones industrializadas de Europa y Norteamérica en su nivel riqueza y avances tecnológicos, comenzaron a cuestionar la concepción del desarrollo humano basada en el crecimiento económico y buscaron formular una nueva propuesta de desarrollo humano que fuese más incluyente (Villegas, 2015; Picazzo et al., 2011) e integral (Martínez, 2009; Rojas \& López, 2003).

Uno de estos teóricos, de acuerdo con Álzate y García (2016), fue Manfred MaxNeef, quien afirmó que un modelo de desarrollo a escala humana debería considerar los requerimientos individuales de las personas como colectivos, y reconocer sus derechos (García, 2007) para permitirles así acceder a una mejor calidad de vida (Payarés \& Garnica, 2010; Max-Neef et al., 2010).

En consonancia con esta idea, Díaz et al. (2009), citando a Amartya Sen y Martha Nussbaum, plantean que un desarrollo a escala humana depende de potenciar las capacidades de las personas (Colmenarejo, 2016; Martínez, 2015), y de darles oportunidades (Monereo, 2015; London \& Formichella, 2006). Potenciar aptitudes en el ser humano implica educarlo con miras a tener oportunidades de empleo que le permitan contribuir al desarrollo económico de la sociedad, alcanzar sus metas personales (Restrepo-Ochoa, 2013) y mejorar su calidad de vida (Muñoz-Duque, 2018; Sánchez-Vidal, 2017), a partir del acceso a servicios de salud (Peroni, 2009), agua, saneamiento y nutrición (Casa-Zamora, 2002).

De esta manera, se pueden distribuir mejor los recursos económicos entre las personas, se puede reducir la pobreza, y se logra una mayor equidad social (Bolívar \& Elizalde, 2009) que redunda en un desarrollo real de las naciones (Reyes, 2008). Esta redistribución de los recursos se tiene que hacer tanto en zonas urbanas como rurales, y parte del empoderamiento de las personas, es decir, educarlas para que puedan emprender sus propios negocios (Álvarez-Aros \& Bernal-Torres, 2017; Parra, 2010; Cabrales, 2009) en lugar de depender de las oportunidades de empleo que les brinden otros, y en formarlos para aprender a convivir en sociedad, participar de manera responsable en las decisiones políticas (Gómez, 2013; Sen 2000) y cuidar el medio ambiente con un consumo de recursos sustentable (Iturralde, 2019). 
Teniendo en cuenta lo postulado, esta nueva concepción del desarrollo humano basado en las capacidades llegó a constituirse en una teoría que le apuntaba a un desarrollo más cualitativo, a diferencia del modelo clásico del desarrollo basado en un crecimiento cuantitativo por acumulación de recursos o riquezas. Hacia 1990, economistas que apoyaban esta teoría propusieron un índice de desarrollo humano (IDH) que permitiría comparar la calidad de vida de los países y, de esta manera, establecer qué tan desarrolladas estaban las naciones (Veres, 2014; Peláez-Herreros, 2012).

Algunas de las críticas que le han hecho a este modelo, es que si bien tiene planteamientos interesantes y necesarios, tienden a ser bastante idealistas y distan mucho de la solución a las problemáticas de buena parte de las personas alrededor del mundo porque su implementación requiere de un proceso lento, costoso y que se enfrenta con barreras difíciles de sortear como lo son la corrupción de las clases dirigentes (Esteves, 2005) -que hace trampas para no distribuir los recursos de manera equitativa entre las personas más necesitadas- y la deuda externa de las naciones con economías emergentes -que tienen que pedir préstamos significativos de dinero para poder actualizarse tecnológicamente respecto a las naciones industrializadas y al mismo tiempo dar respuesta a las constantes problemáticas de sus numerosas poblaciones- (Álvarez et al., 2017).

En condiciones de pobreza, hay quienes, al no encontrar oportunidades laborales en sus países de origen, que les permitan satisfacer sus necesidades básicas, han optado por migrar hacia otras naciones en busca de empleo; tal es el caso de venezolanos, mexicanos y oriundos de países del África, que han realizado grandes viajes y han tenido que enfrentar situaciones de xenofobia, escases de alimentos e, incluso, la muerte. El reto, entonces, de los académicos que están a favor de la teoría de desarrollo a escala humana en la actualidad, consiste en sensibilizar a las clases dirigentes para que sean transparentes en la forma como distribuyen los recursos y apoyen causas humanitarias en favor de los más pobres, tanto de sus propias naciones como de naciones extranjeras. 


\subsection{Concepto de desarrollo humano desde la}

\section{sustentabilidad}

Así como desde la década de 1980 se planteó un modelo de desarrollo que defendía el bienestar del ser humano, la equidad en la distribución de los recursos y la potencialización de sus capacidades, hubo otros líderes sociales de esa época como Irving Stowe, Dorothy Stowe y Jim Bohlen del movimiento GreenPeace (Del Río Paredes, 2005) y la exprimera ministra noruega Gro Harlem Brundtland (Ramírez et al., 2004), que plantearon la búsqueda de un modelo de desarrollo humano sustentable que abogara por el cuidado del ecosistema y sus elementos, para conservar el equilibrio entre el bienestar humano y de la naturaleza a largo plazo.

Para el desarrollo, es necesaria la conservación de los recursos naturales, sobre todo los no renovables. El daño a los ecosistemas se intensificó con la industrialización; este inició en Inglaterra durante el siglo XIX y luego se extendió por todo el mundo, se comenzaron a usar combustibles fósiles para el funcionamiento de maquinaria de transporte e industrial, como en el carbón, la gasolina y el gas natural, los cuales generan polución en el aire y dificultan la respiración de las personas.

De igual manera, el posterior uso de embalajes plásticos para envolver alimentos y medicamentos, y de productos químicos con compuestos Fluoro carbonados (CFC) como ambientadores, desodorantes e insecticidas, comenzó a generar la acumulación de residuos químicos que van dañando la capa de ozono y desencadenan el calentamiento global que, a su vez, ocasiona sequias, inundaciones y efectos ambientales adversos.

Muchos científicos, al percatarse de las consecuencias adversas de la tecnificación masiva y de la sobreexplotación de recursos naturales, empezaron a informar a los líderes políticos y a las autoridades en el tema, para poder tomar medidas preventivas y de control que dieran paso a un modelo de desarrollo humano sustentable o protector del medio ambiente.

Este modelo de desarrollo humano sustentable se fundamentó en algunos planteamientos teóricos como: la necesidad de cuidar el medio ambiente, la disminución y regulación de la contaminación del medio ambiente derivada de los procesos industriales, el aprovechamiento adecuado de los recursos naturales, el reciclaje (Sanmartín 
et al., 2017) y la reutilización de materias primas (Porcelli \& Martínez, 2018). El propósito de estos planteamientos es promover el bienestar humano y de la naturaleza, mediante la prolongación de la vida y la preservación de la salud.

Con fundamento en los planteamientos de esa época y los aportes de la Ellen MacArthur Foundation (2015), emergió una nueva escuela de pensamiento denominada economía circular, que en oposición a la economía lineal clásica, que se basa en acciones como extraer, procesar, consumir y eliminar, propone volver a utilizar materias primas ya existentes, buscar nuevas fuentes de energía renovables, disminuir la contaminación en diferentes sectores del planeta y poder manejar problemas derivados de la producción industrial que afectan negativamente el desarrollo humano. Desde la perspectiva ambiental, los problemas urgentes de resolver son: la polución del aire, el calentamiento global, la contaminación de las aguas y la acumulación de desechos tóxicos, los cuales reducen la salud del ser humano y de las especies vivientes.

De todas formas, iniciativas similares de este tipo ya se habían comenzado a formular en el ámbito internacional desde la Organización de las Naciones Unidas, la cual, con el apoyo de varios países, desarrolló en 1992 la Conferencia de Río de Janeiro para que organizaciones no gubernamentales, científicos y universidades contribuyeran a proteger el medio ambiente; luego entre 1997 y 2005, el Protocolo de Kioto se propuso como otra alternativa de acción a favor del medio ambiente (Velásquez de Castro, 2005). A partir de la Convención Marco de las Naciones Unidas sobre el Cambio Climático, con miras a atenuar la polución del aire y en 2015 fomentó la firma por parte de varias naciones el Acuerdo de Paris, durante la XXI Conferencia de Cambio Climático, con miras a generar conciencia sobre la importancia de controlar el cambio en la temperatura global, bajar las emisiones de carbono, y proteger la producción de alimentos frente a los efectos derivados de los contaminantes industriales (García Arbeláez, 2016; Vallejo, 2016; Higgings \& Escobar, 2016).

Pese a los planteamientos sugeridos por la Organización de las Naciones Unidas (García Arbeláez, 2016; Vallejo, 2016; Higgings \& Escobar, 2016). Con el objetivo de mitigar los efectos ambientales de la producción industrial, aún en la actualidad existen barreras que impiden que se lleven a cabo las ideas de este modelo de desarrollo humano sustentable como son: la falta de voluntad de algunas potencias mundiales para reducir la contaminación de sus industrias, es el caso puntual de Estados Unidos y China, que son los mayores contaminantes del mundo (Cuevas \& González, 2018) y no se han acogido a los pactos internacionales; y la falta de una educación adecuada en la población mundial para aprender a reciclar, reutilizar las materias primas y disminuir la polución. 
Ante esta situación, varios gobiernos alrededor del globo están implementando el uso de fuentes de energía alternativas (Cadena, 2008) como la eólica, la solar y las que emplean biocombustibles, para ir reemplazando gradualmente los combustibles fósiles y atenuar así el efecto del calentamiento global. Además, están desarrollando campañas de concientización en la población, con lo que buscan promover prácticas limpias de: reutilización, reciclaje y consumo de productos orgánicos (Martínez et al., 2011), que no tienen sustancias químicas industriales.

\subsection{Reflexiones sobre el desarrollo humano para las nuevas generaciones}

Las conceptualizaciones que se han hecho desde la economía respecto al estudio del desarrollo humano le han dejado a la pedagogía algunas reflexiones valiosas en términos de tópicos que se deben introducir en la formación de los adolescentes, estudiantes y universitarios.

Por ejemplo, es necesario inculcar en los adolescentes valores como compartir, cuidar y proteger al ser humano, el aire, el agua y el ecosistema, incluso, desde los primeros años de escolaridad (De Castro et al., 2009). A nivel formal, la educación primaria debe introducir el tema del ahorro de recursos no renovables, uso de tecnologías limpias, reutilización y reciclaje, en sus clases de ciencias naturales (Martínez, 2010), mientras las lecciones sobre tópicos sociales pueden abordar el tema de las donaciones de recursos a los menos favorecidos y de la responsabilidad social con los grupos marginados de la sociedad. En los estudios universitarios se propone, por ejemplo, incluir en todos los programas de pregrado cátedras de emprendimiento sostenible (Rodríguez, 2016) y de responsabilidad social empresarial (Vargas, 2011), que les enseñen a los estudiantes a ser gestores de bienes y servicios, pero pensando tanto en el progreso del ser humano como en el cuidado del medio ambiente.

De esta manera, se puede comenzar a generar un impacto positivo en los jóvenes, para que ellos incentiven un desarrollo humano centrado en el bienestar y la protección del medio ambiente (González \& Arias, 2009), ya que en la actualidad los temas mencionados previamente se tocan de manera tangencial en los diferentes niveles de formación y no tienen la misma importancia de asignaturas como matemáticas, 
informática e inglés, que son vistas como prioritarias, cuando en realidad son temas secundarios para abordar las problemáticas de la desigualdad en el acceso a los recursos y de la destrucción del planeta.

Cabe mencionar que la Organización para la Cooperación y el Desarrollo Económico (OCDE, 2017), desde la década de los noventa, ha venido realizando la aplicación de las Pruebas PISA en adolescentes de varios países del mundo, para evaluar su nivel de competencia en tres áreas del conocimiento que son: lectura, matemáticas y ciencias, porque se parte del supuesto que son áreas del conocimiento fundamentales; pero dicha prueba no le da relevancia a asignaturas como ética ${ }^{1}$, ecología $^{2}$ o economía ${ }^{3}$, que son quizás materias cuyo contenido está directamente relacionado con la cotidianidad de los educandos y las problemáticas coyunturales que la humanidad afronta en la actualidad. La falencia de esta entidad es seguir pensando que la competitividad es un elemento esencial del progreso de las naciones, cuando lo que se requiere es fomentar el emprendimiento sostenible en las nuevas generaciones, para que puedan independizarse económicamente y proteger el medio ambiente (Rodríguez, 2016).

En el campo académico, se ha gestado otra iniciativa para promover la competitividad en Latinoamérica, a partir de la alfabetización económica en los niños y jóvenes, se trata de la propuesta de Marianella Denegri Coria, quien plantea que además de los conceptos académicos que se les enseñan a los estudiantes de diferentes niveles de escolaridad, es necesario formarlos en ser críticos y tomar decisiones económicas acertadas en su vida diaria relativas al ahorro y la adquisición de bienes y servicios (Denegri, Sepúlveda et al., 2014) y el endeudamiento (Mansilla et al., 2016), así como motivarles a realizar proyectos de emprendimiento económico (Denegri et al., 2006).

Particularmente, para la etapa de la formación inicial de los niños, Denegri y sus colegas (2006) propusieron un programa curricular denominado "Yo y la economía", que articula conceptos económicos con otras asignaturas como sociales, matemáticas y lenguaje, de manera interdisciplinaria. Además, afirman Denegri, Del Valle et al. (2014) que en América Latina existen vacíos de formación en economía, y, por ende, son los estudiantes de las licenciaturas en pedagogía, quienes deben prepararse en esta área para así replicar dicho saber en los colegios e instituciones educativas. 
Si bien lo anteriormente expuesto es interesante respecto al manejo del dinero y la inversión de recursos monetarios, la propuesta no profundiza en temas éticos como la igualdad en el acceso a los recursos o el compartir con los demás, ni tampoco considera temas propios de la economía sustentable como son: las consecuencias del uso excesivo de materias primas en el medio ambiente, el uso de formas de energía alternativa y estrategias de producción limpia.

Desde esta perspectiva, se está inculcando implícitamente en los estudiantes la mentalidad clásica de los pensadores mercantilistas, quienes se enfocaban en la búsqueda de la riqueza por la riqueza, y esto a largo plazo es lo que genera problemas como la corrupción en la administración de los recursos, la competitividad a ultranza y el daño al medio ambiente.

De ahí que se necesita desarrollar modelos de formación económica que encaminen a los estudiantes hacia el emprendimiento sustentable y ético, es decir, que se fundamenten en principios como el respeto a los otros, la solidaridad con los menos favorecidos, el cuidado del planeta, la autonomía económica y la calidad de vida basada en la felicidad y no en el tener.

En síntesis, no se trata de formar solamente seres humanos productivos en términos económicos, sino también seres humanos felices, que contribuyan al desarrollo de su país generando empleo, sean honestos en el manejo de los recursos, ayuden a los menos favorecidos, cuiden el medio ambiente y se esfuerzen por preservar las especies vivientes del planeta tierra. De nada sirve formar seres humanos muy productivos a nivel económico, pero que son corruptos, egoístas, ambiciosos y destructivos, como ocurre actualmente alrededor del globo.

\subsection{Propuesta de un modelo de formación en emprendimiento sustentable y ético}

Las instituciones educativas alrededor del mundo deben reformular la educación de la niñez y de la juventud, dado que los modelos actuales imparten conocimientos desde asignaturas aisladas, teóricas y acríticas, que guardan poca relación con las problemáticas coyunturales que afronta el planeta en la actualidad. 
En esta nueva concepción, las clases relevantes ya no son matemáticas, lectura y ciencias, sino ética, ecología y economía, porque las nuevas generaciones necesitan corregir los errores que han cometido sus antepasados, aprendiendo a valorarse a sí mismos, a las demás personas, a los seres vivos y los recursos de la naturaleza, para poder enfocar sus acciones hacia una correcta administración y protección de estos en la cotidianidad y en el contexto de trabajo.

Una propuesta de formación en emprendimiento sustentable y ético debería tanto trabajarse desde los primeros años de escolaridad, como lo ha venido planteando el gobierno colombiano en los últimos años (Ministerio de Educación Nacional, 2012) con la Ley 1014 de 2006 (Congreso de la República de Colombia, 2006), como articularse con la educación superior, con el propósito de que exista una continuidad entre los diferentes grados de formación. Inicialmente, en los primeros años de escolaridad, se podrían trabajar temas que vinculen la ética, la ecología y la economía, con las demás materias del currículo y, a su vez, con el emprendimiento sostenible.

En la Tabla 6.1 se describe la propuesta de formación en emprendimiento sostenible y ético, con las unidades temáticas tentativas que se deberían trabajar. Es importante clarificar que en los colegios el emprendimiento sostenible y ético podría desarrollarse como una asignatura y en las universidades como una cátedra o curso transversal y obligatorio en todas las carreras.

La propuesta es inspirar y propiciar nuevas formas de negocios que movilicen la economía, pero también que respeten el medio ambiente y generen condiciones de equidad para los menos favorecidos, que es lo que le falta contemplar a la cátedra actual de cultura del emprendimiento, porque no tiene una fundamentación valórica adecuada, que les muestre a los estudiantes la importancia del respeto, la solidaridad, el cuidado del otro y del ambiente. 
Tabla 6.1. Unidades temáticas dentro de la formación en emprendimiento sostenible y ético

\begin{tabular}{|c|c|c|c|}
\hline Unidad temática & Aspectos éticos & Aspectos ecológicos & Aspectos económicos \\
\hline La vida humana & Respeto a la vida. & $\begin{array}{l}\text { Rol del ser humano en el pla- } \\
\text { neta. }\end{array}$ & $\begin{array}{l}\text { Necesidades humanas, satis- } \\
\text { facción. }\end{array}$ \\
\hline Los seres vivos & $\begin{array}{l}\text { Respeto y cuidado de } \\
\text { los seres vivos. }\end{array}$ & $\begin{array}{l}\text { Rol del ser humano en la con- } \\
\text { servación del planeta. }\end{array}$ & $\begin{array}{l}\text { Gestión adecuada de los recur- } \\
\text { sos naturales. }\end{array}$ \\
\hline El desarrollo humano & $\begin{array}{l}\text { La felicidad y el bien- } \\
\text { estar como valores. }\end{array}$ & $\begin{array}{l}\text { Formas de desarrollo humano } \\
\text { sustentables. }\end{array}$ & $\begin{array}{l}\text { Inversión, ahorro y satisfac- } \\
\text { ción. }\end{array}$ \\
\hline $\begin{array}{l}\text { La corrupción como } \\
\text { problema }\end{array}$ & $\begin{array}{l}\text { Equidad y honestidad } \\
\text { como valores. }\end{array}$ & $\begin{array}{l}\text { Distribución de recursos para } \\
\text { la limpieza, cuidado y embe- } \\
\text { llecimiento del entorno. }\end{array}$ & $\begin{array}{l}\text { Rendición de cuentas e inver- } \\
\text { sión de recursos. }\end{array}$ \\
\hline $\begin{array}{l}\text { Los grupos sociales } \\
\text { marginados }\end{array}$ & $\begin{array}{l}\text { Solidaridad y equidad } \\
\text { como valores. }\end{array}$ & $\begin{array}{l}\text { Rol de apoyo a los menos } \\
\text { favorecidos y cuidado del } \\
\text { entorno. }\end{array}$ & $\begin{array}{l}\text { Consumo racional y preven- } \\
\text { ción de la pobreza. }\end{array}$ \\
\hline $\begin{array}{l}\text { La contaminación } \\
\text { ambiental }\end{array}$ & $\begin{array}{l}\text { La sustentabilidad } \\
\text { como valor. }\end{array}$ & $\begin{array}{l}\text { Fuentes de energía sustenta- } \\
\text { bles y compuestos amigables } \\
\text { con el medio ambiente. }\end{array}$ & $\begin{array}{l}\text { Economía circular y produc- } \\
\text { ción limpia. }\end{array}$ \\
\hline $\begin{array}{l}\text { El emprendimiento } \\
\text { como alternativa labo- } \\
\text { ral }\end{array}$ & $\begin{array}{l}\text { La innovación y la } \\
\text { autonomía como } \\
\text { valores. }\end{array}$ & $\begin{array}{l}\text { La generación de empleos } \\
\text { como motor de desarrollo y el } \\
\text { cuidado del ambiente. }\end{array}$ & $\begin{array}{l}\text { Pautas para la creación de } \\
\text { microempresas }\end{array}$ \\
\hline
\end{tabular}

\section{Conclusión}

Durante el recorrido del texto se ha explicado el concepto de desarrollo humano surgido desde la economía, pero se ha abordado desde tres miradas que son el crecimiento económico, el bienestar del ser humano y la sustentabilidad.

En sus inicios, los pensadores mercantilistas y los pensadores pioneros (Ricoy, 2005) consideraban que la acumulación de riquezas materiales, el libre comercio y el ahorro, conducirían al desarrollo de las naciones europeas, por lo que tal desarrollo estaba asociado con el crecimiento, pero situaciones como las guerras mundiales, la pobreza, el subdesarrollo de varias naciones y el calentamiento global, le mostraron a la humanidad que este modelo presentaba falencias como la desigualdad en el acceso a los recursos y la contaminación derivada de la sobreexplotación de los mismos.

Para dar respuesta a estado desatinos, surgieron dos nuevos modelos de desarro1lo. Por un lado, el modelo de desarrollo humano liderado por Amartya Sen y Martha Nussbaum (Colmenarejo, 2016), quienes propusieron que era necesario buscar 
el bienestar del ser humano y la potencialización de sus capacidades, con miras a garantizar condiciones de acceso equitativo a los recursos para todas las personas; y por otro lado, el modelo de desarrollo sustentable, encabezado por la Organización de las Naciones Unidas (García Arbeláez, 2016; Vallejo, 2016; Higgings \& Escobar, 2016), que defiende formas de producción limpia, la protección del ecosistema y la disminución de la polución, para consolidar una economía circular que responda tanto a los requerimientos de las personas como del medio ambiente.

Estos modelos le dejaron algunas enseñanzas a la pedagogía como ciencia de la educación, para el caso: la necesidad de enseñar a las nuevas generaciones a crear su propio empleo a partir de propuestas de emprendimiento, y la necesidad de comenzar a utilizar formas de energía, producción y consumo sustentables que ayuden a cuidar el medio ambiente, disminuir el efecto de la polución y cuidar los recursos no renovables. En esta misma línea, Max-Neef et al. (1986) en su libro Desarrollo a Escala Humana. Una opción para el futuro, plantean que la economía de un país debe dar respuesta a las necesidades del ser humano de subsistencia, protección, afecto, entendimiento, participación, ocio, creación, identidad y libertad, más allá del crecimiento financiero. La satisfacción de estas necesidades se puede lograr en la medida en que se forme a las personas para buscar y crear sus propias oportunidades, con miras a que puedan satisfacerlas por sí mismas y no dependiendo, como se ha hecho hasta ahora, del Estado o de instituciones particulares.

El reto, entonces, que tiene la pedagogía como ciencia de la educación a futuro es crear nuevos modelos de formación que promuevan un desarrollo humano sustentable en los diferentes niveles educativos y les permitan a los jóvenes generar su propio empleo y desarrollar habilidades para la vida tales como el emprendimiento y la cooperación, con miras la construcción de un mundo mejor.

El emprendimiento es una habilidad para la vida que se puede desarrollar en los adolescentes enseñándoles a crear oportunidades de negocio a partir de aquellas actividades productivas en las cuales se puedan destacar y les permitan poner al servicio de otros sus intereses y talentos. Por ejemplo, si un adolescente descubre que tiene interés por el deporte y se ha destacado en actividades deportivas como el boxeo, se le puede orientar para que desarrolle un emprendimiento laboral enfocado hacia esa área, como un gimnasio o escuela deportiva en la cual pueda generar empleo propio y para otras personas. 
De igual forma, es importante potenciar en los adolescentes la cooperación como una habilidad para la vida, ya que complementa a la del emprendimiento, y les ayuda a ser solidarios con las necesidades de otras personas y del medio ambiente. Desde esta perspectiva, una empresa sin cooperación tiende a volverse un negocio monopolizante, excluyente y que promueve la avaricia; y para evitar esto se debe mostrar a los jóvenes que todo emprendimiento debe ser responsable con las personas y el medio ambiente; es decir, tiene que buscar procesos de producción limpia, ofrecer productos y servicios de buena calidad y accesibles monetariamente para todas las personas, hacer un aprovechamiento adecuado de los desechos, y generar oportunidades de empleo que mejoren la calidad de vida de las personas.

Aunque tradicionalmente se ha hablado de diferentes tipos de habilidades para la vida, tanto el emprendimiento como la cooperación son destrezas esenciales que deben desarrollar los adolescentes con miras a generar un verdadero desarrollo humano en las diferentes naciones del mundo, que trascienda el mero crecimiento económico y realmente tenga un impacto significativo en la vida de las personas a mediano y largo plazo.

\section{Referencias}

Almandoz, A. (2010). Entre guerra fría y tercer mundo. Urbanización y subdesarrollo en Latinoamérica, 1960-1980. Argos, 27(53), 193-217. http://ve.scielo.org/scielo. php?script $=$ sci_arttextypid=S0254-16372010000200010

Álvarez, M., Álvarez, M., \& Álvarez, S. (2017). La Deuda Pública, el crecimiento económico y la política. Polis, 13(2), 41-71. http://www.scielo.org.mx/pdf/polis/ v13n2/1870-2333-polis-13-02-41.pdf

Álvarez-Aros, M., \& Bernal-Torres, C. (2017). Modelo de innovación abierta: Énfasis en el potencial humano. Información Tecnológica, 28(1), 65-76. http://dx.doi. org/10.4067/S0718-07642017000100007

Alzate, M., \& García, L. (2016). Revisión del estado de la cuestión sobre las comprensiones del desarrollo humano y el desarrollo social. Revista Aletheia, 8(1), $62-79$. 
Benz, W. (2005). El fin de la Guerra Fría. Su significado para Europa y el Tercer Mundo. Revista Ciencia y Cultura, (17), 81-86. http://www.scielo.org.bo/pdf/rcc/ n17/a11.pdf

Binder, K. (2002). Factores determinantes de la contaminación ambiental y del uso de los recursos naturales. Innovar, 12(20). http://www.scielo.org.co/pdf/inno/v12n20/ v12n20a07.pdf

Bolívar, G., \& Elizalde, A. (2009). Desarrollo humano y justicia. Polis, Revista de la Universidad Bolivariana, 8(23), 7-17.

Bosenberg, L. (2006). Las guerras mundiales: problemas y controversias en torno a los orígenes. Anuario Colombiano de Historia Social y de la Cultura, (33), 289309. https://www.redalyc.org/pdf/1271/127112581011.pdf

Cabrales, O. (2009). La gerencia del talento humano bajo la perspectiva de la condición humana. Revista de la Facultad de Ciencias Económicas, 17(1), 155-178.

Cadena, A. (2008). Fuentes energéticas alternativas. Revista de Ingeniería, (28), 6063. http://www.scielo.org.co/pdf/ring/n28/n28a9.pdf

Casa-Zamora, J. (2002). Salud, desarrollo humano y gobernabilidad en América Latina y el Caribe a inicios del siglo XXI. Revista Panamericana de Salud Pública, 11(5/6), 397-408. https://iris.paho.org/handle/10665.2/8715

Chaves, J. (2004). Desarrollo tecnológico en la primera revolución industrial. Norba, Revista de Historia, 17, 93-109.

Choque-Larrauri, R., \& Chirinos-Cáceres, J. (2009). Eficacia del Programa de Habilidades para la Vida en adolescentes escolares de Huancavelica, Perú. Revista Salud Pública, 11(2), 169-181. http://www.scielo.org.co/pdf/rsap/v11n2/v11n1a02. pdf

Chonchol, J. (1998). Impacto de la globalización en las sociedades latinoamericanas: ¿que hacer frente a ello? Estudos Avançados, 12(34), 163-218. http://www.scielo. br/pdf/ea/v12n34/v12n34a20.pdf

Colmenarejo, R. (2016). Enfoque de capacidades y sostenibilidad. Aportaciones de Amartya Sen y Martha Nussbaum. Ideas y Valores, 65(160), 121-149. 
Congreso de la República de Colombia. (2006). Ley 1014 de enero 26 de 2006. De fomento a la cultura del emprendimiento. https://www.colciencias.gov.co/sites/ default/files/upload/reglamentacion/ley-1014-2006.pdf

Cuevas, A., \& González, J. (2018). Potencial liderazgo chino en la lucha global contra el cambio climático en el siglo XXI. México y la Cuenca del Pacífico, 7(21), 95120. http://www.scielo.org.mx/pdf/mcp/v7n21/2007-5308-mcp-7-21-95.pdf

De Castro, A., Cruz, J., \& Ruiz-Montoya, L. (2009). Educar con ética y valores ambientales para conservar la naturaleza. Convergencia. Revista de Ciencias Sociales, 16(50), 353-382. http://www.scielo.org.mx/pdf/conver/v16n50/ v16n50a14.pdf

Del Río Paredes, S. (2005). Contaminación química en la infancia: bioacumulación y efectos potenciales. Revista Española de Salud Pública, 79(2), 221-228. http:// scielo.isciii.es/pdf/resp/v79n2/colaboracion7.pdf

Denegri, M., Del Valle, C., González, Y., Etchebarne, S., Sepúlveda, J., \& Sandoval, D. (2014). ¿Consumidores o ciudadanos? Una propuesta de inserción de la educación económica y financiera en la formación inicial docente. Estudios Pedagógicos, 49(1), 75-96. https://scielo.conicyt.cl/pdf/estped/v40n1/art05.pdf

Denegri, M., Sepúlveda, J., González, T., Romero, G., Ulloa, J., \& Vásquez, D. (2014). Actitudes hacia el consumo, compra y materialismo en estudiantes universitarios de pedagogía en Chile. Fronteras - Revista de Ciencias Sociales y Humanidades, 1(2), 45-62. https://www.researchgate.net/publication/319986713_Actitudes_hacia_el_ consumo_compra_y_materialismo_en_estudiantes_universitarios_de_pedagogia en_Chile

Denegri, M., Del Valle, C., Gempp, R., \& Lara, M. (2006). Educación económica en la escuela: hacia una propuesta de intervención. Estudios Pedagógicos, 32(2), 103120. https://www.redalyc.org/articulo.oa?id=173514131005

Díaz, M., Giradles, R., \& Armas, D. (2009). El desarrollo humano local en los entornos virtuales: aplicación tecnológica Universitas Cuba. ACIMED, 20(1), 1-9.

Domínguez, R., \& Caria, S. (2018). Raíces latinoamericanas del otro desarrollo: estilos de desarrollo y desarrollo a escala humana. América Latina en la Historia Económica, 25(2), 175-209. 
Ellen MacArthur Foundation. (2015). Growth Within: a circular economy vision for a competitive Europe. https://www.ellenmacarthurfoundation.org/assets/downloads/ publications/EllenMacArthurFoundation_Growth-Within_July15.pdf

Estenssoro, F. (2010). Crisis ambiental y cambio climático en la política global: un tema crecientemente complejo para América Latina. Universum, 25(2), 57-77. https://scielo.conicyt.cl/pdf/universum/v25n2/art_05.pdf

Esteves, A. M. (2005). Reflexiones teóricas sobre la corrupción: sus dimensiones política, económica y social. Revista Venezolana de Gerencia, 10(29), 43-85. http://ve.scielo.org/scielo.php?script=sci_arttextypid $=\mathrm{S} 1315-99842005000100004$

Flores, N., \& Rodríguez, R. (2011). Crecimiento económico y desarrollo humano. Observatorio Laboral Revista Venezolana, 4(7), 55-70. https://www.redalyc.org/ pdf/2190/219022147004.pdf

García Arbeláez, C., Vallejo, G., Higgings, M. L., \& Escobar, E. M. (2016). El Acuerdo de París. Así actuará Colombia frente al cambio climático. 1 ed. WWFColombia. Cali, Colombia. Documento recuperado de: https://www.minambiente. gov.co/images/cambioclimatico/pdf/colombia_hacia_la_COP21/el_acuerdo_de_ paris_frente_a_cambio_climatico.pdf

García, O. (2007). Propuesta de desarrollo a escala humana para las mujeres rurales del municipio de Siachoque Boyacá - Colombia. Revista Apuntes del CENES, 27(43), 257-274. https://revistas.uptc.edu.co/index.php/cenes/article/view/219/223

Gómez, A. (2013). Ética del desarrollo humano según el enfoque de las capacidades de Martha Nussbaum. Phainomenon, 12(1), 19-28. http://revistas.unife.edu.pe/ index.php/phainomenon/article/view/238/351

González, E., \& Arias, M. (2009). La educación ambiental institucionalizada: actos fallidos y horizontes de posibilidad. Perfiles Educativos, 31(124), 58-68. http:// www.scielo.org.mx/pdf/peredu/v31n124/v31n124a5.pdf

González, E., \& Figueroa, L. (2009). Los valores ambientales en los procesos educativos: realidades y desafíos. REICE. Revista Iberoamericana sobre Calidad, Eficacia y Cambio en Educación, 7(2), 95-115. https://www.redalyc.org/ pdf/551/55111725006.pdf 
Granados, O. (2010). Imperios y colonialismo, 1870-1914 ¿una era de globalización, geopolítica o nacionalismo económico? Revista de Relaciones Internacionales, Estrategia y Seguridad, 5(1), 51-82. http://www.scielo.org.co/pdf/ries/v5n1/ v5n1a04.pdf

Guardiola, J., \& Bernal, J. (2010). Comercio internacional y crecimiento económico: ¿cómo influyen en el hambre de América Latina? Nutrición Hospitalaria, 25(3), 44-49. http://scielo.isciii.es/pdf/nh/v25s3/07_articulo_07.pdf

Haro-Martínez, A., \& Taddei-Bringas, I. (2014). Sustentabilidad y economía: la controversia de la valoración ambiental. Economía, Sociedad y Territorio, 14(46), 743-767. http://www.scielo.org.mx/pdf/est/v14n46/v14n46a7.pdf

Hevia, R. (2015). La guerra fría como conflicto económico. Capitalismo y comunismo [Tesis de la Facultad de Ciencias Económicas y Empresariales, Universidad Pontificia Comillas]. Repositorio. https://repositorio.comillas.edu/rest/bitstreams/5716/ retrieve

Iturralde, C. (2019). Los paradigmas del desarrollo y su evolución: del enfoque económico al multidisciplinario. Retos Revista de Ciencias de la Administración y Economía, 9(17), 7-23. https://doi.org/10.17163/ret.n17.2019.01

Juarros, M. (2006). ¿Educación superior como derecho o como privilegio? Las políticas de admisión a la universidad en el contexto de los países de la región. Andamios, 3(5), 69-90. http://www.scielo.org.mx/pdf/anda/v3n5/v3n5a5.pdf

London, S., \& Formichella, M. (2006). El concepto de desarrollo de Sen y su vinculación con la educación. Economía y Sociedad, 11(17), 17-32. https://www. redalyc.org/pdf/510/51001702.pdf

Mallorquín, C. (2005). Raúl Prebisch y el deterioro de la tesis de los términos de intercambio. Revista Mexicana de Sociología, 67(2), 379-426. http://www.scielo. org.mx/pdf/rms/v67n2/v67n2a5.pdf

Mansilla, L., Denegri, M., \& Álvarez, B. (2016). Relación entre actitudes hacia el endeudamiento y locus de control del consumidor en estudiantes universitarios. Suma Psicológica, 23, 1-9. http://www.scielo.org.co/pdf/sumps/v23n1/v23n1a01. pdf 
Martínez, P. (2015). El “enfoque de las capacidades" de Martha Nussbaum frente al problema de la ética animal. Veritas, (33), 71-87.

Martínez, G., Oaxaca, J., \& Guerra, R. (2011). Productos orgánicos: agronegocio exitoso en México. Revista Mexicana de Agronegocios, 15(28), 503-513. https:// www.redalyc.org/pdf/141/14115904006.pdf

Martínez, R. (2010). La importancia de la educación ambiental ante la problemática actual. Revista Electrónica Educare, 14(1), 97-111. https://www.redalyc.org/ pdf/1941/194114419010.pdf

Martínez, M. (2009). Dimensiones básicas de un desarrollo humano integral. Polis, Revista de la Universidad Bolivariana, 8(23), 119-138. https://scielo.conicyt.cl/ pdf/polis/v8n23/art06.pdf

Max-Neef, M., Elizalde, A., Hopenhayn, M., Herrera, F., Zemelman, H., Jatobá, J., \& Weinstein, L. (2010). Desarrollo a escala humana. Opciones para el futuro (Nueva Edición). Biblioteca $\mathrm{CF}+\mathrm{S}$.

Max-Neef, M.; Elizalde, A., \& Hopenhayn, M. (1986). Desarrollo a Escala Humana una opción para el futuro. Fundación Dag Hammarskjold. http://www. daghammarskjold.se/wp-content/uploads/1986/08/86_especial.pdf

Ministerio de Educación Nacional. (2012). La cultura del emprendimiento en los establecimientos educativos. Orientaciones generales. Guía $N^{\circ} 39$. Ministerio de Educación Nacional de la República de Colombia. https://www.mineducacion.gov. co/1759/articles-287822_archivo_pdf.pdf

Monereo, C. (2015). Martha C. Nussbaum - Otro enfoque para la defensa del ser humano y de los derechos de las mujeres. Seqüencia (Florianópolis), 36(70), 93114. https://www.scielo.br/pdf/seq/n70/0101-9562-seq-70-00093.pdf

Muñoz-Duque, L. (2018). Correr el riesgo: ¿desventaja social o capacidad? Cad. Saúde Pública, 34(5), 1-11.

Nieto, M. (2009). Ciencia, imperio, modernidad y eurocentrismo: el mundo atlántico del siglo XVI y la comprensión del Nuevo Mundo. Historia Crítica, 362, 12-32. https://www.redalyc.org/pdf/811/81112369002.pdf 
Organización para la Cooperación y el Desarrollo Económico. (2017). Marco de evaluación y de análisis de PISA para el desarrollo: lectura, matemáticas y ciencias, versión preliminar. OECD Publishing. https:/www.oecd.org/pisa/aboutpisa/ ebook\%20-\%20PISA-D\%20Framework_PRELIMINARY\%20version_SPANISH. pdf

Parra, L. (2010). Modelo para el desarrollo del potencial humano basado en competencias para el desarrollo de la actividad empresarial, en la población vulnerable de Santiago de Cali. Entramado, 6(1), 22-39.

Payarés, B., \& Garnica, L. (2010). Cultura y economía en el desarrollo social humano. Humanidades Médicas, 10(3), 1-16.

Peláez-Herreros, O. (2012). Análisis de los indicadores de desarrollo humano, marginación, rezago social y pobreza en los municipios de Chiapas a partir de una perspectiva demográfica. Economía, Sociedad y Territorio, 12(38), 181-213. http:// www.scielo.org.mx/pdf/est/v12n38/v12n38a7.pdf

Peroni, A. (2009). El desarrollo local a escala humana: experiencias de desarrollo comunitario en el sector salud. Chile. Polis, Revista de la Universidad Bolivariana, $8(22), 99-120$.

Picazzo, E., Gutiérrez, E., Infante, J., \& Cantú, P. (2011). La teoría del desarrollo humano y sustentable: hacia el reforzamiento de la salud como un derecho y libertad universal. Estudios Sociales, 19(37), 254-279. http://www.scielo.org.mx/ pdf/estsoc/v19n37/v19n37a10.pdf

Porcelli, A., \& Martínez, A. (2018). Análisis legislativo del paradigma de la economía circular. Revista Direito GV, 14(3), 1067-1105. http://www.scielo.br/pdf/rdgv/ v14n3/2317-6172-rdgv-14-03-1067.pdf

Portillo-Torres, M. (2017). Educación por habilidades. Perspectivas y retos para el sistema educativo. Revista Educación, 41(2), 1-22. https://www.redalyc.org/ articulo.oa? $\mathrm{id}=44051357008$

Ramírez, A., Sánchez, J., \& García, A. (2004). El desarrollo sustentable: interpretación y análisis. Revista del Centro de Investigación. Universidad La Salle, 6(21), 55-59. https://www.redalyc.org/pdf/342/34202107.pdf 
Restrepo-Ochoa, D. (2013). La salud y la vida buena: aportes del enfoque de las capacidades de Amartya Sen para el razonamiento ético en salud pública. Cad. Saúde Pública, 29(12), 2371-2382.

Reyes, G. (2008). Desarrollo humano: desafío permanente en el ámbito universitario. Acta Colombiana de Psicología, 11(2), 153-156. https://www.redalyc.org/ pdf/798/79811214.pdf

Ricoy, C. (2005). La teoría del crecimiento económico de Adam Smith. Economía y Desarrollo, 138(1), 11-47. https://www.redalyc.org/pdf/4255/425541308001.pdf

Rodríguez, D. (2016). Emprendimiento sostenible, significado y dimensiones. Revista Katharsis, 21, 419-448. https://dialnet.unirioja.es/servlet/articulo? codigo=5850542

Rodríguez, M., \& Mendoza, H. (2007). Sistemas productivos y organización del trabajo: Una visión desde Latinoamérica. Gaceta Laboral, 13(2), 218-241. http:// ve.scielo.org/scielo.php?script=sci_arttextypid=S1315-85972007000200004

Rojas, F., \& López, C. (2003). Desarrollo humano y salud en América Latina y el Caribe. Revista Cubana Salud Pública, 29(1), 8-17. http://scielo.sld.cu/pdf/rcsp/ v29n1/spu03103.pdf

Sánchez-Vidal, A. (2017). Empoderamiento, liberación y desarrollo humano. Psychosocial Intervention, 26, 155-163. http://scielo.isciii.es/pdf/inter/v26n3/11320559-inter-26-03-00155.pdf

Sánchez, A. (2006). Crecimiento económico, desigualdad y pobreza: una reflexión a partir de Kuznets. Problemas del Desarrollo, 37(145), 11-30. http://www.scielo. org.mx/pdf/prode/v37n145/v37n145a2.pdf

Sanmartín, G., Zhigue, R., \& Alaña, T. (2017). El reciclaje: un nicho de innovación y emprendimiento con enfoque ambientalista. Revista Universidad y Sociedad, 9(1), 36-40. http://scielo.sld.cu/pdf/rus/v9n1/rus05117.pdf

Sen, A. (2000). El desarrollo como libertad. Gaceta Ecológica, 55, 14-20. 
Suárez, S., \& Molina, E. (2014). El desarrollo industrial y su impacto en el medio ambiente. Revista Cubana de Higiene y Epidemiología, 52(3), 357-363. https:// www.redalyc.org/pdf/2232/223240764008.pdf

Velásquez de Castro, F. (2005). Cambio climático y protocolo de Kioto. Ciencia y estrategias: compromisos para España. Revista Española de Salud Pública, 79(2), 191-201. https://www.redalyc.org/pdf/170/17079209.pdf

Veres, E. (2014). Medición del desarrollo humano: un índice alternativo al IDH2010. Especial referencia a los países latinoamericanos. Investigación Económica, 73(288), 87-115. http://www.scielo.org.mx/pdf/ineco/v73n288/v73n288a4.pdf

Vargas, G. (2011). Responsabilidad social empresarial, ciudadanía y desarrollo. Cuadernos de Administración, 24(43), 177-191. https:/www.redalyc.org/ pdf/205/20521435008.pdf

Villegas, N. (2015). El desarrollo humano como eje central en el diseño de un modelo de medición multidimensional de la pobreza para Venezuela: una visión desde el "Enfoque de Capacidad". Argos, 32(62), 185-203. http://ve.scielo.org/pdf/ag/ v32n62/art11.pdf 


\section{Información de los autores}

\section{Laura Stella Parra Espitia}

Doctoranda en Educación de la Universidad Internacional Iberoamericana. Licenciada en Ciencias Sociales y Magíster en Educación de la Universidad Pedagógica Nacional. Cuenta con experiencia investigativa en recuperación de procesos sociales tomando como herramienta la historia oral, y en el diseño, construcción y ejecución de proyectos escolares en derechos humanos y convivencia. En la actualidad, se desempeña como docente investigadora de la Facultad de Psicología de la Universidad Católica Luis Amigó y forma parte del grupo de investigación Ayelén. Entre sus publicaciones se encuentran los artículos titulados: "Deserción escolar y desarrollo social: una mirada sobre el programa 'Volver a la escuela' en Bogotá", "El derecho a la educación en poblaciones excluidas: el caso del programa volver a la escuela", "Reconstruyendo las prácticas sociales en los espacios públicos de Bogotá de 1910 a 1948 desde la historia oral", "Consejería psicológica virtual en la universidad colombiana: más allá del rendimiento académico" y "Diferencias y relaciones en las habilidades y competencias investigativas de los licenciados en Colombia".

\section{Arcadio de Jesús Cardona Isaza}

Magíster en Psicología de la Universidad de La Sabana. Psicólogo, licenciado en Pedagogía Reeducativa, Filosofía y Teología. Su trabajo investigativo se centra en las competencias socioemocionales, la toma de decisiones y factores de riesgo y de protección en adolescentes con conducta antisocial y delictiva. Ha sido director de programas de prevención y rehabilitación en adicciones y de conducta delictiva y antisocial. Se ha desempeñado como rector de instituciones educativas y como docente universitario en el campo de la Psicología Clínica, es consejero en adicciones de la Federación Latinoamericana de Comunidades Terapéuticas y se ha desempeñado como coordinador general de la Red de Conocimiento Especializado de Promoción y Evaluación de Habilidades para la Vida. Ha desarrollado procesos de investigación con el Grupo Etikos de la Universidad de San Buenaventura, el grupo Ayelén de la Universidad Católica Luis Amigó, y el grupo Procesos Psicológicos y Contexto Social de la Facultad de Psicología de la Universidad de La Sabana. 


\section{Sebastián Toro Vélez}

Magíster en Educación de la Universidad del Cauca de Popayán, licenciado en Filosofía de la Universidad Católica Luis Amigó, sede Medellín; a la fecha se desempeña como decano de la Facultad de Humanidades, Ciencias Sociales, Artes y de la Educación de la Corporación Universitaria Unicomfacauca de Popayán, Colombia; ha desarrollado diversas investigaciones y publicaciones en torno a la pedagogía social, reeducativa y en diversos contextos culturales en temas coyunturales como la paz. Así mismo, ha presentado sus construcciones académicas en diferentes escenarios tanto nacionales como internacionales.

\section{Germán Andrés Torres Escobar}

Psicólogo y magíster en Pedagogía de la Universidad de La Sabana. Magíster en Psicología Educacional de la Universidad de los Andes de Chile. Ha trabajado como orientador escolar de primaria y bachillerato en colegios privados, en donde ha realizado talleres de prevención de conductas de riesgo, pautas de crianza y hábitos de estudio, además de efectuar asesorías personalizadas para jóvenes y niños con dificultades académicas, interpersonales y familiares. Actualmente, se desempeña como docente universitario especializado en asignaturas de medición y evaluación psicológica, así como también en asignaturas relacionadas con personalidad y metodología de la investigación cuantitativa. Como parte de su rol, ha investigado acerca del tema de la deserción universitaria y sus causas en programas de educación virtual y distancia.

\section{Roger Martínez Correa}

Psicólogo de la Universidad Católica Luis Amigó, con amplia experiencia en el desarrollo tanto de procesos sociales con población vulnerable, especialmente con programas dirigidos a niños, niñas y adolescentes, como de programas dirigidos a víctimas del conflicto armado. Ha sido ponente del simposio Aspectos psicosociales de la Migración y coautor de la publicación "Experiencias de migración, uso de redes virtuales y afrontamiento", en la cual compartió algunas de sus vivencias en diferentes lugares del país con respecto al desarrollo del entorno laboral. Actualmente se desempeña como profesional psicosocial en el desarrollo de estrategias de recuperación emocional dirigidas a víctimas del conflicto armado en Colombia, para la Organización Internacional para las Migraciones-OIM-en Colombia. 


\section{Diana Margarita Morales Arrieta}

Psicóloga de la Universidad Católica Luis Amigó, actualmente se encuentra cursando la maestría en Derechos Humanos en la Universidad Pedagógica y Tecnológica de Colombia. Trabajó para la Oficina Pastoral para la Atención de la Niñez y la Familia, como psicóloga del Sistema de Responsabilidad Penal para Adolescentes. También coordinó el Club Amigó Zagales, programa del ICBF que atiende a niños, niñas y adolescentes en condición de vulneración. Cuenta con amplia experiencia en el apoyo y gestión de proyectos sociales en temas de promoción de la calidad de vida y salud mental con madres gestantes adolescentes, inclusión social en población LGBTIQ y proyectos de recuperación emocional con niños, niñas, adolescentes y adultos víctimas del conflicto armado.

Actualmente, se desempeña en el ámbito de la psicología jurídica y forense apoyando procesos periciales y proyectos sociales en la región del Magdalena Medio y Santander.

\section{Gloria Inés De Salvador}

Psicóloga sistémica especializada en Farmacodependencia, con experiencia en programas de prevención selectiva e indicada para población joven consumidores no problemáticos de sustancias psicoactivas. Cuenta con amplia experiencia en el diseño, desarrollo y supervisión de programas en contexto escolar y comunitario, desde el enfoque de minorías activas, para la prevención de problemáticas de relevancia social.

Formadora Nacional desde propuesta TREATNET, para la optimización de la práctica clínica de equipos psicosociales que trabajan con población consumidora de sustancias psicoactivas. Actualmente, se desempeña como la directora de la Fundación Prever I. P. S. de la ciudad de Bogotá. 


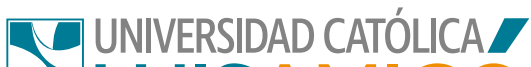 DLUISAMIGO

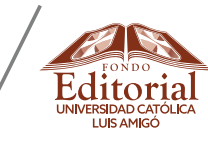

En 1993, la Organización Mundial de la Salud propuso un enfoque de desarrollo psicosocial denominado habilidades para la vida; su objetivo era prevenir e intervenir en problemas relacionados con el consumo de drogas, la delincuencia y los comportamientos sexuales de riesgo, entre otros. Desde entonces, se han implementado programas basados en este enfoque para abordar diversas situaciones de riesgo. El libro "Habilidades para la vida. Aproximaciones conceptuales" presenta aportes teóricos actualizados de las habilidades para la vida, que incluyen las habilidades cognitivas, emocionales y sociales, con una perspectiva orientada a favorecer la salud mental y el crecimiento humano. Los aportes teóricos expuestos pueden ayudar a los profesionales psicosociales como psicólogos, pedagogos, terapeutas familiares y otros actores que trabajan con personas en riesgo psicosocial. Asimismo, constituyen una base conceptual para fundamentar el enfoque de habilidades para la vida. 